\title{
The effect of early oral feeding compared to standard oral feeding following total laryngectomy: a systematic review
}

\author{
Stephanie Kay Martin \\ Master of Clinical Science candidate \\ Joanna Briggs Institute \\ Faculty of Health Sciences \\ The University of Adelaide \\ Australia.
}

$8^{\text {th }}$ August 2013 


\section{Table of contents}

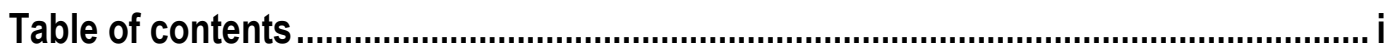

Table of tables and figures ............................................................................ iv

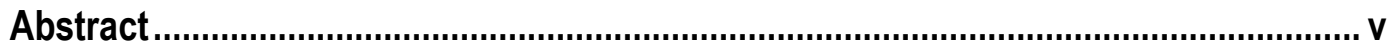

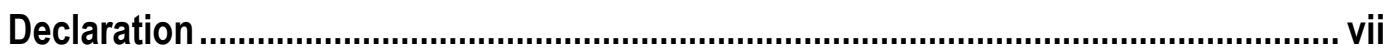

Acknowledgements ............................................................................................. vii

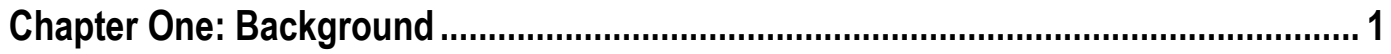

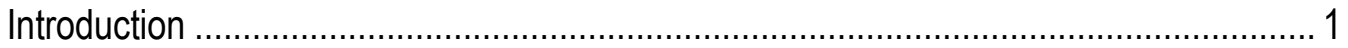

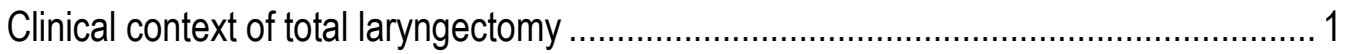

Historical development of total laryngectomy .......................................................... 3

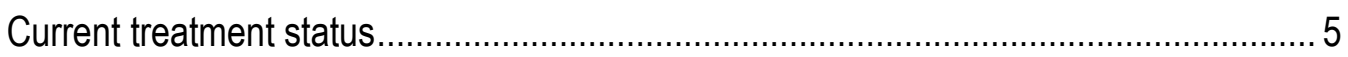

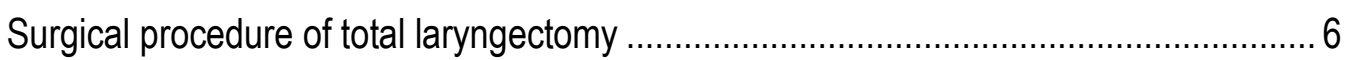

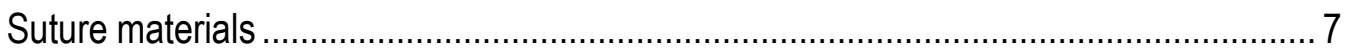

Post-operative management following total laryngectomy ......................................... 8

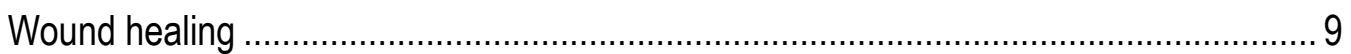

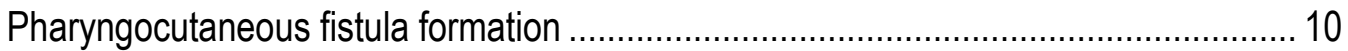

Management of pharyngocutaneous fistula ........................................................... 12

Risk factors for pharyngocutaneous fistula......................................................... 13

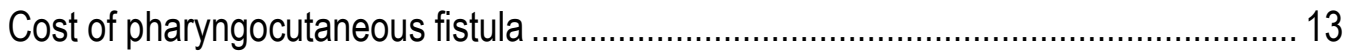

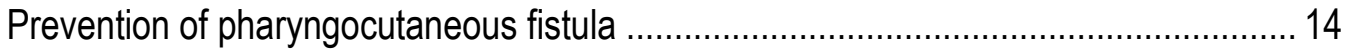

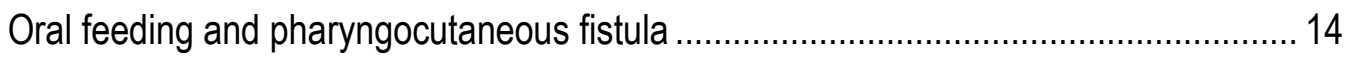

Why a systematic review on oral feeding in total laryngectomy is required .................. 15

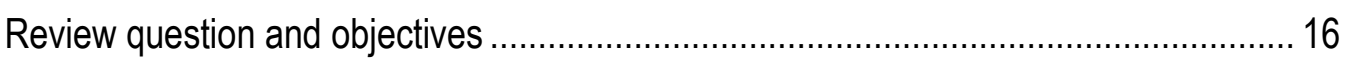

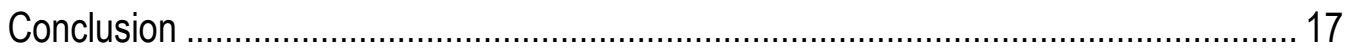

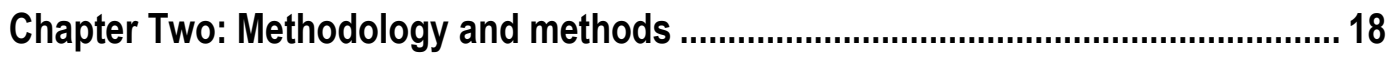

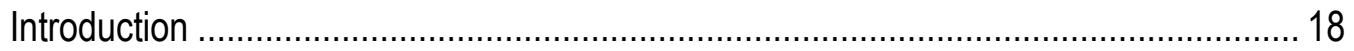




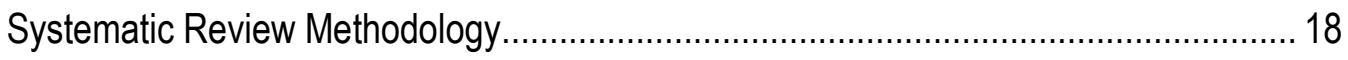

Development of Evidence Based Health Care .................................................... 18

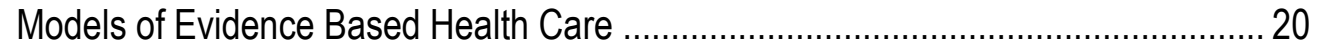

Joanna Briggs Institute Model of Evidence Based Health Care ............................... 21

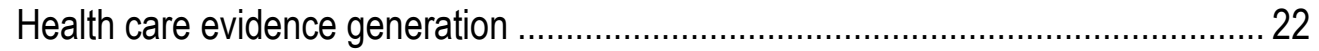

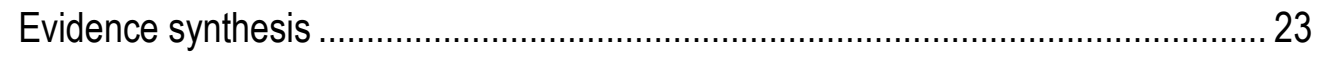

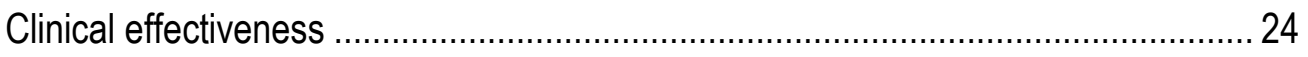

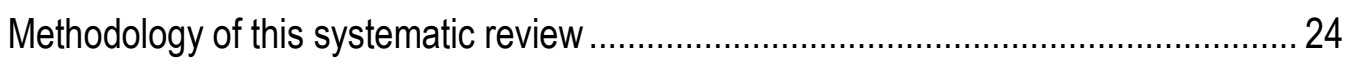

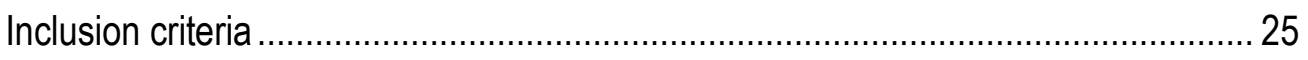

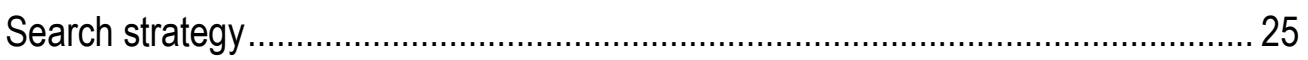

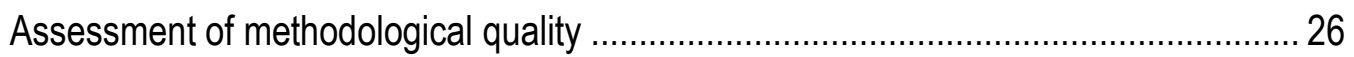

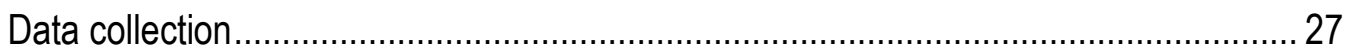

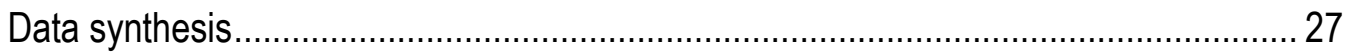

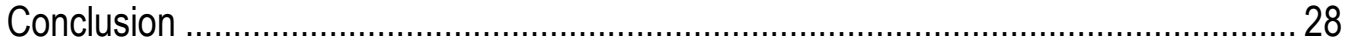

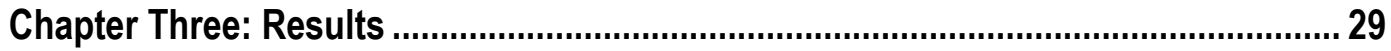

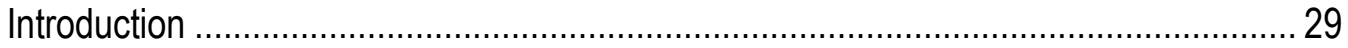

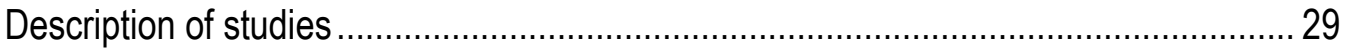

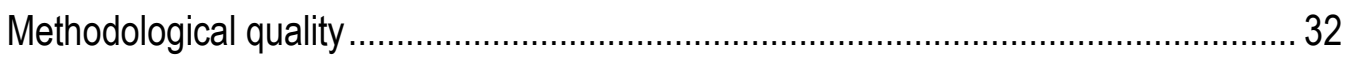

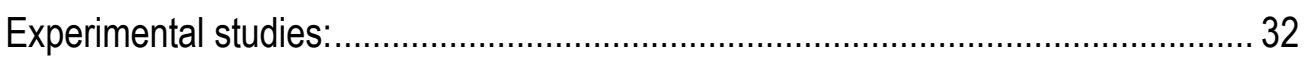

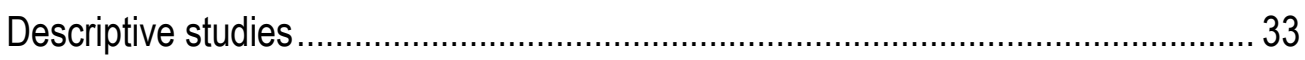

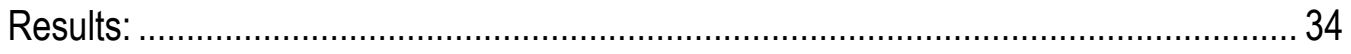

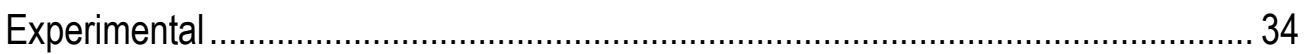

Descriptive studies:

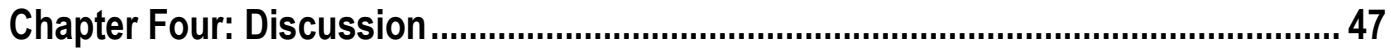

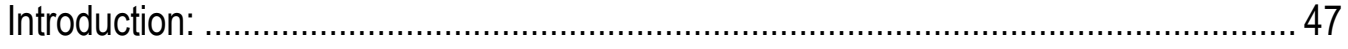

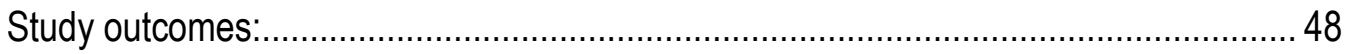

Experimental: the effect of early feeding on incidence of pharyngocutaneous fistula 48 
Experimental: the effect of early feeding on length of stay

Descriptive: the effect of early feeding on pharyngocutaneous fistula ..................... 50

Descriptive: the effect of early feeding on length of stay ......................................51

Other risk factors for pharyngocutaneous fistula: experimental and descriptive .......52

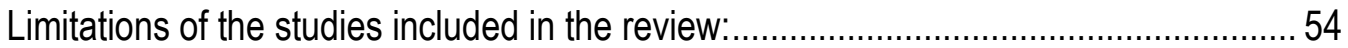

Limitations of experimental studies included in the review:.................................... 54

Limitations of descriptive studies included in the review: ...................................... 59

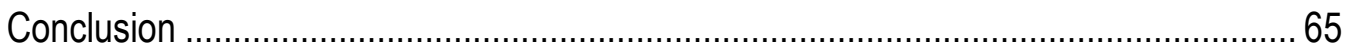

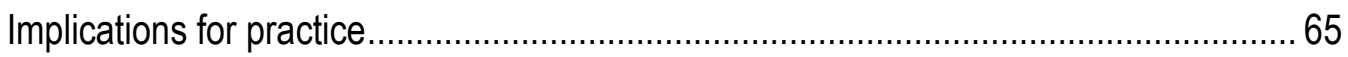

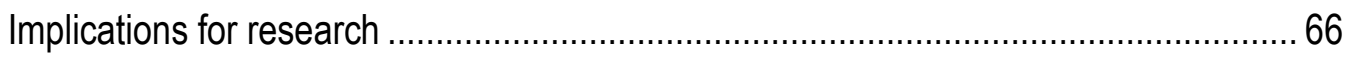

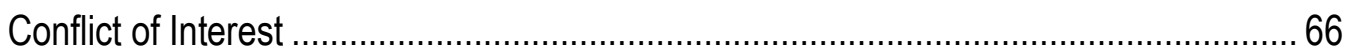

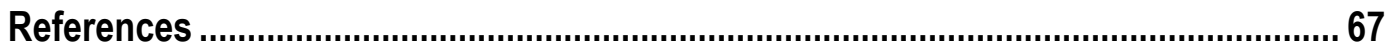

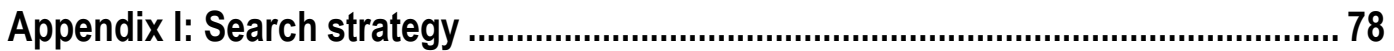

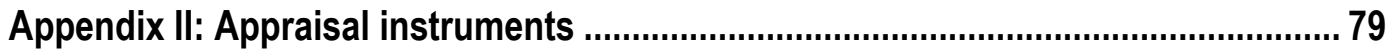

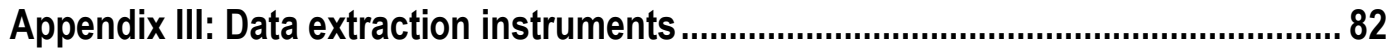

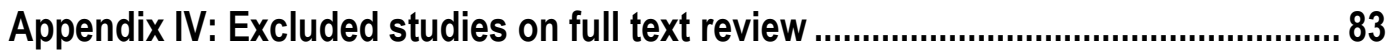

Appendix V: Included studies in the systematic review............................................ 84

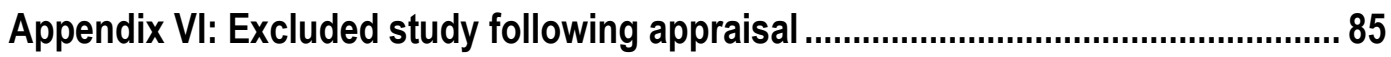




\section{Table of tables and figures}

Figure 1: Pre and post-operative changes associated with total laryngectomy .............................. 2

Table 1 : Number of studies found and retrieved ..........................................................................

Flowchart 1: number of studies found and retrieved .................................................................

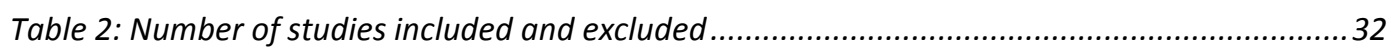

Table 3: Results of critical appraisal of included Randomised Control Trial / Pseudo-randomised

Trial n..........................................................................................................................

Table 4: Results of critical appraisal of included descriptive studies ............................................. 34

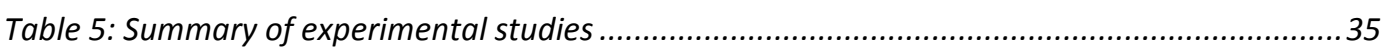

Table 6: Number, age and gender of experimental studies ...........................................................

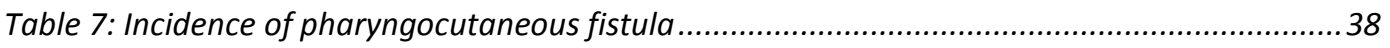

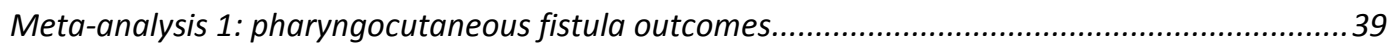

Table 8: Length of stay relating to development of pharyngocutaneous fistula, Seven, Callis and

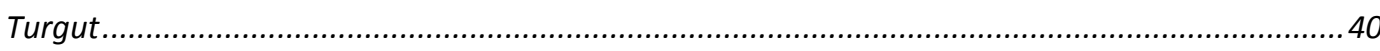

Table 9: Length of stay relating to development of pharyngocutaneous fistula, Medina and Khafif

Table 10: Overview of descriptive studies ............................................................................. 41

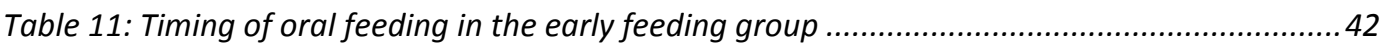

Table 12: Inclusion and exclusion criteria, and incidence of pharyngocutaneous fistula .................42

Table 13: Studies excluding pre-operative radiotherapy and/or chemotherapy..............................43

Table 14: Studies including primary and salvage total laryngectomy.............................................4

Table 15: Length of stay comparison with fistula present or absent. ..............................................46 


\section{Abstract}

Pharyngocutaneous fistula is reported to be the most common early complication following total laryngectomy with significantly increased morbidity and mortality rates as well as increased resource utilisation. Post-operatively, the presence of a pharyngocutaneous fistula can double the length of an average patient hospital stay. Multiple risk factors for pharyngocutaneous fistula have been investigated in the literature. Common clinical practice is to delay the introduction of oral feeding following surgery to reduce the formation of a pharyngocutaneous fistula.

The objective of this review was to identify and synthesise the best available evidence on the effects of early oral feeding compared to standard oral feeding following total laryngectomy on the incidence of pharyngocutaneous fistula and hospital length of stay.

This review considered studies that included adults who commenced early oral feeding following total laryngectomy surgery. The intervention of interest was early oral feeding defined as oral intake in the first 6 days post-operatively. The comparator was standard care defined as oral intake from day 7 onwards. Outcome measures of interest included the incidence of pharyngocutaneous fistula and hospital length of stay. A three tier search strategy was undertaken across 10 major databases. Nine studies in total met the inclusion criteria and on the basis of appraisal, eight were of suitable methodological quality, including three experimental and five descriptive studies.

Experimental studies appraised supported that early oral feeding does not increase the incidence of pharyngocutaneous fistula in the clinical context of primary total laryngectomy and this was substantiated by meta-analysis. Descriptive studies also supported these findings. The search process highlighted a lack of quality papers seeking to address the impact of salvage total laryngectomy on the incidence of pharyngocutaneous fistula. Results for the effectiveness of early oral feeding versus standard oral feeding on length of stay were inconclusive.

It was concluded that early oral feeding prior to day seven in non irradiated or nonextensively irradiated patients undergoing primary total laryngectomy does not result in an increase or change in pharyngocutaneous fistula formation. This conclusion is supported by meta-analysis.

Although the descriptive literature also favours early oral feeding in less homogenous laryngectomy populations, the level of evidence is not high. As a result, conclusions could 
not be drawn in these populations. Findings relating to the impact of early oral feeding on length of stay were mixed and inconclusive.

Implication for clinical practice and further research are presented.

\section{Keywords}

oral feeding, total laryngectomy, fistula 


\section{Declaration}

I, Stephanie Martin, certify that this work contains no material that has been accepted for the award of any other degree or diploma in any University of any other tertiary institution, and, to the best of my knowledge and belief, contains no material previously published or written by any other person, except where due reference has been made in the text. In addition, I certify that no part of this work will, in the future, be used in a submission for any other degree or diploma in any university or other tertiary institution without the prior approval of the University of Adelaide and where applicable, any partner institution responsible for the joint award of this degree.

I give consent to this copy of my thesis, when deposited in the University Library, being made available for loan and photocopying, subject to the provisions of the Copyright Act 1968.

I also give permission for the digital version of my thesis to be made available on the web, via the University's digital research repository, the Library Catalogue, and also through web search engines, unless permission has been granted by the University to restrict access for a period of time.

Stephanie Martin

$08 / 08 / 2013$ 


\section{Acknowledgements}

This thesis would not have been possible without the help and assistance of a number of people.

Firstly, I would like to thank Associate Professor Zoe Jordan and Professor Simon Carney for their patience, support and encouragement during the writing of this thesis.

My colleagues in both the Department of Speech Pathology and Audiology, and the Department of Otolaryngology at Flinders Medical Centre, South Australia assisted me with invaluable clinical and research experience and I am very grateful for their interest, emotional support and humour.

I would also like to thank and acknowledge my family who encouraged me to take a "deep breath" and to "give it a go" when considering taking on this study and allowed me to disappear for hours on end to ensure its completion. 


\section{Chapter One: Background}

\section{Introduction}

Pharyngocutaneous fistula is reported to be the most common early complication following total laryngectomy with significantly increased morbidity and mortality rates as well as increased resource utilisation. 123 Post-operatively, the presence of a pharyngocutaneous fistula can double the length of an average patient hospital stay. ${ }^{4,5}$ Multiple risk factors for pharyngocutaneous fistula have been investigated in the literature. Common clinical practice is to delay the introduction of oral feeding and feed enterically following surgery to reduce the formation of a pharyngocutaneous fistula.

The author's interest in this topic is based on many years of speech pathology clinical practice in the area of head and neck cancer predominantly in rehabilitation of communication and swallowing. The speech pathologist is a dedicated member of the multi-disciplinary head and neck team involved with these patients in all phases of their care. The speech pathologist is intricately involved in the early acute phases following total laryngectomy surgery and supports the patient in stoma care, return to functional communication and swallowing rehabilitation. The speech pathologist is often present for the first attempts of oral intake and may be one of the first members of the team alerted to the possible presence of a pharyngocutaneous fistula following introduction of oral intake. Seeking the evidence relating to the question of this systematic review will help to inform the author's own clinical practice and has developed a deeper understanding of issues in what is a clinically complex management area.

\section{Clinical context of total laryngectomy}

Total laryngectomy is a surgical procedure that involves removal of the larynx, along with a number of tracheal rings and the hyoid bone. There is no longer any connection between the upper airway and the trachea. ${ }^{6}$ The person permanently breathes through a stoma at the base of the neck. 
Figure 1: Pre and post-operative changes associated with total laryngectomy

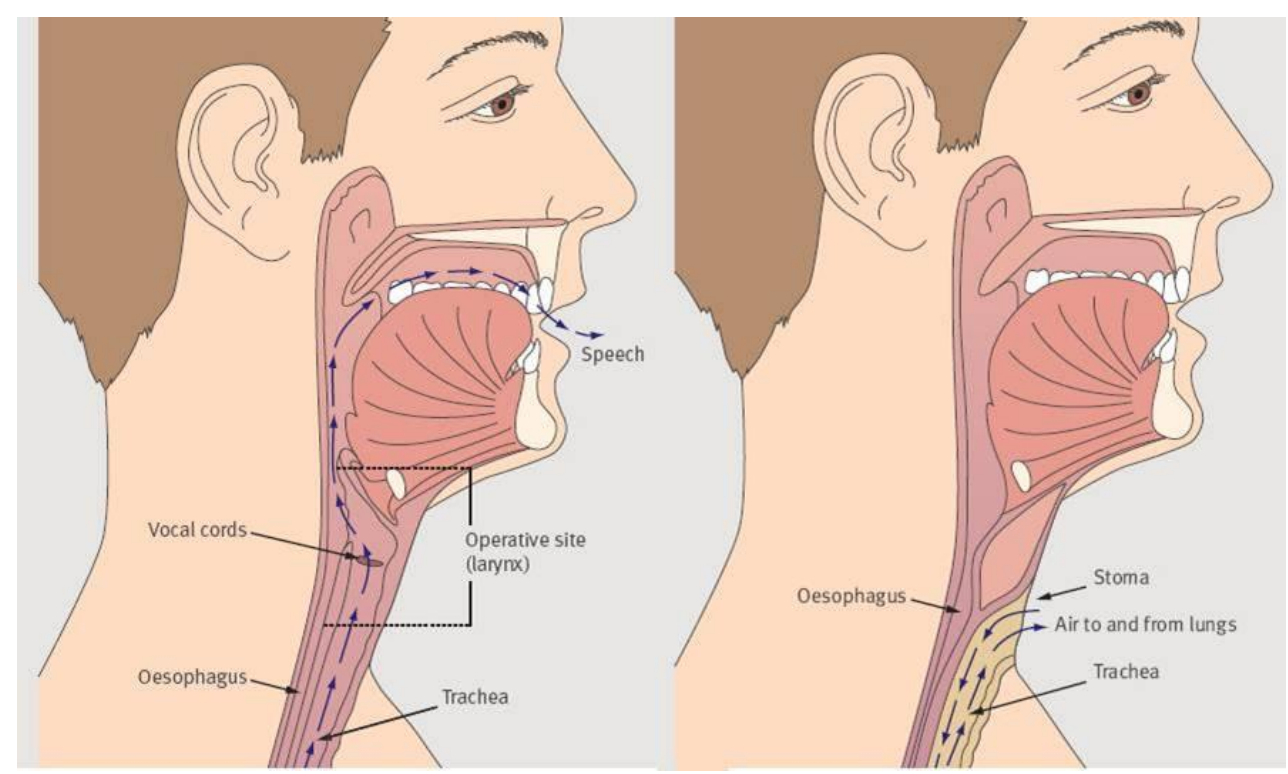

(reproduced with kind permission of the National United Kingdom Safety Project www.tracheostomy.org.uk)

Total laryngectomy is performed predominantly for oncological reasons but may be indicated in conditions of severe chronic aspiration due to glottic incompetence or for chondroradionecrosis of the larynx. ${ }^{7}$

Laryngeal cancer is the most common head and neck cancer ${ }^{8,9}$ with up to $95 \%$ being squamous cell carcinomas (SCC). ${ }^{10,}{ }^{11}$ An estimated 12,360 adults in the USA will be diagnosed with laryngeal cancer in 2012 (9840 men and 2520 women) with 3650 deaths. ${ }^{11}$ In Australia, the risk of being diagnosed by age 85 with laryngeal cancer is 1 in 275 with 214 deaths reported in 2007. 12

Major risk factors for laryngeal SCC are tobacco, smoking and alcohol consumption. 10, 13, 14 There are also occupational risk factors which include exposure to asbestos, chemicals and solvents. ${ }^{13}$ More recently the role of the human papilloma virus (HPV) is increasingly recognised in head and neck cancers but not fully yet understood. The UK Head and Neck Cancer Guidelines ${ }^{15}$ report that recently, HPV may be associated with up to $20 \%$ of laryngeal cancers.

Clinical presentation of laryngeal cancer is highly variable and dependent on site and size of the tumour. Typical symptoms include hoarseness, pain, swallowing difficulty, a palpable neck mass and possibly airway compromise at more advanced stages. ${ }^{15}$

The consequences of total laryngectomy whether performed as a primary treatment or later as a salvage procedure, are significant. Total laryngectomy results in significant anatomical 
and physiological changes to the structures and mechanisms involved in eating, drinking, breathing and communicating. ${ }^{16}$ There are alterations to taste, smell and coughing. Difficulty swallowing is also a reported negative outcome of total laryngectomy with an incidence ranging from $10-60 \% .^{16}$ These altered or diminished functions can have a significant effect on the person's quality of life ${ }^{17}$ and physical and psychosocial adjustment is complex. ${ }^{18}$

Post-operatively, rehabilitation is required to develop functional communication. There are a number of methods available including oesophageal speech or the use of an augmentative device such as an electrolarynx. ${ }^{6}$ The impact of communication changes following surgery should not be underestimated. The extent to which a patient will be able to communicate post-operatively, using the options available to them, can affect social behaviour and communication competence. ${ }^{18}$

\section{Historical development of total laryngectomy}

It is generally agreed that Bilroth successfully performed the first total laryngectomy in 1873 in Vienna which was reported on by his assistant at the $3^{\text {rd }}$ Congress of Surgeons. ${ }^{19}$, 20 His patient, a 36 year old religious instructor, successfully survived the two hour operation and was able to communicate two weeks later using a prosthetic device. The patient unfortunately developed recurrence of his laryngeal cancer seven months later and died. Bilroth's surgical procedure differed from that performed today in that the epiglottis and hyoid were preserved and the trachea and pharynx remained connected with a valve to protect the airway. 20

Many years prior to Bilroth, in an attempt to remove cancerous lesions of the larynx, surgeons performed operations with less effective outcomes. The era of successful laryngeal surgery began in the 1850s when Buck, in New York, removed a laryngeal cancer by performing a thyrotomy. This procedure was performed without anaesthesia and the patient survived 18 months following it. 19

Bottini of Turin, in 1875, performed a total laryngectomy on a patient who survived for ten years. ${ }^{19,} 20$ Initial attempts at laryngectomy did not separate the trachea from the digestive system and as such complications were high. Ferlito et al $(2002)^{20}$ report, that in 1880, the operative or early post-operative mortality rates were approximately fifty percent. These were high risk operations with patients dying from infection, haemorrhage and sepsis. ${ }^{21}$ 
This high mortality rate resulted in the development of a two stage procedure by Gluck in Germany, where a tracheal separation was performed first, followed by laryngectomy and pharyngeal closure two weeks later. ${ }^{19}$ In the 1890s, with his pupil Sorenson, Gluck then developed a successful single-stage operation similar to contemporary techniques. At the 1892 Philadelphia County Medical Society Meeting, Solis-Cohen reported on carrying out a total laryngectomy by use of techniques similar to Gluck-Sorenson. ${ }^{19}$

Of historical and political interest around this time of advancing surgical technique, is the case of the Prussian Crown Prince, the late Emperor Frederick III of Germany who died from advanced laryngeal cancer in 1888. He presented with a small laryngeal lesion, initially thought to be malignant by Frederick's German physicians, however due to the high risk of complications associated with the newly reported laryngectomy surgery, a further opinion was sought. This opinion was provided by Dr Morrell Mackenzie, described as the father of British Otolaryngology. ${ }^{22}$ A biopsy taken by Dr Mackenzie was analysed by the leading European pathologist of the time and described as benign. As a result, no surgery was undertaken.21, 22 Unfortunately for Frederick, a biopsy at a later stage, when symptoms increased, showed a malignant lesion and a tracheostomy was performed for airway management. During this time, Frederick ascended to the throne however sadly died after reigning for only ninety-nine days. Mackenzie received considerable criticism for his role in Frederick's medical care in both England and in Germany. He later published a book ${ }^{23}$ on the controversy and despite being a best seller at the time, the book was viewed as unethical by the Royal College of Physicians and forced his resignation. Hughes $(2009)^{22}$ suggests that most documents relating to the case and its consequences are affected by a high degree of bias and an understanding of what truly transpired is incomplete. The timing of Frederick's death is seen as important by historians as it was potentially a turning point in German history. ${ }^{24}$ Frederick, who was viewed as a liberal and dreamt of democracy, was followed by his son William II who led Germany down an imperialistic path ultimately into World War 1.

Total laryngectomy surgery did not reach an acceptable risk level until the $20^{\text {th }}$ century 21 with the development of improved anaesthesia techniques and better post-operative care. The end of World War II heralded the development of the use of antibiotics to promote wound healing, blood bank development to replace blood loss during surgery, and improvements in skin grafting techniques. ${ }^{25}$ 
A significant effect on treatment outcomes was in the area of lymph node surgery. ${ }^{21}$ Of interest is that even in 1847, Celius reported that disease control was impossible if spread had occurred into the neck. ${ }^{21}$ Neck dissection, first described as a standard procedure in 1906, has now developed into the current regime practised today.

Ongoing attention to functional outcomes around speech and swallowing led to the introduction of a modification of the total laryngectomy technique by Blom and Singer in the 1980s to allow the introduction of trachea-oesophageal puncture for placement of a voice prosthesis to aid communication. ${ }^{25}$

Radiation treatment for laryngeal cancer received increased interest during the first half of the $20^{\text {th }}$ century. ${ }^{19}$ The introduction of a combined program of radiotherapy and surgery was presented by Doctors Goldman and Silverstone in treating patients with advanced hypopharyngeal cancer. ${ }^{25}$ As a result, improved survivorship was recognised but so too were the complications of surgery following radiotherapy.

\section{Current treatment status}

Over the last decade, treatment for laryngeal cancer has shifted towards organ sparing management approaches ${ }^{8}$ using a combination of surgery and radiotherapy. Advances in transoral endoscopic laser surgery, radiotherapy and chemotherapy, as well as the ability to use these modalities in combination, have moved initial treatment away from major surgeries such as total laryngectomy promoting reduced mortality, higher rates of laryngeal preservation, preserved laryngeal function and improved quality of life.$^{26}$

Treatment options for laryngeal cancer are ultimately determined by the site and extent of the tumour. ${ }^{13}$ The rules for tumour classification and staging were formulated by the European Union for International Cancer Control and the American Joint Committee on Cancer. ${ }^{16}$ The TNM classification system is used where T1-4 relates to the size of the tumour, N1-3 describes lymph node involvement and M 0-1 if metastases present/absent. 10, 13

In advanced laryngeal disease, primary total laryngectomy may be indicated particularly if other surgeries or concurrent chemotherapy/radiotherapy alone are not appropriate. ${ }^{16,} 27$ In addition, salvage total laryngectomy is indicated where chemo-radiotherapy, radiotherapy alone or other surgeries have failed in disease control. ${ }^{27}$ Agrawal (2008) ${ }^{27}$ reports conversion to total laryngectomy in $16 \%$ of patients having undergone concurrent 
chemo-radiotherapy and 31\% with radiotherapy alone. Salvage procedures are described as being technically more difficult with a higher post-operative complication rate. 19, 27

Hypopharyngeal cancer is reportedly more aggressive ${ }^{16}$ and often more advanced at time of diagnosis. Surgical input for advanced lesions predominantly results in a combination of total laryngectomy, partial or total pharyngectomy and modified radical neck dissection. ${ }^{16}$

\section{Surgical procedure of total laryngectomy}

Primary total laryngectomy involves removal of the entire larynx from the base of the tongue to the trachea including the epiglottis and the hyoid bone along with the strap muscles of the neck. ${ }^{16}$ The trachea and oesophagus are separated by primary closure of the pharynx and by suturing the trachea to the supra sternal notch. The surgical defect consists of pharyngeal mucosa and remnants of constrictor muscles.

There are several variations in how pharyngeal closure is achieved and is dependent on the surgeon's experience and preference as well as consideration of variables such as preoperative radiotherapy. ${ }^{28}$ Features of pharyngeal closure include the direction of the closure, the level of the closure and suture technique. ${ }^{29}$ To assist in post-operative speech rehabilitation, a pharyngeal constrictor myotomy may be performed to reduce constrictor spasm or hypertonicity. ${ }^{30}$

The literature describes three possible patterns of closure namely horizontal/transverse, vertical and T or Y-shaped closure. ${ }^{16,3029}$ The aim of each technique is to optimise postoperative function for speech and swallowing and to minimise or avoid wound breakdown and subsequent pharyngocutaneous fistula formation. ${ }^{31}$ Cheesman (1998) in Maclean $(2008)^{28}$ advocates for a transverse/horizontal closure as the preferred way to close the pharynx to gain optimal post-operative function however this form of closure reportedly requires a minimum of three centimetres of mucosa which is not always technically possible. ${ }^{28}$ A recent survey of Australian head and neck surgeons demonstrated wide variation in closure technique. ${ }^{28}$

Level of closure can include the mucosa and muscle, or mucosa only. ${ }^{32}$ The more usual method of reconstruction reported involves the mucosa, submucosa and the pharyngeal constrictor muscle. ${ }^{33} 16$ The survey reported above ${ }^{28}$ demonstrated that the majority of Australian head and neck surgeons (57.7\%) utilise this level of closure however a number of respondents recommended differing surgical techniques dependent on the patient's presentation. 
A continuous or interrupted closure, dependent on the surgeon's preference is used with particular attention to inversion of the mucosal edges into the pharynx. ${ }^{33} 30$ After the first mucosal layer is closed, some surgeons advocate for saline injection into the mouth to observe for any initial signs of fluid leakage as a result of incomplete pharyngeal closure. ${ }^{31}$ Pharyngolaryngectomy for more advanced cancers involving the hypopharynx, results in more extensive resection than a standard total laryngectomy. As well as removing the structures as in a standard total laryngectomy, the resection may involve part of the pharynx (total laryngectomy and partial pharyngectomy) or the entire pharynx (pharyngolaryngectomy). ${ }^{16}$ Reconstruction of the pharynx involves the use of reconstructive tissue flaps as there is insufficient pharyngeal tissue remaining for effective closure. The aim is to recreate the tube of the pharynx and to achieve effective swallowing post-operatively. ${ }^{30}$ Flap selection depends on the size of the pharyngeal defect, the patient's physical status and access to microsurgical facilities. ${ }^{30}$ Commonly used reconstruction flaps cited in the literature include radial forearm flaps, pectoralis major flaps, lateral or antero-lateral thigh flaps, free jejunal grafts and gastric pull-ups. ${ }^{16}$ The types of tissue used may impact on post-operative speech and swallowing outcomes.

Lymph node metastasis in cancer of the larynx is a critical factor in determining disease advancement and prognosis. ${ }^{30}$ Depending on the extent of involvement of the lymph nodes, a modified radical or selective neck dissection is undertaken unilaterally or bilaterally. ${ }^{16}$ The classical radical neck dissection consists of surgical clearance of all lymph nodes from the five areas of the neck as well as removal of one or more of the following: internal jugular vein, sternocleidomastoid muscle and spinal accessory nerve. ${ }^{30}$ Modifications to the procedure have been described to reduce the associated functional impairment and cosmetic changes, as shoulder and neck dysfunction have been identified as quality of life issues. ${ }^{15}$ Selective neck dissection aims to remove selective lymph node groups at certain levels while preserving the other surrounding important structures and associated functions. ${ }^{30}$

\section{Suture materials}

A number of suture materials have been used in association with total laryngectomy. Suture thread can be made from a variety of materials and described as absorbable and non absorbable. Absorbable suture material is required for pharyngeal closure. ${ }^{33}$ Originally suture material was made from biological products such as catgut and silk. Catgut is absorbable within ninety days and tensile strength remains for at least seven days. These 
properties made it popular for use in rapidly healing areas and where access for suture removal is difficult. 34

Most modern sutures are synthetic. Vicryl has taken the place of catgut where an absorbable suture is required such as in pharyngeal closure. It holds its tensile strength for three to four weeks and is completely absorbed within 60 days. ${ }^{34}$ Non-absorbable sutures are made of special silk or the synthetics polypropylene, polyester or nylon. These forms of sutures are widely used for pharyngeal closure due to the lack of absorption. ${ }^{33} 34$

\section{Post-operative management following total laryngectomy}

The early post-operative phase focuses on acute wound healing, stoma care and early pulmonary management. ${ }^{16}$ Low pressure suction drains are placed peri-operatively to prevent accumulation of fluids within the tissues. These are monitored carefully in the early post-operative phase for any changes to the amount and consistency of wound drainage. Drains are routinely removed in the first three to five days post-operatively once output has reduced to a satisfactory level. ${ }^{16}$ Suture lines around the neck and stoma are regularly cleaned and monitored with sutures removed within seven to ten days if healing is satisfactory. A feeding tube is inserted at the time of surgery typically prior to pharyngeal closure.16 This tube may be nasogastric or through a surgically created tracheaoesophageal fistula which will ultimately be used for voice prosthesis placement once enteric feeding can be ceased.

Effective nutrition is considered vital in the case of head and neck cancer 35 however the presence of a nasogastric tube is not always without complications. Nasogastric tubes can prove difficult to re-insert following resection of a head and neck cancer if displacement or blockage occurs due to post-operative swelling, impaired swallowing and tissue sensation. Eley (2012) $)^{35}$ reports on the use of nasogastric tubes in a cohort of 144 patients having undergone oral cancer resection. Tube replacement was found to be an average of 1.9 tubes per patient post-operatively (one to five tubes per patient). Other reported problems include patient discomfort with nasal and mucosal irritation possible. ${ }^{35}$

Within the context of total laryngectomy, it has been proposed that the presence and motion of a nasogastric tube can irritate newly created suture lines. ${ }^{36}$ It has also been shown to be an ascending path for intestinal pathogens in wound infections. ${ }^{37}$ Early complications following total laryngectomy include bleeding, infection, wound breakdown and pharyngocutaneous fistula formation. ${ }^{27}$ 
A pharyngocutaneous fistula is a pathway between the pharynx and the cutaneous skin typically occurring along surgical incision lines or less frequently around the tracheostoma. ${ }^{138}$ A pharyngocutaneous fistula occurs following total laryngectomy surgery when there is a breakdown of the mucosal closure resulting in salivary and secretion leakage into the surrounding tissue ultimately communicating with the skin. ${ }^{39}$ It is the result of a breakdown in the post-operative wound healing process.

\section{Wound healing}

Wound healing can be defined as the restoration of tissue continuity after injury and involves wound closure and restoration of function to damaged tissues. ${ }^{40}$ Healing can take two forms as described by Galen (129-199BC) as primary or secondary intention depending on the physician's aim on treating the wound. This is relevant in considering pharyngeal closure following laryngectomy surgery as well as pharyngocutaneous development and management.

Primary intention is the closure of a wound so that there is approximation of wound edges or by placement of a flap, or wounds formed and closed during surgery. Minimisation of scarring occurs. At this level, epithelial proliferation occurs rapidly usually within the first 24 hours sealing the wound at the level of the basal cells of the epidermis. There is minimal granulation tissue and only small fibrous scarring. Primary intention is the aim following laryngectomy surgery. 40

Secondary intention is where the wound is large or where approximation of tissue edges cannot easily take place or when infection if present. The wound is left open to heal spontaneously. This type of tissue injury leads to a complex, continuous repair process charcterised by inflammation, new tissue formation and matrix formation and remodelling. 40

The inflammatory phase is a local protective tissue response to injury which aims to rid the area of damaged tissue and locally reduce infection. It encourages the formation of granulation tissue and occurs from the time of tissue injury to approximately the fourth day of healing. 40

New tissue formation or proliferation overlaps with and follows the inflammatory response approximately five days post injury. The cells responsible for the ongoing wound repair migrate and proliferate into the wound site for the next 10-14 days. This phase is characterised by re-epithelialisation and further granulation tissue formation. 40 
Matrix formation and remodelling is normally regarded as the third and final phase of wound healing occurring for many months or years following granulation tissue formation. During this phase, granulation tissue is gradually replaced and remodelled forming scar tissue which is less cellular and vascular than the preceding granulation. The scar tissue remains functionally less adaptive as the original skin and never gains its full tensile strength. The accumulation, remodelling and realignment of collagen plays a role in developing increasing tensile strength to the residual scar. This is important in improving the mechanical function of the scar better resembling the uninjured skin. ${ }^{40}$

There are numerous factors that influence this process of healing. With increasing age, the onset of the inflammatory phase is delayed and longer. Collagen organisation is also reduced resulting in decreased tensile strength.

Adequate nutrition is critical for wound healing. ${ }^{41}$ Sequelae of malnutrition include loss of muscle tissue, impaired ability to resist infection and increased risk of complication. ${ }^{41}$ Patients with head and neck cancer are at high risk of malnutrition secondary to the site of the cancer, the disease process itself and the results of treatment. ${ }^{41} 42$ At time of diagnosis, it is reported that $50-70 \%$ patients with head and neck cancer already have malnutrition. The patient may present with long term dietary habits and life style factors that predispose to poor nutrition. ${ }^{15} 42$ Multi-modality cancer treatment can increase the incidence of nutrition related problems. ${ }^{41}$ The presence of chronic conditions such as diabetes, certain drugs and presence of infection can all influence the wound healing process.

In the context of total laryngectomy performed as a salvage procedure, previous irradiated tissue results in permanent damage to the skin's vascular system. The normal healing process is subsequently altered. ${ }^{43}$ As a result of reduced blood supply, wounds heal poorly and are more vulnerable to infection. ${ }^{40}$

\section{Pharyngocutaneous fistula formation}

Fistula formation is reported to be most common in the immediate post-operative period following total laryngectomy $1,38,44$ but there have been reported cases of late onset up to 153 day post-operatively. ${ }^{1}$ The presence of a fistula is usually apparent within 7-11 days post surgery, in many cases before a patient has commenced oral intake. ${ }^{45-47}$

Clinical signs of a pharyngocutaneous fistula include increased neck drain output, wound erythema with soft tissue swelling and neck and facial oedema. ${ }^{39,} 48 \mathrm{~A}$ fever may be present particularly in the context of visible discharge from the wound. Friedman (1999) 4 
found that fever in the first 48 hours post-operatively correlated with the development of pharyngocutaneous fistula following major head and neck surgery. Further contamination of surgical wounds by oral and pharyngeal contents can lead to further wound breakdown and skin flap and soft tissue necrosis. ${ }^{39}$

A pharyngocutaneous fistula may be demonstrated radiologically or by the presence of saliva or oral intake on the skin surface after swallowing. ${ }^{38}$ In clinical practice, a patient may be observed while attempting to swallow a small amount of liquid to determine any clear signs of fistula presence. If a fistula is demonstrated, nasogastric tube feeding is utilised and conservative measures instigated.49 Galli (2009)49 reports that videofluoroscopy/barium swallow is the "gold standard" for assessment of swallowing providing dynamic criteria to define structure and physiology of the post-operative swallow.

Krouse (1992) ${ }^{50}$ in the assessment of 109 patients following total laryngectomy, concludes that a barium swallow performed one to two weeks following surgery was a strong predictor of clinical fistula. A sinus tract of more than two centimetres demonstrated radiologically was predictive, but not preventative of pharyngocutaneous fistula development. Smaller tracts (i.e. less than two centimetres) appeared to be clinically insignificant.

Sarra (2009) $)^{51}$ also reports utilising a radiological study or a methylene blue test to test for fistula formation. This test involves a small amount of blue dye taken orally with the goal of demonstrating any pharyngeal communication with the suture lines. The patient's skin is monitored for any visible dye or discolouration that may suggest wound breakdown. ${ }^{16}$ Kapila et al (2012) 52 advocate the use of this method as safe, quick and effective in determining chyle and anastomotic leaks post head and neck surgery by monitoring wound drains or suture lines for leakage. Ward (2006) ${ }^{16}$ suggests that the blue dye swallowing assessment is only able to reliably assess for a subcutaneous fistula as internal tracts or fistulae are only visible radiologically.

Van La Parra et al (2007)53 developed a grading system to better describe radiological findings in relation to pharyngocutaneous fistula due to inconsistency in terminology used across reporting. They found that not all clinical fistulas could be demonstrated radiologically with a $33 \%$ false negative rate. Given this, they suggest that clinical signs and symptoms continue to be critical in the case of small fistulae that may be hard to demonstrate radiologically. This is supported by Makitie et al $(2006)^{39}$ who reinforce the 
importance of clinical surveillance given the possibility of false negative rates in radiological detection of pharyngocutaneous fistula.

Pharyngocutaneous fistula is reported to be the most common early complication after total laryngectomy with significant increased morbidity and mortality rates as well as increased resource utilisation and patient anxiety. ${ }^{1-3}$ The presence of a fistula delays other postoperative rehabilitation such as a return to or continuation with oral feeding, speech pathology communication intervention and post-operative radiotherapy. ${ }^{2} \mathrm{~A}$ patient's psychological well-being can also be affected. ${ }^{2}$ Post-operatively, the development of a pharyngocutaneous fistula can double the length of an average patient hospital stay. 4,5

The incidence of pharyngocutaneous fistula following total laryngectomy varies widely in the published literature from $0-65 \%{ }^{2}$ Iglesias et al $(2011)^{2}$ in reviewing 20 years of literature found an incidence of $9-23 \%$ but reported difficulty in standardising incidence due to a lack of homogeneity in studies appraised.

\section{Management of pharyngocutaneous fistula}

Early recognition of pharyngocutaneous fistula is critical in avoiding secondary wound complications and other more severe outcomes such as flap necrosis, and carotid rupture. ${ }^{39}$, 50 Management of pharyngocutaneous fistula can take a conservative (secondary intention) or surgical pathway (primary intention) dependent on the size and severity of presentation.

Conservative treatment aims to preserve and restore the involved tissue. De Santana and Sawada (2008) ${ }^{1}$ describe this form of management as a complex, dynamic and systemic process which depends on the health status of the patient and is influenced by pre-existing disease, previous radiotherapy and other factors such as age. Aggressive wound care is critical including regular dressings and debridement as well as early and adequate drainage of the site to reduce the incidence of severe vascular complications. ${ }^{39} \mathrm{Re}$ instatement of antibiotic coverage is recommended as well as optimising healing through the maintenance of adequate nutritional support either by nasogastric, tracheaoesophageal tube or gastrostomy tube feeding. A cuffed tracheostomy tube may be required to minimise aspiration of secretions into the tracheostoma. Most small fistulas in non-irradiated tissue will heal spontaneously with appropriate wound care. ${ }^{39}$ It has been reported that $50-80 \%$ of fistulas will heal without surgical intervention. $45,54,55$ 
Surgical repair is indicated in persistent fistula. Primary closure is reportedly rarely possible 39 but may be a consideration if the fistula size is small and the tissue healthy. The majority of fistulas, however, occur in the context of skin loss and mucosal breakdown. Definitive management is reliant on the size of the fistula, the amount of remaining pharyngeal mucosa and the condition of the skin in the surrounding neck. ${ }^{28} \mathrm{~A}$ wide variety of surgical reconstructive techniques are described in the literature with the main surgical principles being a well-vasularised flap for secure neck closure and the ability of the epithelial surfaces to come together without tension. ${ }^{28} \mathrm{~A}$ pectoralis major myocutaenous flap or latissimus dorsii myocutaenous flap are possible options. ${ }^{39}$ In the case of persistent non healing fistula, recurrent disease should always be considered.

\section{Risk factors for pharyngocutaneous fistula}

Significant factors in the development of pharyngocutaneous fistula have been reported as radiotherapy, congestive heart failure, more extensive surgery, extent of neck dissection and clearance, malnutrition, diabetes mellitus, low haemoglobin levels, ASA risk and surgeon experience.2, 36 Other suggested factors include early oral feeding after surgery, hypothyroidism, post-operative vomitting and gastro-oesophageal reflux disease. ${ }^{2}$

A meta-analysis by Paydarfar and Birkmeyer (2006) 3 substantiates that low haemoglobin post operatively, prior tracheostomy, pre-operative radiotherapy and concurrent neck dissection, are associated with increased risk of pharyngocutaneous fistula. Severity and duration of fistula in pre-operatively irradiated patient was greater in those that had not been irradiated. 3

\section{Cost of pharyngocutaneous fistula}

With pharyngocutaneous fistula shown to double ${ }^{1}$ or even triple ${ }^{56}$ a hospital length of stay, the economic factors are significant. Parikh et al (1998)57 report on the Toronto Hospital experience of pharyngocutaneous fistula in a retrospective review of 123 patients who had undergone surgery for laryngeal or pharyngeal cancer. Taking into consideration operative procedures and the demonstrated increased length of stay for those with fistula development, it was estimated that each fistula cost on average $C \$ 58,000$ or a total of $\mathrm{C} \$ 400,000$ per annum. More recent costing estimates associated with pharyngocutaneous fistula are unavailable.

Patients with head and neck cancer are already at risk of psychosocial problems such as anxiety and depression due to the effects of the cancer location and physical changes 
associated with treatment. ${ }^{58}$ Management of a pharyngocutaneous fistula is likely to result in further delays in re-establishing functions such as eating, drinking and communicating and the commencement of vital post-operative radiotherapy. These delays may add to the already emerging psychological trauma ${ }^{17}$ and necessary physical and psychosocial adjustments experienced by this population. Postponements in initiating radiotherapy can also reduce the effectiveness of such treatment in disease control. ${ }^{58}$

\section{Prevention of pharyngocutaneous fistula}

Makitie et al (2006) ${ }^{39}$ stress that pre-operative recognition of at risk patients may assist to reduce fistula formation. This identification through the presence of comorbid factors may influence the surgical approach to pharyngeal closure. Reduction in fistula development may also be assisted by optimisation of pre-morbid conditions such as diabetes, vascular disease and anaemia. ${ }^{39}$

The use of prophylactic antibiotic management is a standard of care following total laryngectomy and has been reported to reduce severe wound infection by fifty percent. ${ }^{39}$ Seikaly et al (1995) ${ }^{59}$ also demonstrated that prophylactic use of gastro-oesophageal reflux treatment reduced the pharyngocutaneous fistula incidence and length of stay following total laryngectomy.

Meticulous surgical technique is discussed in depth within the head and neck literature as being imperative in pharyngocutaneous fistula prevention. ${ }^{39,60,61}$

\section{Oral feeding and pharyngocutaneous fistula}

There is a historical assumption that delaying oral feeding following total laryngectomy is helpful in reducing the formation of pharyngocutaneous fistula. ${ }^{36}$ The hypothesis is that feeding orally stresses the suture lines and therefore may contribute to wound breakdown and subsequent development of fistula. Boyce in 198960 found by questionnaire that $85 \%$ of American Society Head and Neck consultants interviewed delayed oral feeding until day seven post-operatively. This is an established practice reported by many authors with oral feeding commenced between days 7-14 post-operatively with enteral feeding provided for nutrition. 19, 27, 60, 62 Leading clinical practice guidelines such as The lowa University Laryngectomy Protocol ${ }^{7}$ also recommend commencing oral intake on day seven post operatively for non-irradiated patient and day 14 for those that have had radiotherapy preoperatively. A patient remains nil by mouth until that time to allow surgical sites to heal, theoretically avoiding stress or pressure through the swallowing of food and/or fluid. 
MacLean, Cotton and Perry (2008)28 in a recent survey of Australian Head and neck surgeons found that although timing of oral feeding varied, the majority of surgeons commenced feeding within a range of 7 to 14 days, most commonly on day seven.

O'Hara et al in 200962 undertook a qualitative study of United Kingdom Ear, Nose and Throat consultants' opinions relating to the timing of oral feeding following laryngectomy. Almost all of the eight consultants interviewed followed the established practice of delaying oral feeding however conceded there was no 'scientific basis', 'real logic' or 'objective evidence' to this.

Soylu et al (2007) ${ }^{36}$ challenge the assumption that early oral feeding increases the postoperative fistula rate. It is suggested that patients are already swallowing their saliva in the early days following surgery and as such, the pharynx is never truly at rest. The presence of the nasogastric tube for alternative feeding may also add to patient discomfort and stress post-operatively.

Paydarfar and Birkmeyer (2006) ${ }^{3}$ further examined this hypothesis through the conduct of a meta-analysis to investigate risk factors for post-laryngectomy pharyngocutaneous fistula. Although raised as a possible confounding factor, early oral feeding was not identified as significant within the meta-analysis itself nor found to be a significant risk factor in other single studies considered for but eventually not included within this meta-analysis.

Early feeding is currently under consideration within the literature and also within clinical practice for this patient group. There are emerging clinical protocols (Robinson $\mathrm{R}$, Speech Pathologist, Head and Neck Oncology, Prince of Wales Hospital NSW, personal email communication, 2012 Mar 6) (Simms V, Clinical Consultant ATOS Medical, personal email communication, 2012 Mar 22) that are trialling early feeding following laryngectomy with select patient groups. Indicators include non-irradiated and well-nourished patients, surgery performed as a primary rather than a salvage procedure and no additional flap reconstruction.

\section{Why a systematic review on oral feeding in total laryngectomy is required}

A review by Dalziel (2001) for the Centre for Clinical Effectiveness ${ }^{63}$ critically appraised two studies related to timing of oral feeding following laryngectomy: one randomised controlled trial and one comparative study. 64,65 These findings showed no significant increase in the rate of pharyngocutaneous fistula with early feeding but the review did not interpret these 
in terms of specific recommendations for clinical practice. The intervention was described as timing of feeding following laryngectomy but not further defined. There was no stated definition of a comparator or of an outcome. This review was completed over ten years ago with a search date limit of 2001 and more recent studies relating to the timing of oral feeding may be available and contribute more fully to the body of evidence.

Jeannon in O'Hara62 reports that incidence of pharyngocutaneous fistula rates for feeding regimes at two to three days were equivalent to those seen at seven to ten days (metaanalysis of 402 patients). The sample however was noted to be significantly heterogeneous making comparisons and conclusions difficult. Although labelled a systematic review, search and appraisal mechanisms were not documented or transparent and only one reviewer was involved in the analysis.

Davidson et $a^{66}$ reviewed the question of when and how oral feeding should be commenced following total laryngectomy for the Clinical Oncological Society of Australia (COSA) evidence based nutritional guidelines for head and neck cancer. Their conclusions were that early feeding following primary total laryngectomy should be considered to reduce length of stay as there has been no difference in the fistula rates compared to delayed feeding at seven days plus. Although this is a recent literature review, the search process did not seek to identify research related specifically to early feeding and incidence of pharyngocutaneous fistula.

As discussed above, several literature reviews associated with the question of early feeding have been identified.62, 63, 66 These reviews were limited by sample size, transparency of process and specificity of question. This systematic review is necessary to rigorously examine the relationship between early oral feeding and pharyngocutaneous fistula following total laryngectomy. The outcomes will contribute to and expand on the knowledge of post-operative care for this patient group as well as direct possible future primary research gaps.

\section{Review question and objectives}

The objective of this review was to identify and synthesise the best available evidence on the effects of early feeding compared to standard oral feeding following total laryngectomy on the incidence of pharyngocutaneous fistula and hospital length of stay.

More specifically, the review questions were: 
What is the effect of early oral feeding following total laryngectomy on the incidence of post-operative pharyngocutaneous fistula?

What is the effect of early oral feeding following total laryngectomy on hospital length of stay?

\section{Conclusion}

Pharyngocutaneous fistula is reported to be the most common early complication following total laryngectomy with significantly increased morbidity and mortality rates as well as resource utilisation. Post-operatively the presence of a pharyngocutaneous fistula can double the average patient hospital stay and delay other vital cancer treatment such as radiotherapy. There is extensive published literature on risk factors for the development of a pharyngocutaneous fistula. Delaying oral feeding following total laryngectomy surgery has historically been advocated as one method to reduce the risk of this complication which can have severe repercussions for the patient, their ongoing cancer treatment, postsurgical rehabilitation and quality of life. There is debate questioning whether this established clinical practice is based in sound theoretical constructs and as a result, early feeding is being considered both within the literature and in clinical practice within some international centres.

The purpose of this systematic review on the effect of early oral feeding compared to standard oral feeding following total laryngectomy is to rigorously consider the best available evidence relating to this question, and translate these findings where possible into recommendations for clinical practice and future primary research. 


\section{Chapter Two: Methodology and methods}

\section{Introduction}

The science of systematic reviews has evolved through the positivist (empirico-analytical) paradigm $^{67}$ which aims to view the world though objectivity so that variables can be manipulated and controlled. As a result, it is postulated that knowledge is generated through controlled experimentation and observation in an attempt to confirm explanations. The positivist paradigm is concerned with quantitative theory. ${ }^{68}$ Areas of health care, particularly those that involve physiological processes are amenable to such a methodology and this systematic review follows a quantitative a-priori protocol based on Joanna Briggs Institute's methodology for reviews of effect. However in considering knowledge generation, it becomes apparent that evidence can go beyond the quantitative domain due to the diversity of problems in health care practices. An important element to the $\mathrm{JBI}$ model is the broadening understanding of the nature of evidence, its translation into health care delivery and the facilitation of improved global health. 68

This chapter discusses the development of evidence based health care and evidence synthesis, and its relationship to the Joanna Briggs Institute model of evidence based health care. The methodology for this systematic review is also presented.

\section{Systematic Review Methodology}

\section{Development of Evidence Based Health Care}

Karl Pearson, in 1904, was most likely the first medical researcher who reported formal techniques to combine data. However in medicine, such techniques were not practised for many years to come. Within the social sciences early interest developed in the synthesis of research findings. In 1976, a psychologist, Gene V Glass created the term meta-analysis in a paper entitled "primary secondary and meta-analysis of research".69 Evidence based medicine emerged in the 1990s through the work primarily of Professor David Sackett and colleagues of the University of Oxford. Sackett and Rosenberg (1995)70 described evidence based medicine to be a lifelong and self directed learning process whereby patient care created the need for information about patient conditions, progression of disease, best form of intervention and broader organisation issues such as cost effectiveness of treatment. They described 5 major principles: ${ }^{70}$ 
- That patient care and broader health care decisions should be based on the best available evidence. The evidence best able to answer a question may be clinical, diagnostic laboratory, published primary research or other sources.

- That the question is determined by the problem rather than historical protocols, traditions, and habits. Information needs should be converted into an answerable question.

- That evidence should be critically appraised on its validity and usefulness.

- That results should be applied to clinical practice.

- That continuous evaluation of performance is vital.

Since that time this approach to evidenced-based medicine has developed rapidly. The British and Canadian movements of evidence based medicine led to the development of databases for systematic reviews, meta-analyses, clinical guidelines and best practice. ${ }^{71} \mathrm{~A}$ number of specialist groups internationally have led to the formation of the Cochrane Collaboration.

The Cochrane Collaboration is named in honour of Archie Cochrane, a British medical researcher who contributed significantly to the development of epidemiology as a science in the 1970-1980s. ${ }^{72}$ Underlying principles were firstly, that limited health care resources should be channelled into areas of health care interventions that had been effectively evaluated, and secondly, the importance of using evidence from randomised controlled trials to inform health care practice due to the reliability of information provided compared to other sources of evidence. Cochrane's challenge to focus on evidence based interventions led to the development of the Oxford Database of Perinatal Trials in the 1980s. In 1987, he highlighted the efficacy of a systematic review of prenatal care, based on randomised controlled trials, and encouraged other specialities to utilise a similar method in establishing evidence for intervention. ${ }^{72}$

The Cochrane Collaboration was founded in 1992 and focuses on the systematic review of randomised controlled trials for specific diseases, patient groups or health care interventions predominantly in the medical specialties. ${ }^{68}$ The collaboration is committed to training and support in systematic review methodology as well as a continuous process of systematic review updates. ${ }^{73}$

The need to minimise cost and increase effectiveness over the last ten years has driven the ongoing development of "best practice" within health care in the westernised world. 68 
Examples of this include the Centre for Evidence Based Medicine in Oxford, the Campbell Collaboration now based in Oslo, the NHS Centre for Reviews and Dissemination in York, the establishment of the Australasian Cochrane Centre initially in Adelaide and now in Monash Victoria, and the Joanna Briggs Institute based in Adelaide, Australia. The premise of "best practice" has been increasingly linked to the best available evidence and, although initially it had a medical focus, it has now evolved to include multi-disciplinary collaboration leading to the term evidence based health care. 68

\section{Models of Evidence Based Health Care}

Evidence based healthcare is growing and becoming increasingly established globally. 68 , 74,75 There are a number of models that attempt to characterise evidence based healthcare and have informed the developing and expanding understanding of evidence. Illustrations of these are detailed below.

The Ace Star Model of Knowledge Transformation ${ }^{76}$ was developed by the University of Texas Health Science Centre in San Antonio and consists of five knowledge transformation steps moving through a star shaped cycle. ${ }^{71}$ The model demonstrates differing forms of sequential knowledge as research evidence moves through the cycle namely discovery research, evidence summary, guideline translation, practice integration and evaluation of outcomes. The model aims to provide a framework for new and old concepts of improving health care as well as seeking to assist in the understanding of the "cycles, nature and characteristics of knowledge" that are used within evidence based practice. ${ }^{76}$

The lowa model of evidence-based practice was developed in 1994 by Titler and colleagues to be used as a framework focussing on translating research findings into improving patient care. ${ }^{77-79}$ Evidence is seen as pivotal in understanding the evidence based health care approach. ${ }^{67}$ The original model has been revised and the translation research model (2001) is based on the "conscientious and judicious use of the best available evidence" in health care decision making. ${ }^{74}$ It is a multi-phase change process with feedback loops. 80 This framework, drawn from Roger's Innovation Framework (2003), expands on the principles of creating and distilling knowledge, how that knowledge is communicated, interaction and communication between context and user, and how evidence is adopted. 79

The Stetler Model of research utilisation ${ }^{81}$ was first reported in 1976, then refined and expanded in $1994 . .^{71}$ Similar to the lowa model, its focus is on how to facilitate the application of research findings into practice both at a health care practitioner level and at 
an organisational level. The six phases are preparation, validation, comparative evaluation, decision making, translation/application and evaluation. All six phases are affected by the setting and influences of the health care environment, the personal characteristics and cognitive processes of the user and ultimately how research findings are utilised. 81

Ryecroft-Malone et al first presented their PARIHS (Promoting Action on Research Implementation in Health Sciences) framework in 1998 and it has undergone further refinement and development over a number of stages. ${ }^{82}$ it is multi-dimensional and attempts to represent the complexities of implementing evidence into practice. Three core elements are proposed for successful implementation to occur: the nature and type of evidence, the context in which evidence is introduced and the way in which factors influence how this process is facilitated. 74,83

Dobrow et al (2004) present a conceptual framework for evidence based decision making which focuses on how context impacts on how evidence is defined and used. ${ }^{84}$ This framework attempts to highlight that both evidence and context are integral to evidence based decision making. They believe that existing models of evidence based health care focussing on evidence cannot adapt to the broader policy environment. They attempt to clarify that evidence changes with the shift from decision making at the clinical level to that at a population policy level. In doing so, "axes of evidence based decision making" are proposed that incorporate both evidence and context. ${ }^{84} \mathrm{It}$ is suggested that the interaction between the two is what informs and is critical to the evidence based health care policy. ${ }^{74}$, 84

\section{Joanna Briggs Institute Model of Evidence Based Health Care}

The Joanna Briggs Institute Model of Evidence Based Health Care (JBI Model) forms the basis of the following systematic review and as such will be explored in more detail.

The JBI Model views evidence based health care as clinical decision making that considers the best available evidence. ${ }^{74}$ Fundamental to the JBI Model is that health practitioners will consider and reflect on research evidence within the context of clinical care, client preferences and their own professional judgement, expertise and experience. Improved global health outcomes is considered as both the objective and the endpoint of each of the model components and is viewed as the underlying foundation of evidence based health care. 68 
The JBI Model aims to address gaps within the research cycle by building on other evolving frameworks within a systematic and developmental approach. ${ }^{85}$ It has been constructed out of experience within the evidence based health care field and through the emerging work of the JBI International Collaboration and the work of the JBI Institute. ${ }^{85}$ The $\mathrm{JBI}$ Model describes the four major principles of evidenced based health care process to be health care evidence generation, evidence synthesis, evidence transfer and evidence utilisation. 68

Health care evidence generation and evidence synthesis will be discussed more fully below. Although it is not within the scope of this systematic review to discuss the theoretical considerations of evidence transfer and utilisation within the JBI Model, it is acknowledged the critical role these principles play in determining systematic review conclusions and implications for practice and research.

\section{Health care evidence generation}

Traditionally, the randomised controlled trial has been the basis of systematic review processes. However, Pearson (1998) ${ }^{86}$ argues that evidence needs to go beyond the quantitative domain due to the diversity of problems in health care practices. Clinicians search out evidence to substantiate the value of a wide range of health care interventions and activities. This variability necessitates diversity in research methodologies that can support and be responsive to multi-disciplinary interventions and be relevant to the needs of consumers. 68

In the JBI Model, there are four types of evidence. ${ }^{74}$ The type of evidence needed depends on the activity and its purpose. These are described as follows:

1. Evidence of feasibility - the extent to which an activity is practical or practicable

2. Evidence of appropriateness - the extent to which an activity or intervention relates to the context in which care is given

3. Evidence of meaningfulness- relates to the personal experience, opinions, values, beliefs and interpretation of the client

4. Evidence of effectiveness - relates to how the activity or intervention achieves the intended effect.

The model emphasizes that evidence to support the diversity of health care needs may draw from experience, expertise or rigourous investigation. 


\section{Evidence synthesis}

Evidence synthesis is "the evaluation or analysis of research evidence and opinion on a specific topic to aid in decision making in health care". 68 Within the JBI Model, there are three elements to this process: theory, methodology and the systematic review.

There has been rapid growth in the use of the systematic review as a source of evidence on which health care decisions are made. 87 The growing volume of health care literature and increasing number of health care interventions and technological advances demand that health care professionals seek evidence to support clinical practice and decision making. Dollaghan (2007) ${ }^{69}$ provides an example of a recent search for information on communication disorders in Pubmed which resulted in approximately 40,000 citations, 5000 from the last five years. With this type of expansion of information, it could be assumed that health practitioners' knowledge is greater. However, Evans and Pearson (2001 $)^{87}$ suggest that clinicians are unable to keep up to date in their areas of clinical practice. This growing gap between best available evidence and implementation into clinical practice is one of the driving forces behind evidence based health care. ${ }^{88}$ In addition, variability in the methodological quality of publications adds to difficulties in confidently translating theory into practice. As a result, systematic reviews are increasingly being sourced to provide the best available evidence to questions posed by professionals. ${ }^{87}$ Clinicians require a systematic, defensible and realistic process for deciding which evidence will best support health decision making. 69

Systematic reviews allow the synthesis of evidence across a number of studies that have been identified and appraised according to clear and well defined criteria. ${ }^{69}$ Stand alone studies often result in inconclusive findings or may have insufficient power to demonstrate significance. A systematic review, and if able to be performed, a meta-analysis make it possible to consider patterns that may emerge across multiple studies. ${ }^{69,89}$

The systematic review process traditionally has focussed on questions of effectiveness however it has become increasingly apparent that this is only one form of evidence required to support health care decision making needs. ${ }^{87}$ Evidence may be gathered legitimately through experience, opinion and research that involves numerical and/or textual data that may be extracted, appraised and synthesized. 85

Within the JBI Model, the systematic review process is fundamental to evidence based health care and in determining the best available evidence from a variety of sources. An 
important element to this model is the broadening understanding of the nature of evidence, its translation into health care delivery and the goal of improved global health. 68,85 The systematic review process within the JBI Model allows the appraisal, extraction and synthesis of evidence relating to Feasibility, Appropriateness, Meaningfulness and Effectiveness, and acknowledges that these forms of evidence are all valid within a systematic review process. 68

There have been numerous hierarchies of evidence based predominantly on methodological design and rigour. ${ }^{84}$ Systematic reviews are starting to be seen as the highest level of evidence because the focus is not on a single finding but rather based on multiple populations, conditions and contexts. ${ }^{87}$ Evans and Pearson $(2001)^{87}$ suggest that the focus of these hierarchies has expanded with scales developing to address questions relating to diagnosis, prognosis and economic issues.

\section{Clinical effectiveness}

Acknowledging that evidence can take diverse forms within the JBI Model, the question posed within this systematic review is one of effectiveness. Clinical effectiveness is about "the relationship between an intervention and clinical or health outcomes". 68 For this form of question, the randomised controlled trial is considered the gold standard ${ }^{90}$ however as discussed above, other forms of evidence may inform the question.

Randomised controlled trials have been favoured over other study designs due to the high internal validity. However it is not possible to have a randomised controlled trial for every clinical question. ${ }^{90}$ Observational methods may play a role in situations where experimentation may not be possible due to cost, ethical or logistical reasons. ${ }^{91}$ The lack of randomisation and differing inclusion criteria may increase the risk of bias however the external validity of observational study findings mean that they may better reflect actual clinical practice. Evans and Pearson (2001) ${ }^{87}$ suggest that observational studies should be considered for inclusion within a systematic review and that results may be complementary to those of a randomised control trial.

\section{Methodology of this systematic review}

A systematic review involves a structuring of the processes through which a thorough review of previous research is carried out.89 This requires a clear statement of the question, definition of subgroups of interest, and methods and criteria for study inclusion. Processes for extraction and synthesis of data should be clearly defined so as to allow 
evidence based conclusions. The processes utilised for the effectiveness of early oral feeding compared to standard oral feeding following total laryngectomy are defined below.

\section{Inclusion criteria}

\section{Types of participants}

This review considered studies that include adults (18 years old or older) regardless of gender and comorbidities who commenced early oral feeding following total laryngectomy surgery. Studies focussing on enteral feeding were excluded from the review.

\section{Types of intervention(s)/phenomena of interest}

This review considered studies that evaluated oral feeding following total laryngectomy.

The intervention of interest was early oral feeding defined as oral intake in the first six days post-operatively. The comparator was standard care and was defined as oral intake from day seven onwards. For the purpose of this review, oral feeding included either food or liquid taken by mouth regardless of quantity or consistency. Oral feeding may be taken in conjunction with non-oral nutrition.

\section{Types of studies}

This review considered both experimental and epidemiological study designs including randomised controlled trials, non-randomised controlled trials and quasi-experimental designs. In the absence of before and after studies, prospective and retrospective cohort studies, and analytical cross sectional studies, the review also considered descriptive epidemiological study designs including case series, individual case reports and descriptive cross sectional studies for inclusion in an effort to inform the effectiveness of this intervention.

\section{Types of outcomes}

This review considered studies that included the following outcome measure: incidence of pharyngocutaneous fistula. In the context of this review, the term incidence referred to the number of new cases of pharyngocutaneous fistula within six months following total laryngectomy surgery.

A further outcome included, but not limited to, was hospital length of stay measured as days of hospital inpatient admission.

\section{Search strategy}

The search strategy aimed to find both published and unpublished studies. A three-step search strategy was utilised in this review. An initial limited search of MEDLINE and 
CINAHL was undertaken followed by analysis of the text words contained in the title and abstract, and of the index terms used to describe the article. As part of this process, potential key words and index terms were individually tested to probe relevance to the inclusion criteria. Search terms yielding irrelevant studies were omitted from the second tier search. A second search using all identified keywords and index terms was then undertaken across all included databases. Search terms were kept broad to capture as many relevant studies as possible due to the nature of the topic question. Thirdly, the reference list of all identified reports and articles was searched for additional studies. Studies published in English were considered for inclusion in this review. Studies published from the inception of included databases to 1/6/2012 were considered for inclusion in this review. It was not anticipated that large numbers of studies, particularly those of high methodological quality, would be sourced in this specialist area, and as a result selected databases were searched from inception to best capture available studies.

The databases searched included EMBASE, Pubmed, Cinahl, Cochrane Library of Systematic Reviews, TRIP, Joanna Briggs Institute Library of Systematic Reviews and Scopus.

The search for unpublished studies included Dissertation abstracts international, Med Nar, Proquest Dissertations and Theses. Initial keywords and search terms used were oral feeding, total laryngectomy and fistula. Search terms for Pubmed and Embase can be found in Appendix 1.

\section{Assessment of methodological quality}

Papers during full text review that met the inclusion criteria outlined above were selected for critical appraisal. These papers were then assessed by two independent reviewers for methodological validity prior to inclusion in the review using standardised critical appraisal instruments from the Joanna Briggs Institute Meta Analysis of Statistics Assessment and Review Instrument (JBI-MAStARI) (Appendix II). The aim of the critical appraisal tool was to assess the validity of each paper and determine possible sources of bias in study design, conduct and analysis. ${ }^{92}$ Each type of study design has an associated appraisal checklist with a series of criteria that can be scored as being met, not met, unclear or if necessary, not appropriate to that particular study.

Experimental papers were assessed against ten appraisal questions and descriptive papers were against nine. To assist in consistency of appraisal across the two reviewers, 
definitions were developed against each possible response to questions being considered. Appraisal initially occurred with each reviewer blinded to the results of the other. Once complete, the primary reviewer was able to compare results of each appraisal. Any disagreements that arose between the reviewers were resolved through discussion and careful consideration of the associated definitions. On one occasion, the opinion of a third reviewer was sought due to differing interpretations of study data with agreement achieved. A cut off point of four out of ten for experimental papers and four out of nine for descriptive papers was decided upon due to the nature of the intervention i.e. oral feeding, and the likely poor ratings against questions of participant blinding. Experimental and descriptive papers that achieved less than four out of ten or nine respectively were considered to be of insufficient methodological quality to include in the final analysis.

\section{Data collection}

Data extraction refers to the process of identifying and recording relevant information to the question being considered within the systematic review.

Data were extracted from papers included in the review using the standardised data extraction tool from JBI-MAStARI (Appendix III), an analytical module of the JBI-SUMARI software. The use of a standardised tool aims to minimise the risk of error in extracting data. The data extracted included specific details about the interventions, populations, study methods and outcomes of significance to the review question and specific objectives.

\section{Data synthesis}

Quantitative data was, where possible, pooled in statistical meta-analysis using JBIMAStARI. Meta-analysis, in a question of effectiveness, is desirable as it provides a statistical summary estimate of the effect size of a treatment/intervention within a specific population. A meta-analysis increases the precision of the estimate of effect size by combining results of individual studies and provides a greater chance of detecting a true effect as statistically significant. 92

All results were subject to double data entry. Effect sizes expressed as risk ratio (for categorical data) and weighted mean differences (for continuous data) and their 95\% confidence intervals were calculated for analysis if indicated.

Heterogeneity was assessed statistically using the standard Chi-square and also explored using subgroup analyses based on the different study designs included in this review. 
Where statistical pooling was not possible the findings were presented in narrative form including tables and figures to aid in data presentation and context where appropriate.

\section{Conclusion}

Within the JBI Model, the systematic review process is fundamental to evidence based health care and in determining the best available evidence from a variety of sources. 67,68 An important element to this model is the broadening understanding of the nature of evidence, its translation into health care delivery and the facilitation of improved global health.

The aim of a systematic review is to consider and synthesize the evidence on a specific clinical question using a rigorous and transparent approach. ${ }^{67} \mathrm{~A}$ consistent apriori protocol driven method, as part of the JBI Model's evidence based health care approach, ensures that the question under consideration is clearly defined, a process of primary study appraisal and data extraction is undertaken in a reliable and repeatable way and that results can be synthesized systematically. These highly defined measures are well positioned within the positivist paradigm due to the strength of research methods that focus on objectivity and the influence on reducing bias. ${ }^{67}$ 


\section{Chapter Three: Results}

\section{Introduction}

Evidence synthesis is the evaluation or analysis of research evidence and opinion on a specific topic to aid in decision-making in health care. ${ }^{68}$ Results should be pooled in such a way as to determine whether the evidence supports the interventions under examination. In a Joanna Briggs Institute systematic review using a quantitative methodology, the results of similar studies can be combined in meta-analysis to determine the overall effect of a particular form of health care intervention compared to another standard form of intervention. ${ }^{92}$ Meta-analysis uses various statistical methods to combine the results of multiple different studies to produce a stronger conclusion than can be derived from any one of the studies on its own. ${ }^{8}$ However, dependent on the design and quality of studies included within the systematic review, statistical pooling may not always be appropriate and as such a narrative format can be used to synthesise study results.

This chapter presents the results from the studies included in the critical appraisal process. Both meta-analysis and narrative formats are used to present the relevant data.

\section{Description of studies}

The search identified a total of 3075 studies. Following removal of duplicates, studies not in English, or outside the date criteria, there were 1621 studies. The titles and abstracts were then reviewed to determine their relevance to the review question and objectives. During this process, 1603 studies were excluded, leaving eighteen studies, which were retrieved in full text for detailed examination. Following the review of the full text, an additional study was retrieved for detailed examination from the reference lists of the studies resulting in nineteen in total.

Ten of the 19 studies were excluded (Appendix IV) as they did not fully meet the inclusion criteria resulting in nine (see table 1) for critical appraisal. Four studies were experimental (two randomised controlled trials, two quasi experimental) in design and five were descriptive. Following appraisal, eight studies were considered to be of high enough quality based on critical appraisal results. 
Table 1 : Number of studies found and retrieved

\begin{tabular}{|c|c|}
\hline Number of studies found & Number selected for retrieval \\
\hline 1621 & 9 \\
\hline
\end{tabular}




\section{Flowchart 1: number of studies found and retrieved}

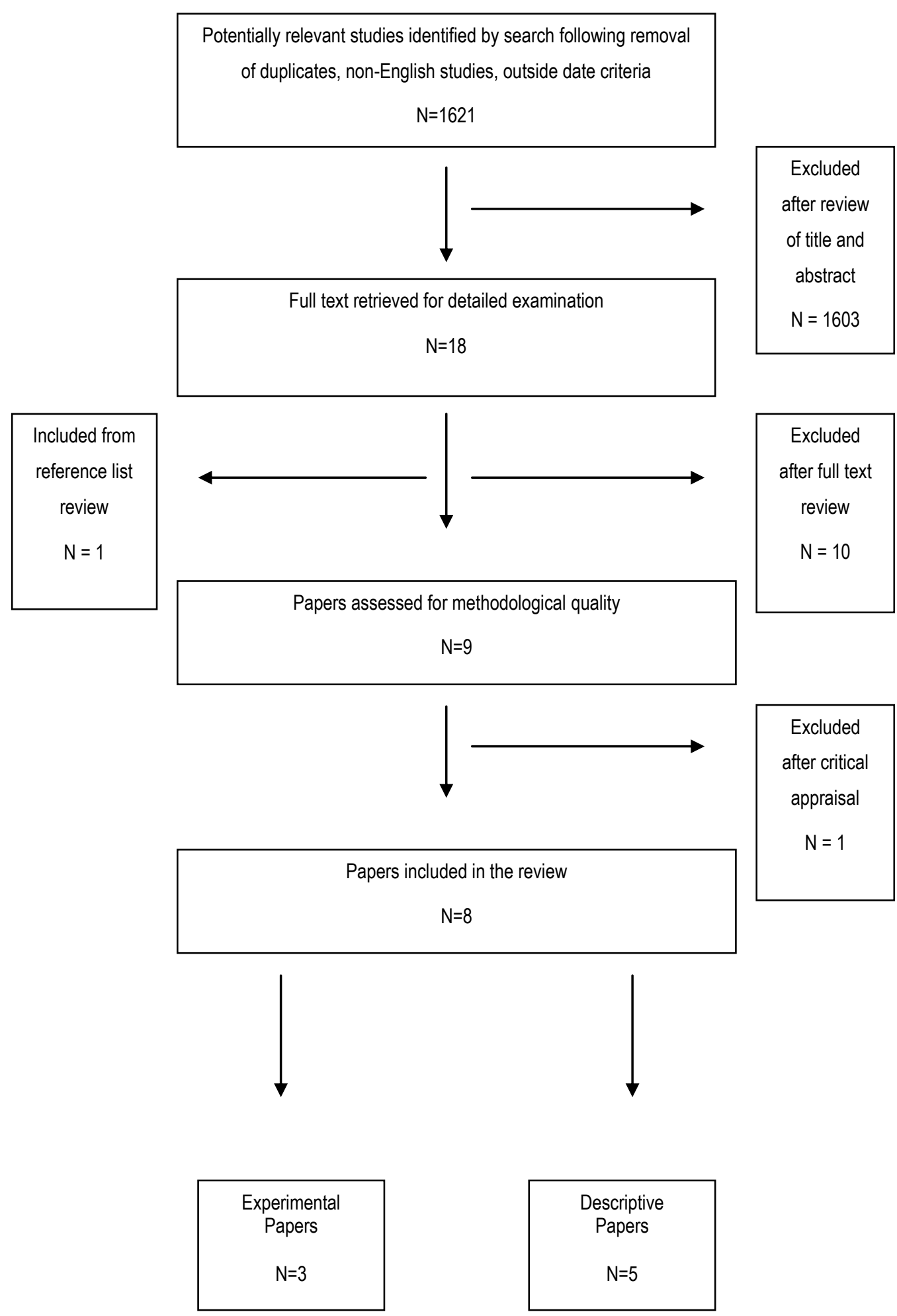




\section{Methodological quality}

Following the search process, nine studies (Appendix V) underwent independent critical appraisal by two reviewers trained in the use of the Joanna Briggs Institute Meta Analysis Statistics Assessment and Review Instrument (JBI-MAStARI) (Appendix II). This included four experimental studies and five descriptive studies. Any disagreements were resolved by discussion and on one occasion seeking the opinion of a third reviewer. A cut off figure of four out of ten for experimental studies was decided upon for inclusion given there were two quasi-experimental studies, which would not rate highly on questions of randomisation and blinding. A similar cut off point of four out of ten for descriptive studies was included given the variation in length and detail of studies within this group.

One experimental study was excluded ${ }^{93}$ due to a poor result against the appraisal questions achieving two out of a total ten points. (Appendix VI) This study, due to its quasiexperimental design, had poor compliance against questions relating to randomisation, blinding of participants for treatment allocation, and concealment of allocation to treatment groups. Although the study described its study group well, it failed to provide sufficient details of the control group other than it being 'similar'. Method of measurement of the primary outcome of pharyngocutaneous fistula was not documented and therefore questions relating to reliability of outcome measurement were assessed as inconclusive.

All other experimental and descriptive studies were included following appraisal.

Table 2: Number of studies included and excluded

\begin{tabular}{|c|c|}
\hline Number of studies included & Number of studies excluded \\
\hline 8 & 1 \\
\hline
\end{tabular}

\section{Experimental studies:}

Overall the methodological quality varied due to the combination of both randomised control trials and quasi-experimental trials in this category. With the exception of one study, 94 questions one, two and three relating to randomisation, blinding of participants to treatment allocation and concealment of allocation to treatment groups resulted in poor compliance across the remainder of the studies. For questions two and three, given that oral feeding is the intervention, it is understandable that blinding for both participants and assessors of outcomes would be a difficult proposition. 
The questions relating to measurement of the outcomes and reliability of outcomes resulted in considerable debate between both reviewers regarding their definition. The outcome of pharyngocutaneous fistula, although a present or absent phenomena, was not always clearly defined as to its method of diagnosis. Although radiological testing is considered clinically to be the most reliable measurement available, an answer of 'yes' was given to questions eight and nine if the method of pharyngocutaneous fistula diagnosis was documented and was the same across all patients.

Length of stay, where included as a secondary outcome, also required a clearly documented definition to receive a 'yes' response during appraisal.

The table below describes the results of appraisal for included studies.

Table 3: Results of critical appraisal of included Randomised Control Trial / Pseudo-randomised Trial

\begin{tabular}{|l|c|c|c|c|c|c|c|c|c|c|}
\hline Citation & Q1 & Q2 & Q3 & Q4 & Q5 & Q6 & Q7 & Q8 & Q9 & Q10 \\
\hline $\begin{array}{l}\text { Medina, J. E. \& Khafif, } \\
\text { A., 2001 65 }\end{array}$ & N & N & N & Y & U & Y & Y & U & U & Y \\
\hline $\begin{array}{l}\text { Sharifian, H. A., Najafi, } \\
\text { M., Khajavi, M., 2008 97 }\end{array}$ & U & N & U & U & U & Y & Y & Y & Y & Y \\
\hline $\begin{array}{l}\text { Seven, H., Calis, A. B., } \\
\text { Turgut, S., 2003 }\end{array}$ & Y & N & Y & Y & U & Y & Y & Y & Y & Y \\
\hline$\%$ & 33.33 & 0.00 & 33.33 & 66.67 & 0.00 & 100.00 & 100.00 & 66.67 & 66.67 & 100.00 \\
\hline
\end{tabular}

\section{Descriptive studies}

All descriptive studies met the criteria of inclusion being four out of nine points during appraisal. The range of complexity of these studies varied significantly.

Similarly to the experimental studies, no study complied with question one relating to randomisation of the sample. All studies included a retrospective case series that was date based therefore being a convenience sample. Variability was noted in how clearly inclusion criteria were considered across the six studies. Strong compliance was gained for question three relating to identification of confounding factors with all studies considering radiotherapy as a minimum within their sample. A number of studies ${ }^{36,65,95}$ considered a critical amount of background clinical and surgical information in an attempt to more fully consider confounding factors in the development of pharyngocutaneous fistula.

There was significant variability in how outcome measures of incidence of pharyngocutaneous fistula and hospital length of stay were defined. Three studies $36,65,96$ 
measured but did not define the method of measurement for the included outcomes which had influence on appraisal questions relating to reliability of outcome measurement. It was agreed by the reviewers that the measurement of the outcomes of both pharyngocutaneous fistula and hospital length of stay if included needed to be defined and documented to gain a 'yes' response.

All studies gained compliance with question nine relating to statistical measurement however there was variability in the complexity of statistics used based on the methodology and data gathered within individual studies.

Table 4: Results of critical appraisal of included descriptive studies

\begin{tabular}{|c|c|c|c|c|c|c|c|c|c|}
\hline Citation & Q1 & Q2 & Q3 & Q4 & Q5 & Q6 & Q7 & Q8 & Q9 \\
\hline $\begin{array}{l}\text { Saydam, L., Kalcioglu, } \\
\text { T., Kizilay, A., } 200295\end{array}$ & $\mathrm{~N}$ & Y & Y & Y & Y & U & Y & Y & Y \\
\hline $\begin{array}{l}\text { Akyol, M. U., Ozdem, C., } \\
\text { Celikkanat, S., } 1995101\end{array}$ & $\mathrm{~N}$ & Y & $Y$ & Y & $\mathrm{N}$ & U & $Y$ & Y & Y \\
\hline Aprigliano, F., 199096 & $\mathrm{~N}$ & Y & $Y$ & U & $\mathrm{N}$ & U & $Y$ & U & Y \\
\hline $\begin{array}{l}\text { Soylu, L., Kiroglu, M., } \\
\text { Aydogan, B., Cetik, F., } \\
\text { Kiroglu, F., Akcali, C., } \\
\text { Ozsahinoglu, C., } 199736\end{array}$ & $\mathrm{~N}$ & Y & Y & U & Y & U & Y & U & Y \\
\hline $\begin{array}{l}\text { Medina,J.E. } \\
\text { Khafif,A.200165 \& }\end{array}$ & $\mathrm{N}$ & Y & Y & U & Y & Y & Y & U & Y \\
\hline$\%$ & 0.00 & 100.00 & 100.00 & 40.00 & 60.00 & 20.00 & 100.00 & 40.00 & 100.00 \\
\hline
\end{tabular}

\section{Results:}

Results will be discussed under experimental and descriptive headings.

\section{Experimental}

All three included studies were published in the last twelve years. One study was undertaken in the United States of America with the other two in Tehran-Iran ${ }^{97}$ and Turkey94 respectively. All studies took place within major teaching hospitals with a focus on education, research and specialised clinical practice.

The study undertaken by Medina and Khafif (2001)65 was based at the University of Oklahoma Health and Science Centre which is a major state training centre for medical, dental and allied health practitioners. The Centre has multiple specialty areas including otolaryngology, head and neck cancer, audiology/speech pathology and plastics and reconstructive surgery. The Department of Otolaryngology reportedly performs in excess of 
four thousand operative procedures per year. The centre provides services to a number of affiliated regional medical centres. ${ }^{98}$

The setting for the study performed by Seven, Calis and Turgut (2003) ${ }^{94}$ was the Logham Hakim Hospital/Shahid Beheshti University in Tehran-Iran. The Shahid Beheshti University of Medical Science provides services for more than ten million residents in Tehran together with training students in many health related areas. It is a leading university with a reputation for excellence in research and teaching. The hospital which has four hundred medical, surgical and paediatric beds has a number of specialised otolaryngology services. ${ }^{99}$

The study by Sharifian, Najafi and Khajavi (2008) ${ }^{97}$ was set at the Sisli Etfal Training and research hospital in Istanbul, Turkey. It is reported to be the second largest state hospital in Turkey with a capacity of one thousand beds. ${ }^{100}$

The three studies included two randomised controlled trials 94,97 and one quasiexperimental study design. 65

Table 5: Summary of experimental studies

\begin{tabular}{|c|c|c|c|c|c|}
\hline Study & Country & Methodology & Population & \multicolumn{2}{|c|}{ Number } \\
\hline & & & & $\begin{array}{l}\text { Standard } \\
\text { oral } \\
\text { feeding }\end{array}$ & $\begin{array}{l}\text { Early } \\
\text { oral } \\
\text { feeding }\end{array}$ \\
\hline $\begin{array}{l}\text { Medina and } \\
\text { Khafif }(2001)^{65}\end{array}$ & USA & $\begin{array}{l}\text { Prospective quasi } \\
\text { experimental }\end{array}$ & $\begin{array}{l}\text { Total laryngectomy excluding } \\
\text { significant pre-operative } \\
\text { radiotherapy, previous resections of } \\
\text { upper aero digestive tract for SCC } \\
\text { and additional primary tumours of } \\
\text { pharynx or oesophagus }\end{array}$ & 18 & 20 \\
\hline $\begin{array}{lr}\text { Seven, } & \text { Calis } \\
\text { and } & \text { Turgut } \\
(2003)^{94} & \end{array}$ & Turkey & Prospective RCT & $\begin{array}{l}\text { Total laryngectomy with primary } \\
\text { pharyngeal closure and were } \\
\text { candidates for trachea- } \\
\text { oesophageal puncture }\end{array}$ & 33 & 32 \\
\hline $\begin{array}{l}\text { Sharifian, Najafi } \\
\text { and Khajavi } \\
(2008)^{97}\end{array}$ & Tehran-Iran & Prospective RCT & $\begin{array}{l}\text { Total laryngectomy excluding pre- } \\
\text { operative radiotherapy, partial } \\
\text { laryngectomy, laryngectomy for } \\
\text { aspiration, and those with invasive } \\
\text { thyroid, post cricoid or cervical } \\
\text { oesophageal cancers }\end{array}$ & 12 & 13 \\
\hline
\end{tabular}

The age of participants in these studies ranged from 34 to 81 years (Table 6), although where mean age comparisons were made, were noted to be comparable across the control and study groups.65, 97 Where gender was documented, males outweighed females however this is a typical clinical proportion for total laryngectomy. ${ }^{11}$ 
Table 6: Number, age and gender of experimental studies

\begin{tabular}{|l|c|c|c|c|}
\hline \multicolumn{1}{|c|}{ Study } & No of participants & Age range & \multicolumn{2}{c|}{ Gender } \\
\hline & & & male & female \\
\hline Medina and Khafif (2001) & 38 & $34-76$ & 31 & 7 \\
\hline Seven, Calis and Turgut (2003) & 65 & $36-81$ & 60 & 5 \\
\hline Sharifian, Najafi and Khajavi (2008) & & & & \\
\hline
\end{tabular}

\section{Pharyngocutaneous fistula}

All included three studies ${ }^{65,94,97}$ examined the primary outcome of this review question, namely the incidence of pharyngocutaneous fistula following total laryngectomy in an early oral feeding group (six days post operatively or less) compared to a standard oral feeding group (seven days post-operatively plus).

Seven, Calis and Turgut $(2003)^{94}$, a prospective randomised controlled trial, was the largest and most robust study with complete data on 65 patients randomly allocated by computer to either the early oral feeding $(\mathrm{N}=32)$ or standard oral feeding $(\mathrm{N}=33)$ group. Both patient groups were highly defined with all patients undergoing total laryngectomy for a laryngeal neoplasm with primary closure and all being candidates for tracheaoesophageal fistula for later placement of a speech valve. Exclusions included patients requiring surgical closure by flap reconstruction and/or for whom a primary tracheaoesophageal fistula was not appropriate. Previous radiotherapy was not an exclusion criterion with five of the sample of 65 having had pre-operative treatment. The initial patient evaluation and data collection was comprehensive with risk factors for pharyngocutaneous fistula taken into full consideration. All patients underwent surgery by the same surgeon following a standard total laryngectomy procedure. After total laryngectomy, patients were randomly assigned to an early oral feeding group (with oral feeding commenced on a clear liquid diet twenty four hours after surgery) or a standard oral feeding group (with enteral feeding occurring through the trachea-oesophageal fistula and oral feeding commencing on the 7th day post-operatively). Diagnosis of pharyngocutaneous fistula was made by direct inspection of neck wounds and the detection of saliva. Two (6\%) pharyngocutaneous fistulae occurred in the early oral feeding group with $3(9 \%)$ in the standard oral feeding group. These findings did not show a significant difference between the two groups ( $p>.05)$. Of interest is that although the overall patient population included five patients with previous radiotherapy, none of these patients developed a pharyngocutaneous fistula. 
Overall the authors conclude that early oral feeding is a safe practice following total laryngectomy with primary closure regarding the development of a pharyngocutaneous fistula.

Sharifian, Najafi and Khajavi (2008) ${ }^{97}$ undertook a prospective randomised controlled trial of 25 patients allocated to an early feeding study group (with oral feeding commenced on water day 3 post-operatively) compared to a standard oral feeding control group (with patients fed through a nasogastric tube and oral feeding commenced day 7 postoperatively). Method of randomisation was not documented. Study $(\mathrm{N}=13)$ and control $(\mathrm{N}=12)$ groups were well defined and were not statistically significantly different in age, tumour stage and location. Exclusion criteria included laryngectomy for aspiration, more extensive surgery including partial laryngectomy, thyroid carcinoma, post cricoid and cervical oesophageal cancers. Patients with a history of pre-operative radiotherapy were also excluded. The same surgeon carried out or supervised the procedure. Diagnosis of post-operative pharyngocutaneous fistula was made by direct inspection of wound lines and the detection of saliva or swallowed material into the suction system or neck wounds. Pharyngocutaneous fistula was noted in one of the 13 study group compared to one of the 12 control group which was not found to be statistically significant $(p>0.05)$. There was also no significant difference in fistula formation between those that underwent radical neck dissection and those that did not, as well as no significance in grade or stage of laryngeal disease in the development of the pharyngocutaneous fistula. The authors conclude that in a selected group of patients, it is possible to initiate oral feeding earlier in the postoperative period than what was formerly thought.

Medina and Khafif (2001) ${ }^{65}$ undertook a two part study of which the first was a sequentially allocated quasi experimental study and the second, a prospective case series. Although the authors ultimately combined their data in discussing their findings, each part is also individually examined and as such are discussed individually under the appropriate study design. In part one, 38 patients were sequentially allocated either to the early feeding study group (oral feeding 48 hours post-operatively) or standard feeding control group (oral feeding 7-10 days post-operatively). Group allocation was 20 and 18 respectively. It is unclear from the study report whether the control group received nasogastric feeding but it is alluded to within the discussion. Patients undergoing partial pharyngectomy or with a history of extensive radiotherapy were excluded. Those that received irradiation through small ports for a T1-T2 glottic carcinoma were not excluded. The authors considered risk 
factors in the development of pharyngocutaneous fistula in their study. Differences in tumour site and stage were not statistically significant. Three patients in the early feeding study group and five in the standard feeding control group had received small port radiotherapy and this difference was not significantly different. More radical neck dissections were performed in the control group than the study group but again not statistically significant. Incidence of pharyngocutaneous fistula was one out of twenty in the study group and two out of eighteen in the control group, which was reported to not be significantly different $(p>0.05)$. The patient with a fistula in the early feeding group had not received pre-operative radiotherapy. The authors conclude that oral feeding 48 hours after total laryngectomy in a selected group of patients is feasible.

\section{Table 7: Incidence of pharyngocutaneous fistula}

\begin{tabular}{|l|c|c|c|}
\hline \multicolumn{1}{|c|}{ Study } & No of participants & \multicolumn{2}{|c|}{$\begin{array}{c}\text { Incidence of } \\
\text { pharyngocutaneous fistula }\end{array}$} \\
\hline & & $\begin{array}{c}\text { Early } \\
\text { oral feeding }\end{array}$ & Standard oral feeding \\
\hline Medina and Khafif & 38 & $1 / 20$ & $2 / 18$ \\
$(2001)^{65}$ & $5 \%$ & $11 \%$ \\
\hline Seven, Calis and & 65 & $2 / 32$ & $3 / 33$ \\
Turgut (2003) ${ }^{94}$ & & $6 \%$ & $9 \%$ \\
\hline Sharifian, Najafi and & 25 & $1 / 13$ & $1 / 12$ \\
Khajavi (2008)97 & & $7.7 \%$ & $8.3 \%$ \\
\hline
\end{tabular}

A meta-analysis was performed of the three included studies given the comparative study and control groups and overall comparable inclusion and exclusion criteria. The inherent differences between the studies taken into consideration when performing this metaanalysis related to:

1. Radiotherapy: Therapeutic radiotherapy was excluded in both Sharifian, Najafi and Khajavi (2008)97 and Medina and Khafif (2001) ${ }^{65}$, (with Medina and Khafif accepting 5x5 $\mathrm{cm}$ portal to larynx only). Although radiotherapy was not excluded in Seven, Calis and Turgut (2003) ${ }^{94}$, only 5/65 participants had undergone previous radiotherapy and none developed a pharyngocutaneous fistula in the course of the study so therefore was not viewed as a confounding factor.

2. Form of enteric feeding: One study ${ }^{94}$ bypassed the use of a nasogastric tube, using feeding through a trachea-oesophageal puncture, which bypasses the suture lines. 

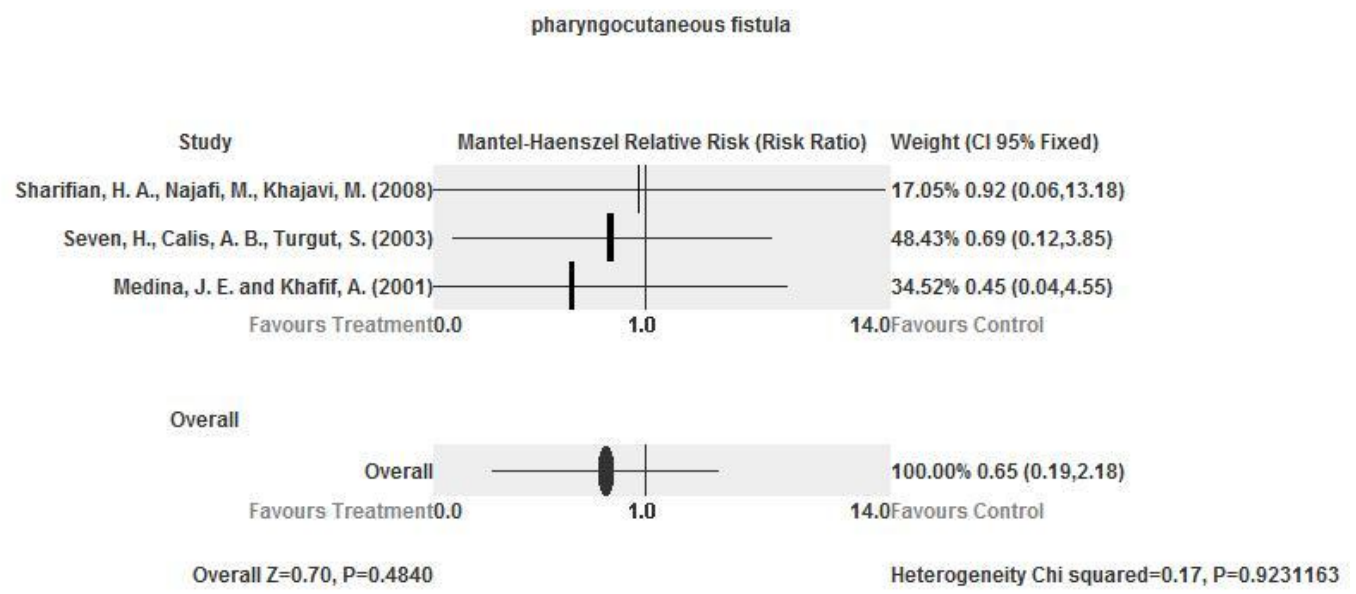

As can be seen from the forrest plot, there is not statistically significant heterogeneity between the included studies (Chi square $=0.17, p=0.92$ ). There is a wide variance in the magnitude of the effect size from the upper and lower confidence intervals. The forrest plot supports that there is no significant difference in the interventions of early compared to standard feeding on the incidence of pharyngocutaneous fistula.

Clinically this suggests that patients undergoing standard primary total laryngectomy may be able to commence oral intake sooner than current guidelines suggest thereby avoiding nasogastric feeding and commencing other forms of rehabilitation such as communication training, sooner within their hospital stay.

\section{Length of stay}

Two experimental studies 65,94 considered this review's secondary objective of hospital length of stay. However this data was not analysed using similar methodology and therefore could not be synthesized. Therefore, findings will be discussed in a narrative form. Seven, Calis and Turgut (2003) $)^{94}$ defined length of stay using standard criteria for discharge which included the removal of wound drains, return of normal diet, and postoperative recovery (defined as not requiring hospital care and ceasing of intravenous medications). If patients could not be discharged for social reasons, length of stay was calculated using the above definition. In patients that did not develop a pharyngocutaneous fistula, length of hospital stay had a range of four to nineteen days for the study group (mean value +/- SD; $7.4+/$ - 3.2 days) and from seven to seventeen days for the control group (mean $8.3+/-2.8$ days). For those that did develop a fistula, it was 26 days (range, 17-35 days) for the study group and 29 days (range, 19-57 days) for the control group. It is 
stated that there is no significant difference for the length of hospital stay for patients with or without pharyngocutaneous fistula $(p>0.05)$. The authors conclude that early oral feeding does not shorten hospital stay for the population studied.

Table 8: Length of stay relating to development of pharyngocutaneous fistula, Seven, Callis and Turgut

\begin{tabular}{|l|l|l|}
\hline Seven, Calis and Turgut (2003) & Early oral feeding & Standard oral feeding \\
\hline Pharyngocutaneous fistula present & 26 days (no SD documented) & 29 days (no SD documented) \\
& Range, 17-35 days & Mean 8.2 days $+/-2.8$ days \\
\hline Pharyngocutaneous fistula absent & Mean 7.4 days +/- 3.2 days & Range, 7 to 17 days \\
& Range, 4-19 days & . \\
\hline
\end{tabular}

Medina and Khafif $(2001)^{65}$ calculated length of stay from the time of total laryngectomy to the time of discharge. Length of stay was significantly longer in the control group ranging from seven to 19 days (mean $+/-$ SD; $11.87+/-3.36$ days) compared to a range of four to ten days in the study group (7.05 +/- 1.67 days). The authors concluded that length of hospital stay was significantly shortened by early initiation of oral feeding in a specific population ( $p<0.05$, student t-test).

Table 9: Length of stay relating to development of pharyngocutaneous fistula, Medina and Khafif

\begin{tabular}{|l|l|l|}
\hline Medina and Khafif (2001) & Early oral feeding & Standard oral feeding \\
\hline Length of stay & $7.05+/-1.67$ days & $11.87+/-3.36$ days \\
& Range, 4-10 days & Range, $7-19$ days \\
\hline
\end{tabular}

Overall length of stay findings were disparate across the two studies and provided inconclusive results for this outcome.

\section{Summary for experimental studies:}

Overall there is limited high quality primary research published comparing early oral feeding to standard feeding. The three studies appraised all support that early oral feeding does not increase the incidence of pharyngocutaneous fistula in the clinical context of primary total laryngectomy and this is substantiated by meta-analysis. The search process highlighted a lack of quality papers seeking to address the impact of salvage total laryngectomy on the incidence of pharyngocutaneous fistula. Hospital length of stay was considered using different methodological approaches across the two studies in which it was an outcome and as such could not be synthesized beyond the individual studies. Results for the effectiveness of early feeding versus standard feeding on length of stay were inconclusive. 


\section{Descriptive studies:}

Five descriptive studies $36,65,95,96,101$ were included following appraisal. Date of publication of included studies ranged from 1990 to 2002. One study was undertaken in the USA 65 , one in Brazil ${ }^{96}$ and three in Turkey. ${ }^{36,95,101}$

The setting of Medina and Khafif's study (2001)65 has been discussed previously within the experimental studies. Two of the Turkish studies ${ }^{36,95}$ were set in large teaching hospitals with strong university affiliation providing a comprehensive clinical, teaching and educational environment. ${ }^{102,103}$ Both had strong Ear, Nose and Throat clinical specialties. The third Turkish study ${ }^{101}$ was set in a large teaching and research based hospital, also with a large otorhinolaryngology department. ${ }^{104}$ Aprigliano's large case series ${ }^{96}$ took place in the largest public hospital in the state of Rio de Janiero. This is a regional tertiary setting of five hundred beds with a head and neck specialty. 105

All five studies considered this review's primary outcome of incidence of pharyngocutaneous fistula and commented on or considered this review's secondary outcome of length of stay to varying levels of assessment.

\section{Table 10: Overview of descriptive studies}

\begin{tabular}{|c|c|c|c|c|c|c|c|}
\hline Study & Country & Methodology & Population & Number & Age & \multicolumn{2}{|c|}{ Gender } \\
\hline $\begin{array}{l}\text { Akyol and } \\
\text { Ozdem } \\
(1995)^{101}\end{array}$ & Turkey & $\begin{array}{l}\text { Retrospective } \\
\text { chart review }\end{array}$ & $\begin{array}{l}\text { Total laryngectomies } \\
\text { performed between } 1986 \\
\text { and 1992, excluding } \\
\text { patients with previous } \\
\text { radiotherapy }\end{array}$ & 110 & $\begin{array}{l}\text { Mean } 61 \\
\text { years } \\
\text { range } 28 \text { - } \\
86\end{array}$ & $103 \mathrm{M}$ & $7 \mathrm{~F}$ \\
\hline $\begin{array}{l}\text { Aprigliano } \\
\text { (1990)96 }\end{array}$ & Brazil & $\begin{array}{l}\text { Retrospective } \\
\text { case review }\end{array}$ & $\begin{array}{l}\text { All total laryngectomies } \\
\text { over a } 21 \text { year period }\end{array}$ & 625 & unknown & \multicolumn{2}{|c|}{ unknown } \\
\hline $\begin{array}{l}\text { Medina } \\
\text { and Khafif } \\
(2001)^{65}\end{array}$ & USA & $\begin{array}{l}\text { Prospective } \\
\text { case series }\end{array}$ & $\begin{array}{l}\text { Total laryngectomy } \\
\text { excluding significant pre- } \\
\text { operative radiotherapy, } \\
\text { previous resections of } \\
\text { upper aero digestive tract } \\
\text { for SCC and additional } \\
\text { primary tumours of } \\
\text { pharynx or oesophagus }\end{array}$ & 35 & $\begin{array}{l}\text { Average } \\
59.4, \\
\text { range 36- } \\
89\end{array}$ & $27 \mathrm{M}$ & $8 \mathrm{~F}$ \\
\hline $\begin{array}{l}\text { Saydam, } \\
\text { Kalcioglu } \\
\text { and } \\
\text { Kizilay } \\
(2002)^{95}\end{array}$ & Turkey & $\begin{array}{l}\text { Retrospective } \\
\text { chart review }\end{array}$ & $\begin{array}{l}\text { All standard Total } \\
\text { laryngectomies or } \\
\text { laryngopharyngectomies } \\
\text { including patients having } \\
\text { previously received } \\
\text { radiotherapy and/or } \\
\text { chemotherapy }\end{array}$ & 48 & $\begin{array}{l}\text { Median } \\
63, \text { range } \\
35-77\end{array}$ & $46 \mathrm{M}$ & $2 \mathrm{~F}$ \\
\hline $\begin{array}{l}\text { Soylu et } \\
\text { al } \\
(1997)^{36}\end{array}$ & Turkey & $\begin{array}{l}\text { Retrospective } \\
\text { review }\end{array}$ & $\begin{array}{l}\text { All Total laryngectomies } \\
\text { between } 1975 \text { and } 1995\end{array}$ & 295 & $\begin{array}{l}\text { Median } \\
56, \text { range } \\
32-79\end{array}$ & $280 \mathrm{M}$ & $15 \mathrm{~F}$ \\
\hline
\end{tabular}

Oral feeding commenced from day one post-operatively to day five with no study implementing nasogastric feeding in early oral feeding groups. The presence of a trachea- 
oesophageal fistula for placement of a feeding tube and later a voice prosthesis, was not stated in three studies $65,96,101$ and not performed in one study. ${ }^{95}$

Table 11: Timing of oral feeding in the early feeding group

\begin{tabular}{|l|l|l|l|}
\hline Study & Day of oral feeding & Nutritional support & Tracheo-oesophageal fistula (TOF) \\
\hline $\begin{array}{l}\text { Akyol and Ozdem } \\
(1995)^{101}\end{array}$ & Day 1 or 2 & $\begin{array}{l}\text { No nasogastric tube } \\
\text { Intravenous fluids only }\end{array}$ & Not stated \\
\hline $\begin{array}{l}\text { Aprigliano } \\
(1990)^{96}\end{array}$ & Day 3 or 4 & No nasogastric tube & Not stated \\
\hline $\begin{array}{l}\text { Medina and Khafif } \\
(2001)^{65}\end{array}$ & Day 2 & No nasogastric tube & Not stated \\
\hline $\begin{array}{l}\text { Saydam, Kalcioglu } \\
\text { and Kizilay } \\
(2002)^{95}\end{array}$ & Day 1 & No nasogastric tube & No TOF \\
\hline
\end{tabular}

\section{Pharyngocutaneous fistula}

All of the five included studies examined the primary outcome of this review question namely the incidence of pharyngocutaneous fistula following total laryngectomy in an early oral feeding group (6 days post operatively or less). Only one study 36 compared the timing of early oral feeding to a standard feeding group (7 days or more).

Table 12: Inclusion and exclusion criteria, and incidence of pharyngocutaneous fistula

\begin{tabular}{|c|c|c|c|c|c|}
\hline Study & Inclusion & Exclusion & $\begin{array}{l}\text { Incidence } \\
\text { of fistula in } \\
\text { early } \\
\text { feeding } \\
\text { group }\end{array}$ & $\begin{array}{l}\text { Incidence } \\
\text { of fistula in } \\
\text { standard } \\
\text { feeding } \\
\text { group }\end{array}$ & $\begin{array}{l}\text { Number of } \\
\text { participants }\end{array}$ \\
\hline $\begin{array}{l}\text { Akyol and } \\
\text { Ozdem } \\
(1995)^{101}\end{array}$ & $\begin{array}{l}\text { All total laryngectomies } \\
\text { between } 1986 \text { and } 1992\end{array}$ & $\begin{array}{l}\text { No pre-operative } \\
\text { radiotherapy }\end{array}$ & $\begin{array}{l}23 / 110 \\
21 \%\end{array}$ & $\begin{array}{l}\text { Not } \\
\text { applicable }\end{array}$ & 110 \\
\hline $\begin{array}{l}\text { Aprigliano } \\
(1990)^{96}\end{array}$ & $\begin{array}{l}\text { All total laryngectomies over a } \\
21 \text { year period }\end{array}$ & Nil & $\begin{array}{l}57 / 625 \\
9.1 \%\end{array}$ & $\begin{array}{l}\text { Not } \\
\text { applicable }\end{array}$ & 625 \\
\hline $\begin{array}{l}\text { Medina } \\
\text { and } \\
\text { Khafif } \\
(2001)^{65}\end{array}$ & $\begin{array}{l}\text { Total laryngectomy performed } \\
\text { between November } 1984 \text { and } \\
\text { March } 1987\end{array}$ & $\begin{array}{l}\text { Significant pre- } \\
\text { operative } \\
\text { radiotherapy, } \\
\text { previous resections of } \\
\text { upper aero digestive } \\
\text { tract for SCC and } \\
\text { additional primary } \\
\text { tumours of pharynx or } \\
\text { oesophagus }\end{array}$ & $2.86 \%$ & $\begin{array}{l}\text { Not } \\
\text { applicable }\end{array}$ & 35 \\
\hline $\begin{array}{l}\text { Saydam, } \\
\text { Kalcioglu } \\
\text { and } \\
\text { Kizilay } \\
(2002)^{95}\end{array}$ & $\begin{array}{l}\text { All standard total } \\
\text { laryngectomies or } \\
\text { laryngopharyngectomies } \\
\text { including patients having } \\
\text { previously received } \\
\text { radiotherapy and/or } \\
\text { chemotherapy }\end{array}$ & $\begin{array}{l}\text { Previous surgical } \\
\text { treatment for } \\
\text { laryngeal cancer, } \\
\text { laryngectomy for } \\
\text { aspiration, locally } \\
\text { invasive thyroid, post } \\
\text { cricoid and cervical } \\
\text { oesophageal cancers }\end{array}$ & $\begin{array}{l}6 / 48 \\
12.5 \%\end{array}$ & $\begin{array}{l}\text { Not } \\
\text { applicable }\end{array}$ & 48 \\
\hline $\begin{array}{l}\text { Soylu et } \\
\text { al } \\
(1997)^{36}\end{array}$ & $\begin{array}{l}\text { All total laryngectomies } \\
\text { between } 1975 \text { and } 1995\end{array}$ & $\mathrm{Nil}$ & $\begin{array}{l}33 / 252 \\
13.1 \%\end{array}$ & $\begin{array}{l}9.3 \% \\
4 / 43\end{array}$ & 295 \\
\hline
\end{tabular}




\section{Studies including salvage laryngectomy:}

No studies exclusively considered the incidence of pharyngocutaneous fistula in patients whose total laryngectomies were performed as a salvage procedure (i.e. following treatment for laryngeal SCC with radiotherapy and/or chemotherapy).

\section{Studies excluding pre-operative radiotherapy/chemotherapy:}

Two studies 65,101 examined only those patients undergoing total laryngectomy as a primary procedure thereby excluding any pre-operative radiotherapy or chemotherapy.

Table 13: Studies excluding pre-operative radiotherapy and/or chemotherapy

\begin{tabular}{|l|l|l|l|l|}
\hline \multicolumn{1}{|c|}{ Study } & \multicolumn{1}{|c|}{ Inclusions } & $\begin{array}{c}\text { Day of early oral } \\
\text { feeding }\end{array}$ & $\begin{array}{c}\text { Incidence of } \\
\text { pharyngocutaneous } \\
\text { fistula }\end{array}$ & \multicolumn{1}{c|}{$\begin{array}{c}\text { Total number of } \\
\text { participants }\end{array}$} \\
\hline $\begin{array}{l}\text { Akyol and } \\
\text { Ozdem } \\
(1995)^{101}\end{array}$ & $\begin{array}{l}\text { Total laryngectomy, } \\
\text { no pre-operative } \\
\text { radiotherapy }\end{array}$ & Day 1 or 2 & $\begin{array}{l}23 / 110 \\
21 \%\end{array}$ & 110 \\
\hline $\begin{array}{l}\text { Medina and } \\
\text { Khafif }(2001)^{65}\end{array}$ & $\begin{array}{l}\text { Total laryngectomy } \\
\text { excluding pre- } \\
\text { operative } \\
\text { radiotherapy }\end{array}$ & Day 2 & $2.86 \%$ & 35 \\
& & & \\
\hline
\end{tabular}

Akyol and Ozdem (1995) ${ }^{101}$ examined 110 patients between 1986 and 1992 retrospectively who underwent total laryngectomy as a primary intervention for carcinoma of the larynx. Seventy five percent of cases were classified as T3-4 carcinomas with the remainder being T2. A nasogastric tube was not inserted and oral feeding was commenced with water on the first pre-operative day followed by clear liquids. Material from suction drains and skin flaps were carefully monitored for the development of a pharyngocutaneous fistula. Pharyngocutaneous fistula developed in $21 \%$ (23 out of 110) of cases within the acute hospital stay. There were no delayed fistulae. The authors conclude that their rate of fistula is comparable to the literature that use a nasogastric tube and delayed oral feeding thereby concluding that early oral feeding does not increase the complication rate.

Medina and Khafif $(2001)^{65}$, examined a further 35 patients who underwent total laryngectomy using a prospective analysis of their practice of instigating oral feeding 48 hours after surgery. Eighty percent of patients had advanced T3-4 carcinomas. Fourteen patients had received previous limited radiotherapy for early glottic cancer through $5 \times 5$ $\mathrm{cm}$ portals. For the remaining 21 patients, total laryngectomy was the primary treatment. One fistula developed (2.86\%) four days following surgery, which closed spontaneously. This occurred in a patient who had not received previous radiotherapy. The authors conclude that initiating oral feeding 48 hours after total laryngectomy in a selected group of patients is a safe clinical practice. 


\section{Studies including all total laryngectomies}

Three of the included studies ${ }^{36,95,96}$ examined the incidence of pharyngocutaneous fistula in a broader population of patients undergoing total laryngectomy. These included a mix of total laryngectomies performed as primary and salvage treatment.

Table 14: Studies including primary and salvage total laryngectomy

\begin{tabular}{|c|c|c|c|c|c|}
\hline Study & Inclusions & $\begin{array}{l}\text { Day of } \\
\text { early } \\
\text { oral } \\
\text { feeding }\end{array}$ & $\begin{array}{c}\text { Incidence of } \\
\text { pharyngocutaneous } \\
\text { fistula in early } \\
\text { feeding group }\end{array}$ & $\begin{array}{c}\text { Incidence of } \\
\text { pharyngocutaneous } \\
\text { fistula in standard } \\
\text { feeding group }\end{array}$ & $\begin{array}{c}\text { Total } \\
\text { number of } \\
\text { participants }\end{array}$ \\
\hline $\begin{array}{l}\text { Aprigliano } \\
(1990)^{96}\end{array}$ & $\begin{array}{l}\text { All total laryngectomies } \\
\text { over a } 21 \text { year period }\end{array}$ & $\begin{array}{c}\text { Day } 3 \text { or } \\
4\end{array}$ & $\begin{array}{l}57 / 625 \\
9.12 \%\end{array}$ & Not applicable & 625 \\
\hline $\begin{array}{l}\text { Saydam, } \\
\text { Kalcioglu } \\
\text { and } \\
\text { Kizilay } \\
(2002)^{95}\end{array}$ & $\begin{array}{l}\text { All total laryngectomies } \\
\text { or } \\
\text { laryngopharyngectomies } \\
\text { including salvage }\end{array}$ & Day 1 & $\begin{array}{c}6 / 48 \\
12.5 \%\end{array}$ & Not applicable & 48 \\
\hline $\begin{array}{l}\text { Soylu et } \\
\text { al } \\
(1997)^{36}\end{array}$ & $\begin{array}{l}\text { All total laryngectomies } \\
\text { including salvage }\end{array}$ & Day 3 & $\begin{array}{l}33 / 252 \\
13.1 \%\end{array}$ & $\begin{array}{l}4 / 43 \\
9.3 \%\end{array}$ & 295 \\
\hline
\end{tabular}

Aprigliano (1990)96 reviewed 625 cases over a period of twenty one years prior to publication of the study. There were no documented exclusions. Fifty two patients (8.25\%) had undergone radiotherapy as curative treatment prior to surgery. No nasogastric tube was inserted and oral feeding was commenced on the third or fourth post-operative day with $150 \mathrm{mls}$ of tea given every three hours. On the following day, milk and fruit juice were added with patients subsequently moved onto a soft diet as tolerated. There were a total of 57 fistulas $(9 \%)$ in the total group. Those that had undergone previous radiotherapy presented with a higher rate of pharyngocutaneous fistula $(8 / 52,15.3 \%)$ than those undergoing total laryngectomy as a primary treatment $(49 / 573,8.5 \%)$. The authors conclude that a nasogastric feeding tube is not necessary after a total laryngectomy therefore allowing oral feeding to commence earlier in the post-operative period.

Saydam, Kalcioglu and Kizilay (2002) ${ }^{95}$ retrospectively reviewed 48 cases excluding those previously surgically treated and patients who had been laryngectomised for intractable aspiration, local thyroid carcinoma or postcricoid or cervical oesophageal cancers. There were 46 males and two females ranging in age from 35 to 77 years (median 63 years). Pre-operative haematologic and nutritional status were within normal limits. Ten cases had received previous radiotherapy to the neck and larynx. Six had partial laryngectomies in addition to the total laryngectomy. Unilateral or bilateral neck dissections were carried out in all cases. A nasogastric tube was not introduced at the time of surgery. All patients were started on sips of water on the first post-operative day. Drains were observed during 
swallowing to detect any sign of leakage that would indicate fistula development. Other fluids were introduced on the second post-operative day usually followed by a progression to soft foods in the absence of any pharyngocutaneous fistula development. Six patients developed a pharyngocutaneous in the acute post-operative phase. Analysis of the tumour differentiation pattern between the fistula and non fistula group showed no statistical difference $(p=0.16)$. Analysis of previous radiotherapy also showed no statistically significant result between the fistula and non fistula group $(p=0.09)$. Pharyngectomy was the only factor demonstrated to be statistically significant in the development of a pharyngocutaneous fistula ( $p<0.05$, fisher exact test). The authors conclude that early oral feeding does not contribute to pharyngocutaneous development after total laryngectomy.

Soylu et al (1997) 36 performed a retrospective case review of 295 patients who underwent total laryngectomy between 1975 and 1995. The population consisted of 280 men and 15 women with age ranging from 32 to 79 years (median age, 56 years). A number of parameters implicated in pharyngocutaneous fistula development were examined namely $T$ stage, pre-operative radiotherapy or tracheostomy, concurrent neck dissection, type of pharyngeal closure, suture material used in pharyngeal closure, and onset of oral feeding. Two hundred and seventy four (92.9\%) patients underwent total laryngectomy as a primary procedure with the remaining $21(7.1 \%)$ undergoing salvage laryngectomy. In 43 patients $(14.5 \%)$ who had undergone surgery prior to 1980 , a nasogastric tube was inserted with oral feeding commencing after the post-operative day ten. Following 1980, 252 patients $(85.5 \%)$ commenced oral feeding on fluids on the third day post-operatively with only intravenous fluids provided until that time. Pharyngocutaneous fistula developed in 37/295 (12.5\%) patients. The rate of pharyngocutaneous fistula between patients in the early feeding group compared to the standard feeding group showed no significant statistical difference. For other parameters considered within the study, there was a significantly statistical difference between advancing $\mathrm{T}$ - stage and the rate of pharyngocutaneous fistula ( $p<0.05$, chi-squared test). The use of vicryl compared to catgut showed a significantly lower rate of pharyngocutaneous fistula ( $p<0.05$, chi-squared test). All other parameters examined including pre-operative radiotherapy did not demonstrate significance. The authors conclude that the pharyngocutaneous fistula rate in this study is within the lower range of that reported in the literature. They state that there is no additional risk in the development of pharyngocutaneous fistula when oral feeding following total laryngectomy is instigated. 


\section{Length of stay}

All five studies $36,65,95,96,101$ commented on or considered this review's secondary outcome of length of stay however was not consistently measured or reported.

Both Akyol and Ozdem (1995) ${ }^{101}$ and Aprigliano (1990) ${ }^{96}$ made conclusions that early feeding may shorten hospital stay but no length of stay data was collected or examined within the studies to support these statements.

Saydam, Kalcioglu and Kizilay (2002) ${ }^{95}$ reported on a hospital length of stay ranging from 10 to 34 days with mean of 13.5 days. The extended length of stay reportedly resulted from a high number of rural patients. No further conclusions or comparisons with the literature were provided.

One study ${ }^{36}$ compared hospital length of stay across the group that did develop a pharyngocutaneous fistula with the group that did not but did not draw conclusions from data.

Table 15: Length of stay comparison with fistula present or absent.

\begin{tabular}{|l|c|c|c|c|}
\hline \multicolumn{1}{|c|}{ Study } & \multicolumn{2}{|c|}{ Length of stay: no fistula development } & \multicolumn{2}{c|}{ Length of stay: fistula development } \\
\hline $\begin{array}{l}\text { Soylu et al } \\
(1997)^{36}\end{array}$ & 12 days & not provided & 41 days & $15-98$ days \\
\hline
\end{tabular}

Medina and Khafif (2001)65 reported an average hospital stay of 6.9 days for the early feeding group within the descriptive part two of the paper. On combining the early feeding length of stay data from part one and two of the study, average hospital length of stay was 7.0 days for the early oral feeding group compared to 11.8 days for the standard oral feeding group which was significantly shorter ( $p<0.0001$, student t-test) in the early feeding group.

\section{Summary descriptive studies}

Incidence of pharyngocutaneous fistula in varying populations varied from $2.86 \%$ to $21 \%$ across the six studies appraised. In the one paper comparing early and standard oral feeding ${ }^{36}$, there was no statistical difference in the incidence of pharyngocutaneous fistula. Overall hospital length of stay data was inconsistently reported. 


\section{Chapter Four: Discussion}

\section{Introduction:}

Pharyngocutaneous fistula is reported to be the most common early complication after total laryngectomy with significantly increased morbidity and mortality rates as well as increased resource utilisation and patient anxiety. ${ }^{1-3}$ The presence of a fistula delays other postoperative rehabilitation such as a return to or continuation with oral feeding, speech pathology communication intervention and post-operative radiotherapy. ${ }^{2} \mathrm{~A}$ patient's psychological well being can also be affected. ${ }^{2}$ Post-operatively, the development of a pharyngocutaneous fistula can double the length of an average patient hospital stay. ${ }^{4,5}$

This review sought to synthesize the best available evidence relating to the timing of oral feeding on the incidence of pharyngocutaneous fistula following total laryngectomy. During the search and retrieval process, eight studies were identified that met the inclusion criteria and were appraised to be of appropriate methodological quality. Three of these studies ${ }^{65,94,}$

97 were experimental in design with the remaining five $36,65,95,96,101$ being of descriptive methodology. Although the total number of studies found was small, it is promising to find higher-level evidence studies being undertaken in this area. However, there were few studies overall and none included in the review focussed on the timing of oral feeding following solely salvage laryngectomy. This is surprising given the global adoption of organ preserving treatment in the management of advanced laryngeal cancer over recent years. ${ }^{106}$

This is the first systematic review undertaken on the timing of oral feeding following total laryngectomy in the English literature. Several literature reviews associated with the question of early oral feeding have been identified. $62,63,66$ However, these reviews were limited by sample size, transparency of process and specificity of question. A systematic review has the advantage over literature reviews in that it allows a "more objective appraisal of the evidence than traditional narrative reviews".89 The systematic review process is clear and reproducible. It may also emphasize a particular area of health care where further research is needed due to the lack of adequate high-level evidence. In addition, meta-analysis, if able to be performed, aims to produce a single estimate of a treatment effect therefore reducing bias and the probability of a false negative result. 89 
This chapter discusses the effect of early oral feeding compared to standard oral feeding following total laryngectomy as well as providing more detailed discussion on included experimental and descriptive studies.

\section{Study outcomes:}

\section{Experimental: the effect of early feeding on incidence of pharyngocutaneous fistula}

The primary outcome of pharyngocutaneous fistula was examined in all three experimental studies. ${ }^{65,94,97}$ All authors concluded that there was no significant difference in the incidence of pharyngocutaneous fistula between the early oral feeding group and the standard oral feeding group. Pharyngocutaneous fistula rate ranged from $5 \%-7.7 \%$ in the early oral feeding group and $8.3 \%-11 \%$ in the standard oral feeding group. This falls well within the lower range of the reported incidence rate of $3 \%$ to $65 \%^{3}$ or if considering literature from the last twenty years, $9 \%$ to $23 \%{ }^{2}$ The variable incidence rate in the literature relates to the lack of homogeneity in many published series and results in a lack of a standardised incidence rate. ${ }^{2}$

Meta-analysis was undertaken using a fixed effect model which assumes all the data sets come from the same population with no heterogeneity and are measuring the same outcome. ${ }^{107}$ Specifically, there is one true effect underlying the studies and that all differences in the data are due to sampling error or chance within each study. ${ }^{92}$ Given the fixed effect model, a Mantel-Haenszel method was used because it has been shown to be more robust when event rates are low and number of studies is small. ${ }^{39}$ Relative risk was chosen as the method of overall effect size as it is considered more intuitively understandable within a clinical context. 89

Meta-analysis supported the conclusion that there is no significant difference in the incidence of pharyngocutaneous fistula with regard to the timing of oral feeding following total laryngectomy for the specific populations studied. All studies performed total laryngectomy with primary pharyngeal closure and neck dissections as clinically indicated. No included studies considered the effect of early oral feeding on salvage laryngectomy as an isolated population or the effect of oral feeding on more extensive surgical resections requiring flap reconstruction. 
Heterogeneity was not significant across the three studies given the overlap of the confidence intervals in the forrest plot and the heterogeneity chi squared value of 0.17 and associated $p$ value of 0.92 .

The inherent differences between the experimental studies taken into consideration when performing this meta-analysis related to:

1. Radiotherapy: Therapeutic radiotherapy was excluded in both Sharifian, Najafi and Khajavi (2008) ${ }^{97}$ and Medina and Khafif (2001) 65 (with Medina accepting radiotherapy via a $5 \times 5 \mathrm{~cm}$ portal to larynx only). Although radiotherapy was not excluded in Seven, Calis and Turgut $(2003)^{94}$, only 5/65 participants had undergone previous radiotherapy and none developed a pharyngocutaneous fistula in the course of the study. As a result, radiotherapy was not viewed as a significant confounding factor in this study.

2. Form of enteric feeding: One study94 bypassed the use of a nasogastric tube for the standard feeding group, using feeding through a trachea-oesophageal puncture at the point of the tracheostoma which avoids the suture lines. The early oral feeding group had no enteric feeding as per early feeding groups in the other experimental studies. It has been postulated in the literature that the physical presence of a nasogastric tube in the vicinity of the newly formed suture lines may cause some irritation as the patient swallows saliva 36,60 and plays a potential role as a pathway for intestinal flora to reach the pharynx thereby increasing the risk of local wound infection and breakdown. ${ }^{37}$ Sharifian, Najafi and Khajavi (2008) $)^{97}$ used nasogastric feeding for the control group and although it was not implicitly stated in the methodology of Medina and Khafif (2001)65 for the control group, nasogastric feeding is alluded to within the study's discussion.

\section{Experimental: the effect of early feeding on length of stay}

Length of stay data was examined in only two of the experimental studies ${ }^{65}, 94$ with definition and interpretation differing in both. Conclusions regarding length of stay between studies were incongruent as each study considered different perspectives. Seven, Calis and Turgut (2003) ${ }^{94}$ considered whether the presence of a pharyngocutaneous fistula impacted adversely on length of stay as opposed to Medina and Khafif (2001)65 who questioned whether early versus standard oral feeding impacted on length of stay.

Seven, Calis and Turgut (2003) ${ }^{94}$ defined length of stay based on standard discharge criteria and recalculated length of stay if discharge was delayed due to social reasons. Length of stay was compared between two groups: those that developed a 
pharyngocutaneous fistula versus those that did not rather than the original control and study groups. There was no consideration of early versus standard oral feeding in the interpretation of the length of stay data. Their conclusion that the presence of a pharyngocutaneous fistula made no significant difference on length of stay is contrary to other reports in the literature where pharyngocutaneous fistula has been reported to double ${ }^{1}$ or even triple ${ }^{43}$ hospital length of stay following total laryngectomy.

Medina and Khafif (2001) ${ }^{65}$ defined length of stay from time of surgery to time of discharge. In comparing control and study groups, length of stay was significantly shorter in the early oral feeding group compared to the standard oral feeding group. Despite these findings, limiting factors in the early discharge of total laryngectomy patients were reported including tracheostomy care and post surgical voice rehabilitation.

Given the inherent differences between the two studies in examining length of stay data, meta-analysis was not possible and further conclusions within the context of the data available are unable to be made.

\section{Descriptive: the effect of early feeding on pharyngocutaneous fistula}

All five studies $36,65,95,96,101$ considered this review's primary outcome of incidence of pharyngocutaneous fistula with early feeding commencing before day seven postoperatively. Sample size across the five studies varied significantly from 20 to 625 patients. Incidence of pharyngocutaneous fistula formation in the early oral feeding populations across the five studies was consistent with the variability reported in the literature over the last twenty years for general fistula formation ( $9 \%$ to $23 \%)^{2}$ ranging from $2.86 \% 65$ to $21 \% .{ }^{96}$

\section{Studies excluding pre-operative radiotherapy/chemotherapy:}

Both studies 65,101 supported early oral feeding and the avoidance of nasogastric feeding following primary total laryngectomy based on comparing fistula incidence rate to the literature.

The low rate of pharyngocutaneous fistula in Medina and Khafif (2001)65 was proposed to relate to the exclusion of radiotherapy in the sample population. Akyol, Ozdem and Celikkanat (1995) ${ }^{101}$, who also excluded radiotherapy, reported an incidence rate of $21 \%$ which is at great variance with the first study. The authors state this pharyngocutaneous fistula rate is comparable to the literature that use a nasogastric tube and delayed oral feeding. Although falling within the accepted pharyngocutaneous fistula literature range, 
compared populations were not all homogenous and included a number of studies that incorporated salvage laryngectomy where the incidence rate is expected to be higher. 43,55 , 108 Akyol, Ozdem and Celikkanat (1995) ${ }^{101}$ offer no further discussion or analysis of patient characteristics to determine other confounding factors contributing to the reported fistula rate within the published series.

\section{All total laryngectomies}

Three studies $36,95,96$ examined the incidence of pharyngocutaneous fistula in a broader population of patients undergoing total laryngectomy. These included total laryngectomies performed as both salvage and primary treatments. Salvage procedures ranged from $7.1 \%$ to $21 \%$ within the three studies. Early oral feeding was not deemed to be a contributing factor in pharyngocutaneous fistula development given the comparable incidence rate to studies where nasogastric tubes were used and feeding was delayed.

Overall the incidence rates of pharyngocutaneous fistula formation (ranging from $9.21 \%$ to $13.1 \%)$ were well within the lower to middle of the reported range ${ }^{3}$ particularly given the inclusion of salvage laryngectomy.

Pre-operative radiotherapy is well considered within the literature as a risk factor for fistula development.3, 55, 109-111 In comparing groups with and without pre-operative radiotherapy, results were conflicting. Saydam, Kalcioglu and Kizilay (2002) ${ }^{95}$ reported no significant difference in the incidence of pharyngocutaneous fistula while Soylu et al (1997) ${ }^{36}$ noted a higher incidence in pharyngocutaneous fistula but this was not statistically significant. Aprigliano (1990)96 noted a higher rate but made no further analysis. These findings are not in keeping with a recent meta-analysis ${ }^{3}$ which concluded that pre-operative radiotherapy is associated with an increased risk of pharyngocutaneous fistula formation. The conflicting results from the appraised studies may relate to the small sample size in Saydam, Kalcioglu and Kizilay $(2002)^{95}$, the disparate numbers in both groups examined in Soylu et al (1997) ${ }^{36}$ and lack of further statistical analysis in Aprigliano (1990). ${ }^{96}$

\section{Descriptive: the effect of early feeding on length of stay}

Length of stay was inadequately examined in all descriptive studies with the exception of Medina and Khafif $(2001)^{65}$ which has been discussed previously as part of experimental studies. 
Akyol, Ozdem and Celikkanat (1995) ${ }^{101}$ and Aprigliano (1990) ${ }^{96}$ drew conclusions regarding the positive impact of early oral feeding on hospital length of stay but unfortunately did not support these conclusions with any further data collection or analysis. Saydam, Kalcioglu and Kizilay (2002) ${ }^{95}$ described the economic and psychosocial benefits of a shortened hospital stay but did not support this with extensive data. Hospital length of stay varied from 10 to 34 days with mean of 13.5 days. Protracted hospital admissions were reportedly due to a large number of rurally based patients requiring additional rehabilitation prior to return home. There was no examination of hospital length of stay based on pharyngocutaneous fistula formation.

Soylu et al (1997) $)^{36}$ compared patients with fistula formation to a group that did not. Average length of stay for no fistula was 12 days (range not given) compared to an average length of stay of 41 days (range 15-98) for the fistula group. Unfortunately no further statistical analysis was performed on the raw data on which to draw conclusions and the authors did not discuss length of stay further within the study.

\section{Other risk factors for pharyngocutaneous fistula: experimental and descriptive}

Multiple risk factors for pharyngocutaneous fistula have been investigated in the literature including prior radiotherapy, concurrent radical neck dissection, poorly differentiated tumours, prior tracheostomy, partial pharyngectomy with laryngectomy, low pre or low post-operative haemoglobin levels and surgical expertise. $3,36,46,95,112$ One of the challenges in examining pharyngocutaneous fistula formation is the significant heterogeneity of studies in the literature. ${ }^{3}$

Experimental studies included within this systematic review provided the highest level of evidence (level 2)113 found within the literature regarding the review outcomes of pharyngocutaneous fistula and length of stay in relation to early oral feeding. There was examination of other risk factors associated with pharyngocutaneous fistula formation as lesser outcomes within these studies namely previous radiotherapy, tracheostomy, concurrent neck dissection, tumour stage, systemic disease, surgical closure and tumour grade ${ }^{94,97}$ with no significant associations able to be found.

Level 3 evidence ${ }^{113}$ from the appraised descriptive studies showed considerable variability in population description, risk factors considered and resulting analysis. Although it is not 
within the scope of this review's question to systematically examine risk factors associated with pharyngocutaneous fistula formation, the following findings were of interest.

Only one appraised study 95 included laryngopharyngectomy (6/48) and found this to be statistically significant in pharyngocutaneous fistula formation ( $p<0.05$ Fisher Exact test). This correlates with findings of increased pharyngocutaneous fistula incidence following pharyngeal resection in other case series in the broader literature.45, 114, 115 In contrast, Schwartz et al (2004),, 111 in reviewing 2000 cases from a large, prospectively collected national dataset, found no statistically significant findings associating flap reconstruction with an increase in wound complications.

There is controversy regarding neck dissection and its relationship to pharyngocutaneous fistula formation. Pre-operative radiotherapy with concurrent neck dissection has been found to be associated with an increased relative risk of pharyngocutaneous fistula formation, ${ }^{3}$ however findings in the literature regarding both functional and radical neck dissection remain ambiguous. A number of studies have found an association with increased incidence of pharyngocutaneous fistula109, 116 but this has not been substantiated by others. ${ }^{60,108,114}$ Soylu et al $(1997)^{36}$ found a reduced incidence of pharyngocutaneous fistula in those that underwent concurrent neck dissection compared to standard total laryngectomy but this was not statistically significant. Akyol, Ozdem and Celikkanat (1995) ${ }^{101}$ had $92 \%$ of population with neck dissection but unfortunately made no analysis of this as an outcome.

Soylu et al (1997) $)^{36}$ found the incidence of pharyngocutaneous fistula significantly lower when a clinical practice change was made in the late 80 s to use Vicryl as compared to catgut ( $p<0.05$, chi square). This is supported by Verma et al (1989) in Galli et al (2005)109 who reported a sharp drop in fistula formation when implementing similar practice changes. Soylu et al (1997) ${ }^{36}$ also concluded that advancing tumour $\mathrm{T}$ stage resulted in a significantly increased incidence of pharyngocutaneous fistula $(p<0.05$, chi square) but this was not upheld by Saydam, Kalcioglu and Kizilay (2002). ${ }^{95} \mathrm{~T}$ stage was not found to be significant risk factor on meta-analysis by Paydarfar. ${ }^{3}$

The above findings reinforce the challenges in undertaking primary research where multiple confounding factors may be present. 


\section{Limitations of the studies included in the review:}

\section{Limitations of experimental studies included in the review:}

The predominant aim of critical appraisal is to assess the methodological quality of each included study and to determine the extent to which bias has been addressed in terms of study design, conduct and analysis. The internal validity of a study can always be questioned if the possibility of bias has not been excluded. ${ }^{92}$

For the three experimental studies ${ }^{65,94,97}$ included in this review, methodological quality varied. Although no experimental study appraised met all the appraisal criteria, this was completely expected due to the nature of the intervention studied (i.e. oral feeding, and the difficulty in blinding subjects and assessors to the intervention).

\section{Study design}

Two studies were described as randomised controlled trials ${ }^{94,97}$ with a further study being a quasi experimental design. 65

Mayer (2010)90 describes that a randomised controlled trial is the strongest single study research design capable of proving a cause-effect relationship and by nature, can reduce uncertainty surrounding conflicting evidence gained from studies of less robust designs. Randomised controlled trials aim to control as many variables as possible so that any outcome differences can be attributed to the intervention alone. ${ }^{67}$ In order to minimise bias, subjects are randomly assigned to interventions and then treated in identical manner for other potential variables.

Accurate randomisation is fundamental to the success of a randomised controlled trial. ${ }^{90}$ An unpredictable sequence for group allocation should be sufficient to prevent selection bias. ${ }^{117}$ Seven, Calis and Turgut (2003) ${ }^{94}$, the highest rating study on appraisal, was the only experimental study that demonstrated true randomisation by employing a computer generated method of allocation post-operatively to either the early oral feeding or standard feeding group. Although Sharifian, Najafi and Khajavi (2008) ${ }^{97}$ stated their participants were "randomly selected", there was no description of how this occurred following surgery and whether allocation was truly unpredictable and concealed sufficiently to prevent selection bias. Medina and Khafif $(2001)^{65}$, within a quasi experimental design, used an allocation process based on sequential date of surgical presentation with the first 19 patients allocated to the control group between 1986 and 1987 and the subsequent 20 patients to the study group. Systematic methods of sequential allocation such as day of 
admission to hospital result in difficulty in concealing the intervention allocation from those recruiting to the study. ${ }^{117}$ Although the quasi experimental design still aims to uncover a relationship between two variables, ${ }^{92}$ this lack of true randomisation may give rise to selection bias and result in unequal qualities in the groups being studied. 90 Medina and Khafif (2001) ${ }^{65}$ did however describe homogeneity across the control and study groups with similar age range, male/female ratio and with no statistically significant difference in tumour location and staging.

\section{Study size}

Sample size across all studies was small ranging from 25 to 65 . At an individual level, each study looking at early feeding and fistula rates was under-powered. Whilst the fistula rates varied between the three studies, if one was to construct a power analysis using the lowest early feeding rate (5\% - Medina and Khafif $\left.(2001)^{65}\right)$ with the highest standard feeding rate $\left(11 \%\right.$ - Medina and Khafif $\left.(2001)^{65}\right)$, to achieve $80 \%$ power using $p<0.05$, a sample size of over 570 patients, 285 in each group would be required. This power analysis was performed using the University of lowa's on-line power calculator. ${ }^{118}$ It is critical that sample sizes of studies are large enough to ensure that estimates of benefit have not arisen by chance. ${ }^{119}$ Meta-analysis, where able to be undertaken within this systematic review, has enhanced the precision of treatment effects leading to a reduced probability of false negative results. ${ }^{89}$

\section{Incomplete data}

Incomplete outcome data either due to attrition during the study or by exclusion from analysis may give rise to the possibility that there is bias in the observed estimate of effect. ${ }^{117}$ To minimise bias in a randomised controlled trial, an intention to treat analysis is recommended. Principles include participants remaining in their originally allocated group, measuring outcome data on all participants and ensuring data from all participants is analysed. ${ }^{117}$ Medina and Khafif $(2001)^{65}$, after enrolling 39 participants, had one patient death in the control group from cardiac arrest following surgery prior to instigation of oral feeding and as a result, there was no data to include in final analysis. Seven, Calis and Turgut (2003) ${ }^{94}$ provided complete data on 65 out of the 67 patients initially enrolled in the study. One patient from the early oral feeding group died post-operatively and another from the standard feeding group dislodged the trachea-oesophageal feeding tube making the patient no longer eligible based on inclusion criteria. These events occurred prior to oral feeding being instigated and as such, did not influence the final data set. In the case of 
these two studies, attrition occurred due to factors out of the control of the authors. No intervention had been instigated and as such no data was available for inclusion in final analysis. Sharifian, Najafi and Khajavi (2008)97 enrolled 28 participants to their study but provided complete data on twenty-five. No reasons for attrition or exclusion were provided and it is unclear to which groups these patients were originally randomised. The authors did not report on the potential of the missing data to impact on their results. It is unclear to what extent this attrition may have influenced the observed treatment effects. Higgins $(2008)^{117}$ states that the potential impact of missing dichotomous outcomes depends on the frequency (or risk) of the outcome. Generally, the higher the ratio of participants with missing data to participants with events, the greater potential there is for bias. Given the reported incidence of pharyngocutaneous fistula is highly variable from $9 \%$ to $23 \%$ over the last twenty years, ${ }^{2}$ the impact of missing data may be highly significant, especially where the reasons for omission are not clearly stated.

\section{Blinding}

Blinding prevents confounding variables from affecting the results of a study. ${ }^{90}$ If all subjects, treating clinicians and assessors of outcomes are blinded to the interventions being provided then any subjective effects that could lead to biased results are limited.90, 117

It was unclear whether participants were blinded to their treatment allocation in any of the three experimental studies ${ }^{65,94,97}$ prior to the introduction of oral intake. Some types of study interventions make blinding challenging. Oral feeding is one such intervention. Once initiated, the nature of this particular intervention is impossible to conceal due to the presence of a nasogastric tube and the introduction of oral trials, and all experimental studies had expectedly poor results on appraisal questions relating to blinding of participants to treatment allocation. Despite this, participant knowledge of assigned intervention is unlikely to have impacted on a physiological outcome such as pharyngocutaneous fistula or a complex process such as length of stay and therefore any risk of bias for this parameter is unlikely to have significantly influenced internal validity of the studies.

Observers or assessors of outcomes should be blinded to minimise bias. This can be difficult in procedural type studies. 90 This was a potential limitation with a risk of observer bias in all three studies. Observer bias occurs when the assessor/researcher knows the goals of the study and allows this to influence their observations. 90 Mayer (2010)90 
suggests that observer bias can be minimised by the use of non-participating evaluation teams. None of the three appraised studies provided information on the relationship of the assessor to the study or discussed any strategies that were instigated to minimise this form of bias. This resulted in difficulty assessing its influence.

\section{Risk of bias in the measurement of outcomes}

Outcome measures should be clearly stated and measurements reproducible and free of bias. ${ }^{90}$ Measurements should be made in a manner that ensures consistency and maximises objectivity in the way results are recorded.

Questions relating to method of measurement of the presence of a pharyngocutaneous fistula and reliability of measurement required considerable debate to reach agreement between reviewers during appraisal. The primary outcome, namely pharyngocutaneous fistula is considered a binary complication ${ }^{3}$ as the patient does or does not have a fistula. Two studies ${ }^{94,97}$ used a direct inspection of drains and suture lines whereas a further study 65 did not document how a pharyngocutaneous fistula was diagnosed. To commence oral feeding and exclude the presence of a pharyngocutaneous fistula, clinicians may use a subjective test such as observation of a swallowed substance, while others may routinely perform a radiological assessment to identify structural change. ${ }^{49}$ Although videofluoroscopy is considered the gold standard in swallowing studies ${ }^{49}$ and provides more objective assessment of structure and function following total laryngectomy, leading clinical guidelines ${ }^{7}$ do not stipulate methods for excluding the presence of a pharyngocutaneous fistula prior to commencement of oral feeding. There is also the possibility of false negative rates in radiological detection of pharyngocutaneous fistula reported in the literature. ${ }^{39,53}$ Therefore, during the appraisal process, reviewers agreed to include direct clinical inspection as a valid clinical measurement of a pharyngocutaneous fistula if reported within the methodology of the study and used consistently across patients. It is important to note that the lack of radiological assessment may have missed early potential fistula development. Whether this is a confounding issue in considering the incidence of pharyngocutaneous fistula, is likely determined by the length of patient follow up. Gourin et al (2012) ${ }^{120}$ states that post-operative complications following head and neck surgery may not be evident at time of discharge which may lead to the incidence of complications being under reported. The majority of fistulas reveal themselves within the early acute post-operative phase $1,38,44$ however there have been some delayed reports up to approximately six months. ${ }^{1}$ All three experimental studies $65,94,97$ followed up participants 
for a minimum of six months post-operatively thereby providing an appropriate time period for follow-up.

There was no description in two of the studies ${ }^{65,94}$ as to professional backgrounds, training, credentials or experience of the people involved in assessing for the presence of a pharyngocutaneous fistula. Sharifian, Najafi and Khajavi (2008) ${ }^{97}$ described a 'physician' as inspecting the post-operative wounds but again no further detail was provided. This made it difficult to determine if outcomes were measured consistently across all participants.

In considering hospital length of stay, only one study65 provided a clear definition. Although number of days can be considered to be a clearly understood measurement, length of stay may be taken from day of surgery or day of admission and therefore a definition is required to determine homogeneity of data sets for this outcome.

All experimental studies overall would have rated higher in the appraisal process if more specific reporting on measurement and definition of outcomes had occurred. A key difficulty in assessing risk of bias is the barrier provided by incomplete reporting ${ }^{117}$ however under reporting has had to be taken into consideration during appraisal in considering the overall design and conduct of the studies in question.

\section{Consideration of other confounding factors:}

All three studies $65,94,97$ described the total laryngectomy procedure as being performed or supervised by the same surgeon reducing the potential confounder of surgeon experience in performing the procedure of total laryngectomy.

Standard surgical procedures for primary total laryngectomy were described by the three studies. Pharyngeal closure techniques reflected the possible variations required to achieve a water tight and unduly tensed suture line namely transverse ${ }^{94}$ or T-shaped. 65 , 94, 97 Level of closure was described within two studies ${ }^{65,} 94$ as two layered and not described by Sharifian, Najafi and Khajavi (2008). ${ }^{97}$ These variations in practice, dependent on amount of mucosa available for closure, are well described within the surgical literature. ${ }^{16,19}$ A recent survey of Australian Ear Nose and Throat surgeons also reflected this variation in surgical technique necessary to achieve effective pharyngeal closure. ${ }^{28}$

Unilateral or bilateral neck dissection was performed as required within all three studies. ${ }^{65}$, 94, 97 As discussed previously, neck dissection and its relationship to pharyngocutaneous 
fistula formation appears to be controversial in the literature. None of the appraised experimental studies found neck dissection to be a confounding 65 or statistically significant factor ${ }^{94,}, 97$ in pharyngocutaneous fistula development.

Length of stay as an outcome can be influenced by numerous confounding factors. Medical literature focussing on length of stay and its influences following head and neck surgery is limited. ${ }^{121}$ Although the presence of a pharyngocutaneous fistula has been demonstrated to impact on hospital length of stay following total laryngectomy, ${ }^{4,5}$ other independent predictors for a prolonged length of stay following major head and neck surgery have been identified by Busaba and Schaumberg (2008).121 Pre-operative characteristics that predicted prolonged length of stay on multivariate analysis were shown to be older age, poorer functional status, two plus alcohol drinks per day and a history of chronic obstructive airways disease or diabetes. Intra-operative variables were reported to be a longer operation time and transfusion. Post-operative predictors were a return to the operating theatre within 30 days and the occurrence of two or more post-operative complications. Both experimental studies within this review that considered hospital length of stay65, 94 were published prior to Busaba and Schaumberg's study. Demographic, disease and treatment factors affecting both studies' primary outcome of pharyngocutaneous development were well controlled and described. Medina and Khafif $(2001)^{65}$ reported no significant differences between study and control groups across multiple factors but did not specifically examine potential confounders for length of stay other than highlighting the influences of post-operative rehabilitation. Seven, Calis and Turgut $(2003)^{94}$, similarly to Medina and Khafif $(2001)^{65}$, reported no significant demographic differences between the two groups under consideration and that factors influencing fistula development were similar. Oral feeding was reported to not be a major determinant in discharge from hospital but other factors preventing discharge were not expanded further. Hospital length of stay is a complex issue. Busaba and Schaumberg's study ${ }^{121}$ may provide further considerations for improved analysis of confounders influencing length of stay following head and neck surgery in future studies exploring this outcome.

\section{Limitations of descriptive studies included in the review:}

\section{Study design:}

The five descriptive studies $36,65,95,96,101$ varied significantly in complexity and methodological quality. No study met the appraisal criteria for randomisation given the 
methods of recruitment used. Four studies were retrospective case series ${ }^{36,95,96,101}$ with one prospective study. 65

Descriptive study design is prone to bias due to the absence of a comparison or control group. A descriptive study does not aim to determine relationships between variables. ${ }^{92}$ However it is not possible to have a randomised control trial for every clinical question. ${ }^{90}$ Alternative methodologies may play a role in situations where experimentation may not be possible due to cost, ethical or logistical reasons. ${ }^{91}$ Case series present with some reported strengths. Clinical information is easily obtainable through existing medical records and the study can be resource efficient to undertake. 90 Inherent weaknesses such as the lack of randomisation and differing inclusion criteria may increase the risk of selection bias $^{90}$ and this must be considered when assessing the evidence and its translation into practice.

Three of the studies $95,96,101$ used a retrospective case review methodology reviewing 48 patients undergoing primary or salvage total laryngectomy or pharyngolaryngectomy, ${ }^{95} 110$ undergoing primary total laryngectomy 101 and 625 patients undergoing primary or salvage total laryngectomy ${ }^{96}$ respectively. Medina and Khafif $(2001)^{65}$ in the second part of the study used a consecutive series of 35 patients with inclusion and exclusion criteria well controlled as in part one of the study.

Soylu et al (1997) 36 also performed a retrospective study of 295 patients with primary or salvage total laryngectomy. Within the context of timing of oral feeding, this study was able to determine a comparative group based on a change of oral feeding protocol however these groups were greatly disparate in sample size, with the early feeding group having 252 participants and the standard oral feeding group having 43 participants.

The heterogeneity of the included descriptive papers may have lead to selection bias. Selection bias occurs if a sample is not randomly selected or if it is unlikely to be representative of the population from which it is taken. 119

\section{Study power}

Sample size was highly variable ranging from $35^{65}$ to 625.96 In descriptive studies, sample size is important as it affects how precise the observed mean or proportion, depending on the type of data, is expected to be. ${ }^{122}$ With two of the studies presenting with sample sizes of less than one hundred participants, ${ }^{65}, 95$ the power of these studies and the resulting measurement of outcome effect can be questioned. 


\section{Incomplete data}

Within the five descriptive studies all data was accounted for. There were no reported withdrawals or losses to follow-up.

Two of the five descriptive studies provided clear inclusion and exclusion criteria. 65, 95 Previous pre-operative radiotherapy, primary or extended laryngectomy, underlying reason for surgery and medical status were the predominant inclusion or exclusion considerations associated with individual study aims Mayer $(2010)^{90}$ suggests that reasons and methods for exclusion must be defined within a study to allow future replication and to minimise bias. Akyol, Ozdem and Celikkanat (1995) ${ }^{101}$ and Soylu et al (1997)36 included all total laryngectomy cases between a set time period with no exclusions documented. Aprigliano $(1990)^{96}$ in his retrospective case series of 625 patients, failed to describe the study population with the exception of pre-operative radiotherapy, and did not document inclusion or exclusion criteria. There is no demographic analysis or consideration of premorbid conditions that may influence outcomes. The total laryngectomy procedure is described as standard with some details of pharyngeal closure and suture technique. It does remain unclear, however whether all procedures were solely routine total laryngectomy or if surgery extended further into the pharynx or neck. Given the size and breadth of the case series, there is a lost opportunity for rich sub group analysis and confounding factors within the study are difficult to address.

\section{Risk of bias in the measurement of outcomes}

Similar issues arose during the appraisal process as for the experimental studies with regard to outcome measurement and definition due to under reporting of methods used.

Three studies ${ }^{36,65,96}$ provided no definition of how a pharyngocutaneous fistula was diagnosed or by whom. Saydam, Kalcioglu and Kizilay (2002) ${ }^{95}$ described a "physician" observing suction drains to detect for any swallowed material that might indicate the presence of a pharyngocutaneous fistula. Akyol, Ozdem and Celikkanat (1995) ${ }^{101}$ reported that patients were monitored during oral feeding for any swallowed material in the suction drains or accumulating under skin flaps. Neither study provided sufficient information to determine the credentials and experience of the assessor(s) or their relationship to the study giving rise to the question of detection or observer bias.

A limitation in four of the five studies was the lack of defined patient post-operative followup. As described previously, although fistula development is most common in the early post-operative period, there have been delayed reports up to six months post-operatively. 
Given that four studies were retrospective reviews, follow-up would have been determined by clinical practice at the time of the study and reliable outpatient attendance and precision of outpatient reporting. None of the retrospective studies ${ }^{36,95,96,101}$ provided information regarding follow-up. Medina and Khafif (2001) ${ }^{65}$ within a prospective case series provided adequate follow-up up to six months post-operatively to account for any delayed development of pharyngocutaneous fistula.

The above limitations may reflect some of the difficulties in retrospective case note reviews. Data collection from medical case notes may be variable in quality. Details recorded in records may be inadequate and therefore may possess questionable reliability. ${ }^{90}$ For the reviewer, recorded information may be dependent on interpretation, making judgements around symptoms and outcomes at risk of subjectivity and bias. Mayer (2010)90 suggests that medical records should be reviewed in a blinded manner with objective and explicit criteria thereby avoiding detection bias. None of the retrospective studies discussed methods for case note review and the possibility of optimisation of objectivity.

\section{Reporting bias:}

Due to publication bias, negative results are rarely reported. ${ }^{123}$ Authors of case series often compare their results to those of other case series within the literature. There is always the risk that authors will select case series for comparison that reflect well on their own results. One study ${ }^{96}$ made no comparison of its findings for pharyngocutaneous fistula with other case series. Saydam, Kalcioglu and Kizilay (2002)95 and Soylu et al (1997) $)^{36}$ compared their incidence of fistula favourably to that within the literature but failed to cite the studies used. Akyol, Ozdem and Celikkanat's (1995) ${ }^{101}$ pharyngocutaneous fistula rate of $21 \%$ was compared favourably to a number of published case series however the studies were not homogenous containing some salvage laryngectomy procedures which would commonly present with a higher rate of complication. Medina and Khafif (2001)65 compared their low rate of fistula to the literature which again included a study with salvage laryngectomy. Despite this, the incidence of pharyngocutaneous fistula is highly variable due to heterogeneity in study populations ${ }^{2}$ making comparisons outside of more rigourous study design challenging.

\section{Consideration of other confounding factors:}

The literature cites many variables that can influence the development of pharyngocutaneous fistula and these have been discussed throughout the background, results and discussion chapters of this thesis. A number of studies ${ }^{36,65,95}$ provided a sound 
statistical analysis of confounding factors within their patient population and their relationship to fistula development. These included consideration of pre-operative factors such as nutritional status, haemoglobin levels, pre-operative radiotherapy, tumour stage and previous tracheostomy. Operative considerations were pharyngeal closure, suture technique and material and neck dissection. Appropriate statistical testing was used to explore the relationships between variables. Two studies did not address confounding factors fully. Aprigliano (1990) ${ }^{96}$ discussed potential theoretical risk factors within the discussion of the study but only considered pre-operative radiotherapy within the study analysis. Akyol, Ozdem and Celikkanat (1995) ${ }^{101}$, similarly to Aprigliano (1990) ${ }^{96}$ provided a theoretical discussion on risk factors but did not provide further analysis on the study sample despite having data on tumour stage and surgical procedures.

\section{Discussion of methods of this systematic review}

This systematic review aimed to synthesize the best available evidence on timing of oral feeding following total laryngectomy. Primary outcome of interest was the incidence of pharyngocutaneous fistula with secondary outcome of interest hospital length of stay. The topics of management of laryngeal cancer and pharyngocutaneous fistula development are complex and this systematic review sought to examine one aspect of these specifically the effect of early oral feeding compared to standard oral feeding following total laryngectomy surgery.

The strength of the systematic review process is in the precision of the a-priori protocol which details predetermined objectives and methods. ${ }^{92}$ This systematic approach allows transparency of process and provides a predetermined plan to ensure scientific rigour and minimise potential bias.

Database searching and review of abstracts and full texts for inclusion in appraisal for this systematic review were only performed by the primary reviewer. It is possible some articles may have been missed despite undertaking a thorough, rigorous search across relevant databases for published and unpublished studies. One study ${ }^{124}$, published in Turkish conference proceedings, was unable to be retrieved through usual library document delivery processes and as a result, the full text could not be reviewed for consideration of inclusion. This was a descriptive case series and as such level of evidence was not viewed as sufficient to create a risk of bias within the systematic review findings. 
The restriction of studies to the English language may have resulted in the exclusion of other potentially relevant non English studies that could have further informed the review questions. Database searching sourced two possible randomised controlled trials published in the Chinese literature. ${ }^{125,126}$ This systematic review was date limited to June 1st, 2012 and there may be further upcoming published studies of interest to the topic. Demir, Hosal and Yilmaz ${ }^{127}$ are awaiting publication of a retrospective case series of 590 patients who underwent early oral feeding following total laryngectomy. As a result, an update of this review in the future may be of benefit.

Methodological limitations of studies included in the review have been examined in both the results and discussion sections. Although a number of experimental studies were included in the review, descriptive studies were also examined and as a result, confounders may be present.

A number of authors within the appraised studies allude to the patient experience of the presence of nasogastric tube and that avoidance of a tube and the introduction of early oral feeding may promote patient comfort and reduce stress. Medina and Khafif (2001)65 discuss that re-introduction of feeding in the early phase of post-operative care spares the potential inconvenience of a nasogastric tube and suggests that the search for patient comfort should continue to be an important factor and influence in the evolution of clinical practice. Akyol, Ozdem and Celikkanat (1995)101, Saydam, Kalcioglu and Kizilay (2002) ${ }^{95}$ and Soylu et al $(1997)^{36}$ all suggest that the presence of a nasogastric tube is uncomfortable, has potential to give rise to mechanical irritation and may be a major stress for many patients post-operatively. The nutritional benefits of enteric feeding in the head and neck population are clear however the complications of nasoenteric feeding are numerous and may include laryngeal irritation, ${ }^{128}$ mucosal ulceration ${ }^{35,129}$ and persistent gastro-oesophageal reflux 128, 130 amongst others. Accidental blockage, displacement and replacement can be problematic in maintaining nutrition, provision of critical medications and impact of re-insertion on wound lines. ${ }^{131}$ Any of these factors may play a role in the overall physical and psychological wellbeing of a patient post-operatively. In a prospective randomised controlled trial looking at early oral feeding following elective colorectal surgery ${ }^{132}$, the authors discuss that the positive psychological impact of oral feeding after surgery may be an important feature in recovery. The experience of the patient in terms of use of nasogastric tube feeding versus early oral feeding is not well defined or assessed within the head and neck literature. There is a reported paucity of qualitative research in 
total laryngectomy which is unexpected given the otherwise large body of research that considers the patient perspective and psychosocial impact of other cancer types and chronic illness. ${ }^{18}$ The focus of this systematic review was effectiveness. Given that within the JBI model of health care, evidence to support the diversity of health care needs may draw from a number of differing sources, an exploration of the meaningfulness through the patient's experience of early oral feeding may further inform this topic of interest.

\section{Conclusion}

This is the first systematic review undertaken on the timing of oral feeding following total laryngectomy in the English literature. This review identified eight studies, three experimental and five of descriptive methodology that assessed the effectiveness of early oral feeding on the primary outcome of incidence of pharyngocutaneous fistula following total laryngectomy. Length of stay as a secondary outcome was also considered as part of the review.

Early oral feeding prior to day seven in non irradiated or non-extensively irradiated patients undergoing primary total laryngectomy does not result in an increase or change in pharyngocutaneous fistula formation. This conclusion is supported by meta-analysis.

Although the descriptive literature also favours early oral feeding in less homogenous laryngectomy populations, the level of evidence is not high. As a result, this review does not offer conclusions relating to early oral feeding in more extensive total laryngectomy procedures requiring flap reconstruction or salvage laryngectomy given the lack of primary research in these populations.

Findings relating to the impact of early oral feeding on length of stay were mixed and inconclusive.

Implications for clinical practice and primary research have been identified and it is hoped that the findings of this review can be utilised within specific clinical post surgical populations.

\section{Implications for practice}

The following are rated using JBI grades of recommendations. ${ }^{133}$

- Introduction of oral feeding can be considered earlier than day seven following primary total laryngectomy (Grade B) 
- Insertion of a nasogastric tube intra-operatively for enteric feeding may be avoided if early oral feeding is to be instigated following primary total laryngectomy (Grade B)

- Introduction of early oral feeding (less than day seven) in more extensive or salvage surgery is not currently supported in the absence of high-level evidence to support change of practice. (Grade C)

\section{Implications for research}

The lack of high level evidence in the area of early oral feeding and salvage laryngectomy results in the need for further rigorous studies to examine the outcome of pharyngocutaneous fistula in this population given the trend towards organ preserving treatments.

There is little evidence on the effectiveness of oral feeding on length of stay following total laryngectomy and therefore more research would assist in addressing the economic and psychosocial benefits of this outcome. Literature focussing on length of stay following head and neck surgery is limited. Evaluation using a prospective randomised multi-centred trial would be the preferred method to address this further but logistical issues may mean such a trial will never be performed.

\section{Conflict of Interest}

There are no conflicts of interest 


\section{References}

1. De Santana M, Sawada N. Pharyngocutaneous fistulae after total laryngectomy: a systematic review. Rev Latam Enfermag. 2008;16(4):772-8.

2. Iglesias-Moreno M, Gimeno-Hernandez J, Gomez-Serrano M, Carricondo F, GilLoyzaga P, Poch-Broto J. Pharyngo-cutaneous fistula: an old problem revisited. Acta Otolaryngol (Stockh). 2011;131(12):1311-8.

3. Paydarfar J, Birkmeyer N. Complications in head and neck surgery: a metaanalysis of postlaryngectomy pharyngocutaneous fistula. Arch Otolaryngol - Head Neck Surg. 2006;132(1):67-72.

4. Friedman M, Venkatesan T, Yakovlev A, Lim J, Tanyeri H, Caldarelli D. Early detection and treatment of postoperative pharyngocutaneous fistula. Otolaryngol - Head Neck Surg. 1999;121(4):378-80.

5. Papazoglou G, Doundoulakis G, Terzakis G, Dokianakis G. Pharyngocutaneous fistula after total laryngectomy: Incidence, cause, and treatment. Ann Otol Rhinol Laryngol. 1994;103(10):801-5.

6. Xi S. Effectiveness of voice rehabilitation on vocalisation in postlaryngectomy patients: a systematic review. Int J Evid Based Healthc. 2010;8(4):256-8.

7. University of lowa. Clinical practice guidelines for total laryngectomy. University of lowa Health Care; 2012 [updated 19/03/2012; cited 2012 March 15]; Available from: http://wiki.uiowa.edu/display/protocols/Total+Laryngectomy.

8. Genden E, Ferlito A, Silver C, Jacobson A, Werner J, Suarez C, et al. Evolution of the management of laryngeal cancer. Oral Oncol. 2007:43(5):431-9.

9. Stephen J, Chen K, Shah V, Havard S, Lu M, Schweitzer V, et al. Human papillomavirus outcomes in an access-to-care laryngeal cancer cohort. Otolaryngol Head Neck Surg. 2012;20(10):1-9. Epub 2012/01/24.

10. Souhami R. Cancer of the head and neck. Cancer and its management. 5th ed., Revised ed. Somerset: Wiley-Blackwell [Imprint]; 2010. p. 150-71.

11. American Society of Clinical Oncology. Head and Neck Cancer: statistics. ASCO; 2012 [updated 2012 Feb 8; cited 2012 April 14]; Available from: http://www.cancer.net/patient/Cancer+Types/Laryngeal+and+Hypopharyngeal+Cancer?se ctionTitle=Statistics. 
12. Australian Institute of Health and Welfare \& Australasian Association of Cancer Registries. Cancer in Australia:an overview 2010, . Cancer Series. Canberra: Australian Institute of Health and Welfare; 2010.

13. Rudolph E, Dyckhoff G, Becher H, Dietz A, Ramroth $\mathrm{H}$. Effects of tumour stage, comorbidity and therapy on survival of laryngeal cancer patients: a systematic review and a meta-analysis. Eur Arch Otorhinolaryngol. 2011;268(2):165-79. Epub 2010/10/20.

14. Dobrossy L. Epidemiology of head and neck cancer: magnitude of the problem. Cancer Metastasis Rev. 2005;24(1):9-17. Epub 2005/03/24.

15. Roland N, Palen V. Head and neck cancer: multidiscplinary management guidelines. London: ENT UK; 2011. Available from: www.bahno.org.uk/dpcs/head_and_neck_cancer.pdf.

16. Ward E, van As Brooks C. Head and neck cancer: treatment, rehabilitation and outcomes. United Kingdon: Plural Publishing Inc; 2006.

17. Armstrong $E$, Isman K, Dooley $P$, Brine $D$, Riley $N$, Dentice $R$, et al. An investigation into the quality of life of individuals after laryngectomy. Head Neck. 2001;January:16-24.

18. Bickford J, Coveney J, Baker J, Hersh D. Living with the altered self: a qualitative study of life after total laryngectomy. Int J Speech Lang Path 2013;15(3):324-33. Epub 2013/04/17.

19. Cummings CW, Tobias J. Cummings Otolaryngology Head and Neck Surgery. 4th ed. USA: Elsevier Mosby; 2005. 2797 p.

20. Ferlito A, Silver C, Zeitels S, Rinaldo A. Evolution of laryngeal cancer surgery. Acta Otolaryngol. 2002;122(6):665-72. Epub 2002/10/31.

21. Cocek A. The history and current status of surgery in the treatment of laryngeal cancer. Acta Medica (Hradec Kralove). 2008;51(3):157-63. Epub 2008/01/01.

22. Hughes J, Almeyda J, Bull T. Morrell Mackenzie and Crown Prince Frederick: an unpublished manuscript from the Royal Society of Medicine Library. J Laryngol Otol. 2009;123:261-5.

23. Mackenzie M. The fatal illness of Frederick the noble. London: Low, Marston, Searle \& Rivington; $1888 . \quad$ Available from: http://openlibrary.org/books/OL23388559M/The_fatal_illness_of_Frederick_the_Noble.

24. Tipton F. A history of modern Germany since 1815. UK: Continuum Books; 2003. 
25. Myers E. The evolution of head and neck surgery. Laryngoscope. 1996;106(8):929-34. Epub 1996/08/01.

26. Silver C, Beitler J, Shaha A, Rinaldo A, Ferlito A. Current trends in initial management of laryngeal cancer: the declining use of open surgery. Eur Arch Oto Rhino Laryngol. 2009;266(9):1333-52. Epub 2009/07/15.

27. Agrawal N, Goldenberg D. Primary and salvage total laryngectomy. Otolaryngol Clin North Am. 2008;41(4):771-80, vii. Epub 2008/06/24.

28. Maclean J, Cotton S, Perry A. Variation in surgical methods used for total laryngectomy in Australia. J Laryngol Otol. 2008;122(7):728-32.

29. Maclean J, Cotton S, Cook I, Szczesniak M, Perry A. Swallowing function following total laryngectomy surgery in Australia. Dysphagia. 2011;26(4):483.

30. Rhys Evans P, Montgomery P, Gullane P. Principles and practice of head and neck oncology. UK: Martin Dunitz; 2003.

31. Harrison L, Sessions R, Hong W. Head and neck cancer: a multidisciplinary approach. 3rd ed. Philadelphia, USA: Lippincott Williams \&Wilkins; 2009. 960 p.

32. Maclean J, Szczesniak M, Cotton S, Cook I, Perry A. Impact of total laryngectomy and surgical closure technique on swallowing biomechanics and dysphagia severity. Otolaryngol Head Neck Surg. 2011;144(21):21-8.

33. Theissing J, Rettinger G, J W. ENT-head and neck surgery:essential procedures. USA: Thieme Publishing Group; 2011.

34. Lai S, Becker D, Edlich R. Sutures and needles. Medscape [Internet]. 201315 June 2013. Available from: http://emedicine.medscape.com/article/884838-overview.

35. Eley K, Shah R, Bond S, Watt-Smith S. A review of post-operative feeding in patients undergoing resection and reconstruction for oral malignancy and presentation of a pre-operative scoring system. Brit J Oral Maxillofacial Surg. 2012;50(7):601-5. Epub 2012/01/11.

36. Soylu L, Kiroglu M, Aydogan B, Cetik F, Kiroglu F, Akcali C, et al. Pharyngocutaneous fistula following laryngectomy. Head Neck. 1997;20(1):22-5.

37. Swift A, Bartzokas C, Corkill J. The clinical significance of the gastro-oral pathway of intestinal bacteria after head and neck cancer surgery. Clin Otolaryngol Allied Sci. 1987;12(6):455-9. Epub 1987/12/01.

38. Markou KD, Vlachtsis KC, Nikolaou AC, Petridis DG, Kouloulas Al, Danilidis IC. Incidence and predisposing factors of pharyngocutaneous fistula formation after total 
laryngectomy. Is there a relationship with tumor recurrence? Eur Arch Otorhinolaryngol. 2004;261(2):61-7.

39. Makitie A, Niemensivu R, Hero M, Keski-Santti $H$, Back L, Kajanti M, et al. Pharyngocutaneous fistula following total laryngectomy: a single institution's 10-year experience. Eur Arch Oto-Rhino-Laryngol. 2006;263(12):1127-30. Epub 2006/10/06.

40. Gleeson M. Scott-Brown's otorhinology, head and neck surgery. 7th ed. UK: Edward Arnold Ltd; 2008.

41. Rhigini C, Timi N, Junet $P$, Bertola A, Reyt E. Assessment of nutritional status at time of diagnosis in patients treated for head and neck cancer. Eur Ann Otorhinolaryngol: Head Neck Dis. 2013;130:8-14.

42. Starmer $\mathrm{H}$, Gourin $\mathrm{C}$. Is speech language pathologist evaluation necessary in the nonoperative treatment of head and neck cancer? Laryngoscope. 2013. Epub 2013/06/06.

43. Klozar J, Cada Z, Koslabova E. Complications of total laryngectomy in the era of chemoradiation. Eur Arch Oto RhinoLaryngol. 2012;269(1):289-93. Epub 2011/04/19.

44. Boscolo-Rizzo P, De Cillis G, Marchiori C, Carpene S, Da Mosto M. Multivariate analysis of risk factors for pharyngocutaneous fistula after total laryngectomy. Eur Arch Otorhinolaryngol. 2008;265(8):929-36.

45. Redaelli de Zinis L, Ferrari L, Tomenzoli D, Premoli G, Parrinello G, Nicolai P. Postlaryngectomy pharyngocutaneous fistula: incidence, predisposing factors, and therapy. Head Neck. 1999;21(2):131-8. Epub 1999/03/26.

46. McCombe A, Jones A. Radiotherapy and complications of laryngectomy. J Laryngol Otol. 1993;107(2):130-2. Epub 1993/02/01.

47. Cavalot A, Gervasio C, Nazionale G, Albera R, Bussi M, Staffieri A, et al. Pharyngocutaneous fistula as a complication of total laryngectomy: Review of the literature and analysis of case records. Otolaryngol - Head Neck Surg. 2000;123(5):587-92.

48. Moses B, Eisele D, Jones B. Radiologic assessment of the early postoperative total laryngectomy patient. Laryngoscope. 1993;103(10):1157-60.

49. Galli J, Valenza V, Parrilla C, Galla S, Marchese M, Castaldi P, et al. Pharyngocutaneous fistula onset after total laryngectomy: scintigraphic analysis. Acta Otorhinolaryngol Ital. 2009;29(5):242-4. Epub 2010/02/18.

50. Krouse $\mathrm{J}$, Metson R. Barium swallow is a predictor of salivary fistula following laryngectomy. Otolaryngol - Head Neck Surg. 1992;106(3):254-7. 
51. Sarra L, Rodriguez J, Garcia Valea M, Bitar J, Da Silva A. Fistula following total laryngectomy. Retrospective study and bibliographical review. Acta Otorrinolaringol Esp. 2009;60(3):186-9. Epub 2009/06/30.

52. Kapila S, Rozen W, Huang T, Wu T, Fairbank S. Determining between chyle leak and anastomotic leak after esophageal reconstruction: the utility of methylene blue dye. Laryngoscope. 2012;122(4):779-80. Epub 2012/02/22.

53. van la Parra R, Kon M, Schellekens P, Braunius W, Pameijer F. The prognostic value of abnormal findings on radiographic swallowing studies after total laryngectomy. Cancer imaging : the official publication of the International Cancer Imaging Society. 2007;7:119-25. Epub 2007/06/15.

54. Parikh S, Irish J, Curran A, Gullane P, Brown D, Rotstein L. Pharyngocutaneous fistulae in laryngectomy patients: the Toronto Hospital experience. J Otolaryngol. 1998;27(3):136-40. Epub 1998/07/17.

55. Virtaniemi J, Kumpulainen E, Hirvikoski P, Johansson R, Kosma V. The incidence and etiology of postlaryngectomy pharyngocutaneous fistulae. Head Neck. 2001;23(1):2933. Epub 2001/02/24.

56. Esteban F, Delgado-Rodriguez M, Mochon A, Solano J, Soldado L, Solanellas J. Study of in-patient hospital stay following total laryngectomy: multivariable retrospective analysis of a 442 total laryngectomies. Acta Otorrinolaringol Esp. 2006;57(4):176-82. Epub 2006/05/12.

57. Parikh S, Irish J, Curran A, Gullane P, Brown D, Rotstein L. Pharyngocutaneous fistulae in laryngectomy patients: the Toronto Hospital experience. J Otolaryngol. 1998;27(3):136-46.

58. National Institute for Clinical Excellence. Guidance on cancer services - improving outcomes in head and neck cancers - the manual. London: 2004.

59. Seikaly H, Park P. Gastroesophageal reflux prophylaxis decreases the incidence of pharyngocutaneous fistula total laryngectomy. Laryngoscope. 1995;105(11):1220-2.

60. Boyce S, Meyers A. Oral feeding after total laryngectomy. Head Neck. 1989;11(3):269-73. Epub 1989/05/01.

61. Bradley P, Narula A. Complications in head and neck surgery. In: Hakim N, Papalois V, editors. Surgical complications: diagnosis and treatment. UK: Imperial College Press; 2003. p. 205-44. 
62. O'Hara J, Lock C, Paleri V, Wight R. Oral feeding regimes following laryngectomy a qualitative study of consultants' opinions in the North of England. Oral Oncol. 2009;45(8):727-30.

63. Dalziel K. Time to commencement of oral feeding following laryngectomy. Evidence centre critical appraisal. Southern Health: Monash University, 2001 B.2001.01.04.1.

64. Rodriguez-Cuevas S, Labastida S, Gutierrez F, Granados F. Oral feeding after total laryngectomy for endolaryngeal cancer. Eur Arch Otorhinolaryngol. 1995;252(3):130-2. Epub 1995/01/01.

65. Medina JE, Khafif A. Early oral feeding following total laryngectomy. Laryngoscope. 2001;111(3):368-72.

66. Davidson W, Hill J, Isenring E, Talwar B, Bell K, Kiss N, et al. Evidenced based practice guidelines for the nutritional management of adult patients with head and neck cancer. Australia: Cancer Council and Clinical Oncological Society of Australia resources,; 2011 [updated 01/04/2011; cited 2012 March 9]; Available from: http://wiki.cancer.org.au/australia/COSA:Head_and_neck_cancer_nutrition_guidelines/Nutr ition_implementation_-_Surgery.

67. Lockwood C, Sfetcu R, Eui G. Synthesizing quantitative evidence, 1st edition: Lippincott, Williams \&Wilkins; 2011.

68. Pearson A, Field J, Jordan Z. Evidence based clinical practice in nursing and health care: assimilating research, experience and expertise. UK: Blackwell Publishing; 2007. $186 \mathrm{p}$.

69. Dollaghan $\mathrm{C}$. The handbook for evidence-based practice in commuication disorders. USA: Paul H Brookes Publishing Co.; 2007.

70. Sackett D, Rosenberg W. The need for evidence-based medicine. J R Soc Med. 1995;86(Nov):620-4.

71. Malloch K, Porter-O'Grady T. Introduction to evidence-based practice in nursing and health care. 2nd ed. USA: Jones \& Bartlett; 2012.

72. The Cochrane Collaboration. History of Archie Cochrane. 2013 [cited 20136 June]; Available from: http://www.cochrane.org/about-us/history/archie-cochrane.

73. The Cochrane Collaboration. The Cochrane Collaboration - about us. 2013 [cited 20136 June]; Available from: http://www.cochrane.org/about-us/. 
74. Pearson A, Wiechula R, Court A, Lockwood C. The JBI model of evidence-based healthcare. Int J Evid Based Healthc. 2005;3(8):207-15. Epub 2005/09/01.

75. Pearson A, Wiechula M, Court A, Lockwood C. A re-consideration of what constitutes "evidence' in the healthcare professions. Nurs Sc Q. 2007;20:85-8.

76. Stevens K. ACE star model of evidence based practice: knowledge transformation. SAn Antonio: The University of Texas Health Science Center; 2004 [cited 20136 June]; Available from: http://www.acestar.uthscsa.edu.

77. Titler M. The evidence for evidence-based practice implementation. . In: Hughes R, editor. Patient safety and quality: an evidence-based handbook for nurses. USA: Agency for Healthcare, Research and Quality; 2008.

78. Titler M. Translating research into practice. Am J Nurs. 2007;107(6 Suppl):26-33. Epub 2007/07/07.

79. Titler M. Translation science and context. Res Theory Nurs Prac: Int J. 2010;24(1):35-55.

80. Melnyk B, Fineout-Overholt E. Evidence based practice in nursing and healthcare: a guide to best practice. 2nd ed. Philadelphia, USA: Lippincott, Williams \& Wilkins; 2011.

81. Stetler C. Refinement of the Stetler/Marram model for application of research findings to practice. NursOutlook. 1994:42(1):15-25.

82. Rycroft-Malone J, Kitson A, Harvey G, McCormack B, Seers K, Titchen A, et al. Ingredients for change: revisiting a conceptual framework. Qual Saf Health Care. 2002;11:174-80.

83. Kitson A, Rycroft-Malone J, Harvey G, McCormack B, Seers K, Titchen A. Evaluating the successful implementation of evidence into practice using the PARiHS framework; theoretical and practical challenges. Implementation Sc. 2008;3(1):1-12.

84. Dobrow M, Goel V, Upshur R. Evidence-based health policy: context and utilisation. Social science \& medicine (1982). 2004;58(1):207-17. Epub 2003/10/24.

85. Pearson A, Weeks S, Stern C. Translation science and The JBI Model of Evidence-based Healthcare. 1st ed. Philadelphia: Lippincott Williams \&Wilkins; 2011.

86. Pearson A. Excellence in care:future dimensions for effective nursing. Nurs Times. 1998;3:25-7.

87. Evans D, Pearson A. Systematic reviews: gatekeepers of nursing knowledge. $J$ Clin Nurs. 2001;10:593-9. 
88. Dawes M, Summerskill W, Glasziou P, Cartabellotta A, Martin J, Hopayian K, et al. Sicily statement on evidence-based practice. BMC medical education. 2005;5(1):1. Epub 2005/01/07.

89. Egger M, Smith G, Altman D. Systematic reviews in health care:meta-analysis in context. London: BMJ Books; 2001.

90. Mayer D. Essential evidence-based medicine. 2nd ed. USA: Cambridge University Press; 2010.

91. Horwitz R, Viscoli C, Clemens J, Sadock R. Developing improved observational methods for evaluating therapeutic effectiveness. Am J Med. 1990;89(5):630-8. Epub 1990/11/01.

92. The Joanna Briggs Institute. Joanna Briggs Institute Reviewer's Manual: 2011 edition. Australia: The Joanna Briggs Institute; 2011.

93. Aswani J, Thandar M, Otiti J, Fagan J. Early oral feeding following total laryngectomy. J Laryngol Otol. 2009;123(3):333-8.

94. Seven $\mathrm{H}$, Calis $\mathrm{AB}$, Turgut $\mathrm{S}$. A randomized controlled trial of early oral feeding in laryngectomized patients. Laryngoscope. 2003;113(6):1076-9.

95. Saydam L, Kalcioglu T, Kizilay A. Early oral feeding following total laryngectomy. Am J Otolaryngol - Head Neck Med Surg. 2002;23(5):277-81.

96. Aprigliano F. Use of the nasogastric tube after total laryngectomy: is it truly necessary? Ann Otol Rhinol Laryngol. 1990;99(7 Pt 1):513-4. Epub 1990/07/01.

97. Sharifian HA, Najafi M, Khajavi M. Early oral feeding following total laryngectomy. Tanaffos. 2008;7(2):64-70.

98. University of Oklahoma. University of Oklahoma Health Sciences Centre. University of Oklahoma; 2013 [cited 201313 June]; Available from: http://www.oumedicine.com/oumedicalcenter/about-ou-medical-center.

99. Shahid Beheshti University of Medical Science. Shahid Beheshti University of Medical Science. 2012 [cited 2013 June 20]; Available from: http://en.sbmu.ac.ir/.

100. Sisli Etfal Training and Research Hospital. Sisli Etfal Training and Research Hospital. 2013 [cited 2013 June 20]; Available from: http://www.sislietfal.gov.tr/.

101. Akyol MU, Ozdem C, Celikkanat S. Early oral feeding after total laryngectomy. Ear Nose Throat J. 1995;74(1):28-30. Epub 1995/01/01.

102. Turkey Medical Tourism. Bayindar Hospital. 2012 [cited 201313 June]; Available from: 
http://www.turkeyhealthguide.com/accredited_medical_institutions/bayindir_hospital.asp?S ayfa=2.

103. Cukurova University. Cukurova University. 2013 [cited 201320 June]; Available from: http://www.cu.edu.tr/eng/detay.aspx?pageld=691.

104. Ankara Numune. Ankara Hospital. 2012 [cited 2013 June 20]; Available from: http://www.anh.gov.tr/.

105. Hospital de Rio de Janiero. Hospital Federal de Bonsucesso. 2013 [cited 2013 June 20]; Available from: http://www.hgb.ri.saude.gov.br/.

106. Robertson S, Yeo J, Dunnet C, Young D, Mackenzie K. Voice, swallowing, and quality of life after total laryngectomy-results of the west of Scotland laryngectomy audit. Head Neck. 2012;34(1):59-65.

107. Perera R, C H, D B. Statistics Toolkit. USA: Blackwell Publishing; 2008.

108. Ganly I, Patel S, Matsuo J, Singh B, Kraus D, Boyle J, et al. Postoperative complications of salvage total laryngectomy. Cancer. 2005;103(10):2073-81.

109. Galli J, De Corso E, Volante M, Almadori G, Paludetti G. Postlaryngectomy pharyngocutaneous fistula: incidence, predisposing factors, and therapy. Otolaryngol Head Neck Surg. 2005;133(5):689-94.

110. McLean J, Nicholas C, Duggal P, Chen A, Grist W, Losken A, et al. Surgical management of pharyngocutaneous fistula after total laryngectomy. Ann Plas Surg. 2012;68(5):442-5. Epub 2011/07/08.

111. Schwartz S, Yueh B, Maynard C, Daley J, Henderson W, Khuri S. Predictors of wound complications after laryngectomy: a study of over 2000 patients. Otolaryngol Head Neck Surg. 2004;131(1):61-8.

112. Boscolo-Rizzo P, Maronato F, Marchiori C, Gava A, Da Mosto MC. Long-term quality of life after total laryngectomy and postoperative radiotherapy versus concurrent chemoradiotherapy for laryngeal preservation. Laryngoscope. 2008;118(2):300-6.

113. The Joanna Briggs Institute. Levels of evidence. 2012 [27/02/2013]; Available from: http://www.joannabriggs.edu.au/Levels\%20of\%20Evidence $\% 20 \% 20$ FAME.

114. Herranz J, Sarandeses A, Fernández M, Barro C, Vidal J, Gávilan J. Complications after total laryngectomy in nonradiated laryngeal and hypopharyngeal carcinomas. Otolaryngol Head Neck Surg. 2000;122(6):892-8.

115. Shemen L, Spiro R. Complications following laryngectomy. Head Neck Surg. 1986;8(3):185-91. Epub 1986/01/01. 
116. Lavelle $\mathrm{R}$, Maw A. The aetiology of post-laryngectomy pharyngo-cutaneous fistulae. J Laryngol Otol. 1972;86(8):785-93. Epub 1972/08/01.

117. Higgins J, Altman D. Assessing risk of bias in included studies. In: Higgins J, Green S, editors. The Cochrane Handbook for Systematic Reviews: The Cochrane Collaboration; 2008. p. 187-241.

118. Lenth R. Java applets for power and sample size [computer software]. University of lowa; 2009 [cited 2013 April 20]; Available from: http://www.stat.iowa.edu/ rlenth/Power. 119. Peat J, Barton B, Elliott E. Statistics workbook for evidence-based health care. UK: BMJ Books; 2008.

120. Gourin C, Frick K. National trends in laryngeal cancer surgery and the effect of surgeon and hospital volume on short-term outcomes and cost of care. Laryngoscope. 2012;122(1):88-94. Epub 2011/11/05.

121. BuSaba N, Schaumberg D. Predictors of prolonged length of stay after major elective head and neck surgery. Laryngoscope. 2007;117(10):1756-63. Epub 2007/08/11.

122. Eng J. Sample size estimation; how many individuals should be studied. Radiology. 2003;227:309-13.

123. Stuart M, Strite S. Evidence and value based solutions for health care. Delfini Group; 2013 [cited 2013 June 18]; Available from: www.delfini.org.

124. Hosal N, Ceryan K, Turan F. Postoperative early oral feeding in laryngectomy. 15th Turkish National ORL Conference Proceedings. 1982:904-7.

125. Song J, Jing S, Shi H. The clinical observation of early oral feeding following total laryngectomy. Lin chuang er bi yan hou ke za zhi $=\mathrm{J}$ Clin Otorhinolaryngol. 2003;17(9):527-8.

126. Zheng XW, Kong WJ. Timing of the oral feeding after total laryngectomy. Lin chuang er bi yan hou ke za zhi = J Clin Otorhinolaryngol. 2004;18(3):189-90.

127. Demir N, Hosal S, Yilmaz T. Early oral feeding after total laryngectomy. Dysphagia. 2011;26(4):465.

128. Baredes S, Behin D, Deitch E. Percutaneous endoscopic gastrostomy tube feeding in patients with head and neck cancer. J Ear Nose Throat 2004;83(6):417-9. Epub 2004/07/23.

129. Iovinelli G, Marsili I, Varrassi G. Nutrition support after total laryngectomy. J Parenteral Enteral Nut. 1993;17(5):445-8.

130. Jones B. Enteral feeding: techniques of administration. Gut. 1986;27(1):47-50. 
131. Lees J. Nasogastric and percutaneous endoscopic gastrostomy feeding in head and neck cancer patients receiving radiotherapy treatment at a regional oncology unit: a two year study. Eur J Can Care. 1997;6:45-9.

132. Reissman D, Teoh T, Cohen S, Weiss E, Nogueras J, Wexner S. Is early oral feeding safe following elective colorectal surgery? Ann Surg. 1995;222(1):73-7.

133. The Joanna Briggs Institute. Grades of recommendations. The Joanna Briggs Institute; 2012 [updated 17 Jan 2013; cited 2013 April 6]; Available from: http://www.joannabriggs.edu.au/Grades\%20of\%20Recommendation.

134. Rodriguez-Cuevas S, Labastida S, Gutierrez F, Granados F. Oral feeding after total laryngectomy for endolaryngeal cancer. Eur Arch Otorhinolaryngol. 1995;252(3):130-2. Epub 1995/01/01.

135. Scott BA. Early oral feeding after total laryngectomy. Ear Nose Throat J. 1995;74(9):657.

136. Bresson K, Rasmussen H, Rasmussen PA. Pharyngo-cutaneous fistulae in totally laryngectomized patients. J Laryngol Otol. 1974;88(9):835-42. Epub 1974/09/01.

137. Saunders WH. Techniques in laryngectomy to minimize postoperative complications and permit immediate feeding. Ann Otol Rhinol Laryngol. 1963;72:431-40. Epub 1963/06/01.

138. Huang C, Choong M, Li T. A decisive observation overcome the hesitation of early oral feeding after head and neck surgery. Am Surg. 2012;78(1):36-7. Epub 2012/01/26.

139. Prasad K, Sreedharan S, Dannana N, Prasad S, Chandra S. Early oral feeds in laryngectomized patients. Ann Otol Rhinol Laryngol. 2006;115(6):433-8.

140. Eustaquio M, Medina J, Krempl G, Hales N. Early oral feeding after salvage laryngectomy. Head Neck. 2009;31(10):1341-5. 


\section{Appendix I: Search strategy}

Pubmed search strategy

1. laryngectomy[mh] OR laryngect* ${ }^{*}[\mathrm{tw}] \mathrm{OR}$ laryngopharyngec* $[\mathrm{tw}]$

2. eating[mh] OR eating[tw]

3. feeding methods[mh] OR feeding methods[tw]

4. food[mh] OR feed ${ }^{*}[\mathrm{tw}]$ OR oral feed ${ }^{*}[\mathrm{tw}]$

5. fistula[mh]

6. 2 OR 3 OR 4 OR 5

7. 1 AND 6

Limits: humans, English language, date limited from database inception to $01 / 06 / 2012$

\section{Embase search strategy}

1. laryngectomy/exp OR laryngectomy*:ti OR laryngectomy*:ab OR laryngopharyngec*:ti OR laryngopharyngec*:ab

2. 'foodintake'/exp

3. feed ${ }^{*}$ :ti OR feed ${ }^{*}: a b$

4. oral*:ti OR oral*:ab

5. 'postoperative complication'/exp

6. 'skin fistula'/exp

7. 2 OR 3 OR 4

8. 5 OR 6

9. 1 AND 7

10. 1 AND 7 AND 8

Limits: humans, English language, date limited from database inception to 01/06/2012 


\title{
Appendix II: Appraisal instruments
}

\author{
MAStARI Appraisal instrument
}

\section{JBI Critical Appraisal Checklist for Randomised Control / Pseudo-randomised Trial}

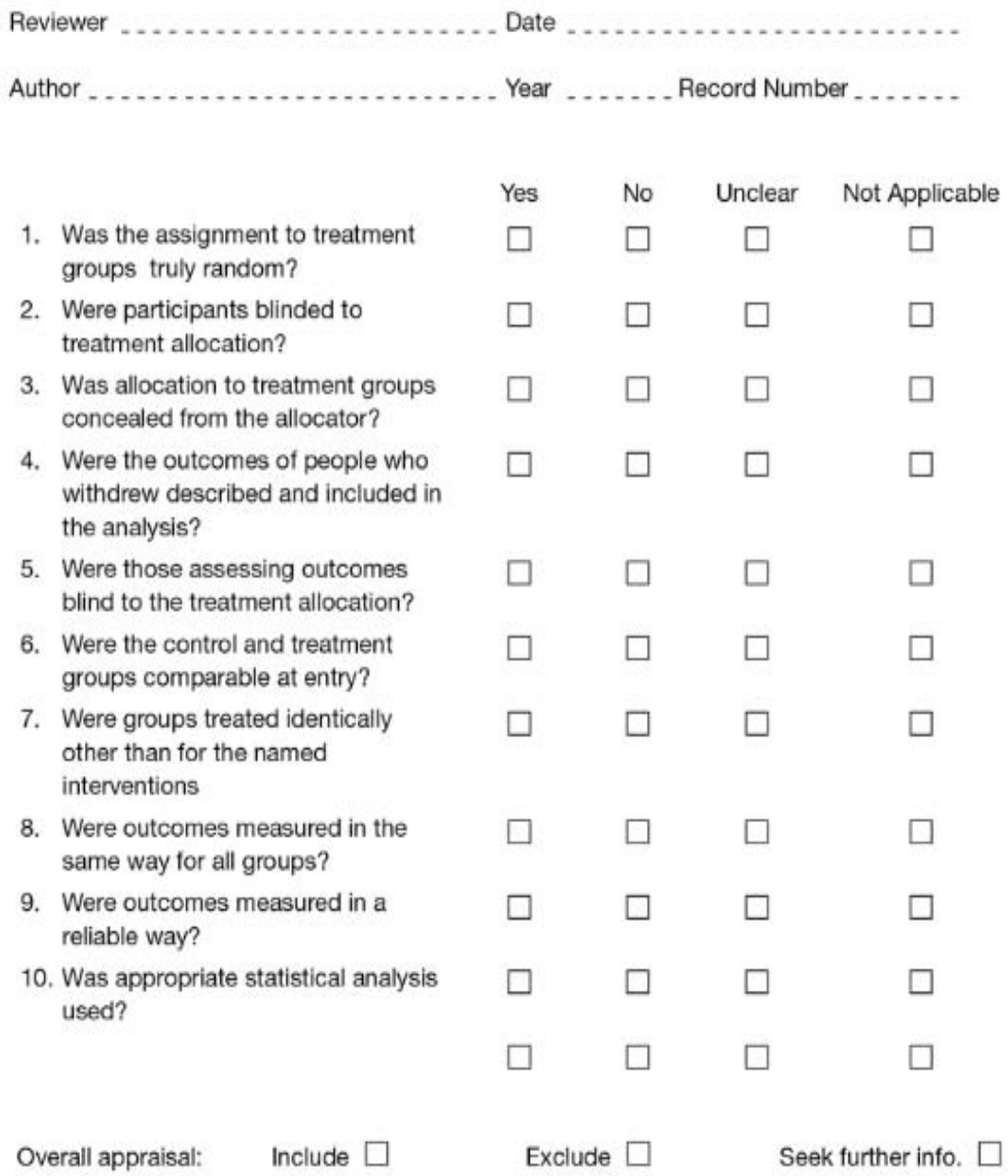

1. Was the assignment to treatment groups truly random?

2. Were participants blinded to treatment allocation?

3. Was allocation to treatment groups concealed from the allocator?

4. Were the outcomes of people who withdrew described and included in the analysis?

5. Were those assessing outcomes blind to the treatment allocation?

6. Were the control and treatment groups comparable at entry?

7. Were groups treated identically other than for the named interventions

8. Were outcomes measured in the same way for all groups?

9. Were outcomes measured in a reliable way?

10. Was appropriate statistical analysis used?

Overall appraisal: Include 


\section{JBI Critical Appraisal Checklist for Comparable Cohort/ Case Control}

Reviewer Date

Author Year Record Number

1. Is sample representative of patients in the population as a whole?

2. Are the patients at a similar point in the course of their condition/illness?

3. Has bias been minimised in relation to selection of cases and of controls?

4. Are confounding factors identified and strategies to deal with them stated?

5. Are outcomes assessed using objective criteria?

6. Was follow up carried out over a sufficient time period?

7. Were the outcomes of people who withdrew described and included in the analysis?

8. Were outcomes measured in a reliable way?

9. Was appropriate statistical analysis used?

Overall appraisal: Include 


\section{JBI Critical Appraisal Checklist for Descriptive / Case Series}

Reviewer ............ Date

Author

Year

Record Number.

Not

1. Was study based on a random or pseudo-

Yes No Unclear Applicable
random sample?

2. Were the criteria for inclusion in the sample clearly defined?

3. Were confounding factors identified and strategies to deal with them stated?

4. Were outcomes assessed using objective criteria?

5. If comparisons are being made, was there sufficient descriptions of the groups?

6. Was follow up carried out over a sufficient time period?

7. Were the outcomes of people who withdrew described and included in the analysis?

8. Were outcomes measured in a reliable way?

9. Was appropriate statistical analysis used?

Overall appraisal:

Include

Exclude

Seek further info 


\section{Appendix III: Data extraction instruments}

\section{MAStARI data extraction instrument}

\section{JBI Data Extraction Form for Experimental / Observational Studies}

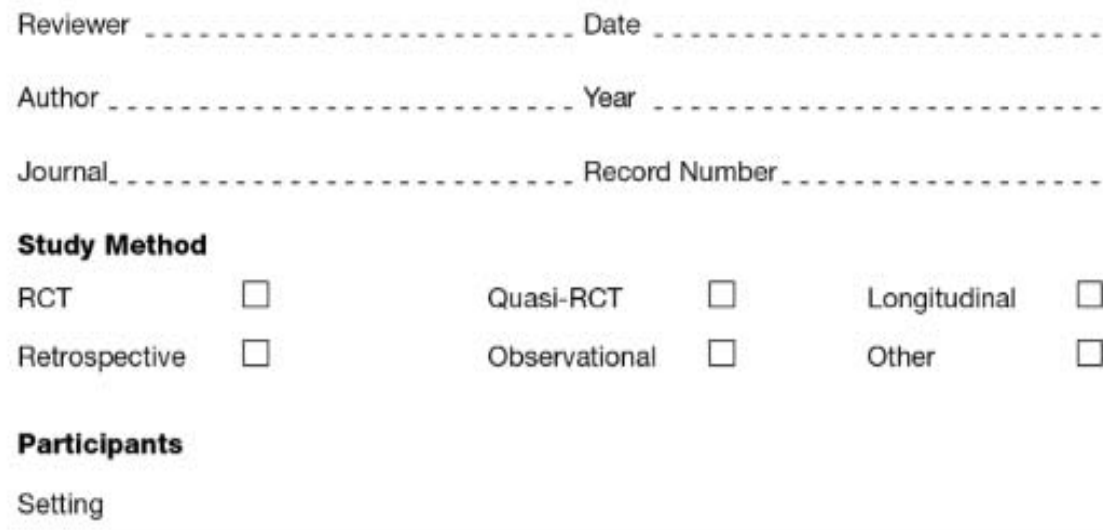




\section{Appendix IV: Excluded studies on full text review}

\begin{tabular}{|c|c|}
\hline Study & Reason for exclusion \\
\hline $\begin{array}{l}\text { Rodriguez-Cuevas S, Labastida S, Gutirerrez F, } \\
\text { Granados F. Oral feeding after total laryngectomy for } \\
\text { endolaryngeal cancer. Eur Arch Otorhinolaryngol. } \\
\text { 1995. 252:130-132134 }\end{array}$ & $\begin{array}{l}\text { Compared oral feeding day } 7 \text { post- } \\
\text { operatively to oral feeding day } 10\end{array}$ \\
\hline $\begin{array}{l}\text { Scott BA. Early oral feeding after total laryngectomy } \\
\text { Ear. Nose. Throat J.1995. } 74 \text { (9) p } 647135\end{array}$ & Letter to the editor only \\
\hline $\begin{array}{l}\text { Bresson K, Rasmussen PA. Pharyngo-cutaneous } \\
\text { fistulae in totally laryngectomized patients. J Laryngol } \\
\text { Otol. } 1974.88 \text { (9) } 835-42^{136}\end{array}$ & $\begin{array}{l}\text { Not related to oral feeding post } \\
\text { surgery }\end{array}$ \\
\hline $\begin{array}{l}\text { Saunders WH. Techniques in laryngectomy to } \\
\text { minimize postoperative complications and permit } \\
\text { immediate feeding. Ann Otol Rhinol Laryngol. } 1963 . \\
72 ; \text { P431-40137 }\end{array}$ & $\begin{array}{l}\text { A technical 'how to do it' study - } \\
\text { describes timing of feeding post } \\
\text { total laryngectomy but no } \\
\text { recruitment of participants }\end{array}$ \\
\hline $\begin{array}{l}\text { Boyce SE, Meyers AD. Oral feeding after total } \\
\text { laryngectomy. Head Neck .1989.11(3) 269-27360 }\end{array}$ & $\begin{array}{l}\text { Compared oral feeding } 5 \text { days } \\
\text { post-operatively or less to oral } \\
\text { feeding } 6 \text { days post-operatively }\end{array}$ \\
\hline $\begin{array}{l}\text { Huang CY, Choong M Y, Li TS. A decisive } \\
\text { observation overcome the hesitation of early oral } \\
\text { feeding after head and neck surgery. Am Surg. } 2012 \text {. } \\
78 \text { (1) } 36-37138\end{array}$ & $\begin{array}{l}\text { Study focussed on position of } \\
\text { patient post operatively rather } \\
\text { than timing of feeding }\end{array}$ \\
\hline $\begin{array}{l}\text { Hosal N, Ceryan K, Turan F. Postoperative early oral } \\
\text { feeding in laryngectomy. 15th Turkish National ORL } \\
\text { Conference Proceedings. 1982. 904-907124 }\end{array}$ & $\begin{array}{l}\text { Unable to locate via usual library } \\
\text { sources or document delivery }\end{array}$ \\
\hline $\begin{array}{l}\text { Demir N, Hosal S, Yilmaz T. Early oral feeding after } \\
\text { total laryngectomy. Dysphagia.2011.26(4) p p 465 }\end{array}$ & $\begin{array}{l}\text { Poster presentation - awaiting } \\
\text { publication of full study }\end{array}$ \\
\hline $\begin{array}{l}\text { Prasad K, Sreedharan S, Dannada NK, Prasad SC, } \\
\text { Chandra S. Early oral feeds in laryngectomised } \\
\text { patients. Ann Otol Rhinol Laryngol.1995.115 (6) 433- } \\
438139\end{array}$ & $\begin{array}{l}\text { Included a variety of head and } \\
\text { neck surgery for SCC - not } \\
\text { exclusively total laryngectomy }\end{array}$ \\
\hline $\begin{array}{l}\text { Eustaquio M, Medina JE, Krempl GA, Hales N. Early } \\
\text { oral feeding after salvage laryngectomy. Head Neck. } \\
\text { 2009. } 31 \text { (10): } 1341-5140\end{array}$ & $\begin{array}{l}\text { Oral feeding commenced on day } 7 \\
\text { post-operatively or less }\end{array}$ \\
\hline
\end{tabular}




\section{Appendix V: Included studies in the systematic review}

\begin{tabular}{|c|c|c|c|}
\hline Study & Methods & Intervention A & Intervention B \\
\hline $\begin{array}{l}\text { Akyol MU, Ozdem } \\
\text { C, Celikkanat S. } \\
\text { 1995101 }\end{array}$ & $\begin{array}{l}\text { retrospective chart } \\
\text { review }\end{array}$ & early oral feeding & None included \\
\hline $\begin{array}{l}\text { Aprigliano F. } \\
1990^{96}\end{array}$ & $\begin{array}{l}\text { retrospective case } \\
\text { series }\end{array}$ & early oral feeding & None included \\
\hline $\begin{array}{l}\text { Medina JE. and } \\
\text { Khafif A. } 2001^{65}\end{array}$ & $\begin{array}{l}\text { Part 1:quasi } \\
\text { experimental trial } \\
\text { with prospective } \\
\text { sequential } \\
\text { allocation } \\
\text { Part 2: prospective } \\
\text { case series }\end{array}$ & early oral feeding & $\begin{array}{l}\text { standard oral } \\
\text { feeding - }\end{array}$ \\
\hline $\begin{array}{l}\text { Saydam L, } \\
\text { Kalcioglu T, } \\
\text { Kizilay A. } 200295\end{array}$ & $\begin{array}{l}\text { retrospective case } \\
\text { series }\end{array}$ & early oral feeding & None included \\
\hline $\begin{array}{l}\text { Seven H, Calis A } \\
\text { B, Turgut S. } \\
2003^{94}\end{array}$ & $\begin{array}{l}\text { prospective } \\
\text { computer } \\
\text { generated } \\
\text { randomised } \\
\text { controlled trial }\end{array}$ & early oral feeding & $\begin{array}{l}\text { standard oral } \\
\text { feeding was } \\
\text { introduced }\end{array}$ \\
\hline $\begin{array}{l}\text { Sharifian H.A. } \\
\text { Najafi M, Khajavi } \\
\text { M. } 200897\end{array}$ & $\begin{array}{l}\text { randomised } \\
\text { controlled trial }\end{array}$ & $\begin{array}{l}\text { early oral feeding } \\
\text { group. }\end{array}$ & $\begin{array}{l}\text { Standard oral } \\
\text { feeding }\end{array}$ \\
\hline $\begin{array}{l}\text { Soylu L, Kiroglu } \\
\text { M, Aydogan B, } \\
\text { Cetik F., Kiroglu } \\
\text { F, Akcali C, } \\
\text { Ozsahinoglu C. } \\
\text { 199736 }\end{array}$ & $\begin{array}{l}\text { retrospective case } \\
\text { series }\end{array}$ & early oral feeding & $\begin{array}{l}\text { Standard oral } \\
\text { feeding }\end{array}$ \\
\hline
\end{tabular}




\section{Appendix VI: Excluded study following appraisal}

Aswani J, Thandar M, Otiti J, Fagan J. Early oral feeding following total laryngectomy ${ }^{93}$

Reason for exclusion: 2/10. Did not meet criteria for inclusion due to methodological quality 